\title{
Piperaceae endémicas del Perú
}

\author{
Blanca León ${ }^{1,2}$
}

${ }^{1}$ Museo de Historia Natural,
Av. Arenales 1256, Aptdo.
14-0434, Lima 14, Perú
${ }^{2}$ Plant Resources Center,
University of Texas at
Austin, Austin TX 78712
EE.UU.
blanca.leon@mail.utexas.edu

\section{Resumen}

La familia Piperaceae es reconocida en el Perú por presentar tres géneros y 830 especies (Brako \& Zarucchi, 1993; Ulloa Ulloa et al., 2004), principalmente hierbas y arbustos. En este trabajo reconocemos 491 especies y 68 variedades como endémicos en dos géneros. El género más rico en especies es Piper. Esta familia requiere mayor atención tanto en su taxonomía como en la representación en los herbarios. Los taxones endémicos se encuentran principalmente en las regiones Bosques Húmedos Amazónicos, Bosques Muy Húmedos Montanos y Bosques Muy Húmedos Premontanos, entre los 100 y $2700 \mathrm{~m}$ de altitud. Se aplicaron las categorías y criterios de la UICN a 209 taxones. Aparentemente, sólo nueve especies se encuentran representadas dentro del Sistema Nacional de Áreas Naturales Protegidas por el Estado.

Palabras claves: Piperaceae, Piper, Perú, endemismo, plantas endémicas.

\section{Abstract}

The Piperaceae are represented in Peru by three genera and 830 species (Brako \& Zarucchi, 1993; Ulloa Ulloa et al., 2004), mainly herbs and shrubs. Here we recognize 491 species and 68 varieties as endemics in two genera. Piper is the genus with the largest number of endemic species. This family requires more attention both in its taxonomy and herbaria collection. These endemic taxa are found mainly in Humid Lowland Amazonian Forests, Very Humid Montane Forests and Very Humid Premontane Forests regions, between 100 and 2700 m elevation. We applied IUCN categories and criteria to 209 taxa. Apparently, only nine taxa have been recorded in the Peruvian System of Protected Natural Areas.

Keywords: Piperaceae, Piper, Peru, endemism, endemic plants.

\section{Peperomia acutifolia C. DC.}

\section{DD}

Publicación: J. Bot. 4: 142-143. 1866.

Colección tipo: R. Spruce 4094

Hemarios: G-DC.

Nombre común: Afasi quihua.

Registro departamental: HU, SM.

Regiones Ecológicas: BMHP; $1350-1500 \mathrm{~m}$.

SINANPE: Sin registro.

Herbarios peruanos: Ninguno.

Observaciones: Hierba conocida de unas pocas localidades, en el noroccidente de la Amazonía peruana. El ejemplar tipo fue recolectado en el siglo XIX, de la cuenca del Mayo.

\section{Peperomia aerea Trel.}

\section{DD}

Publicación: Field Mus. Nat. Hist., Bot. Ser. 13(357): 19. 1936.

Colección tipo: C.O. Schunke 494

Herbarios: $F$.

Nombre común: D esconocido.

Registro departamental: JU.

Regiones Ecológicas: BMHM; $1800 \mathrm{~m}$.

SINANPE: Sin registro.

Herbarios peruanos: Ninguno.

Observaciones: Hierba conocida, aparentemente, sólo de la colección tipo, una planta recolectada en la cuenca del Tulumayo.

\section{Peperomia alatiscapa Trel.}

\section{DD}

Publicación: Field Mus. Nat. Hist., Bot. Ser. 13(2): 20. 1936.

Colección tipo: E.P. Killip \& A.C. Smith 25623

Herbarios: US.

Nombre común: D esconocido.

Registro departamental: PA.

Regiones Ecológicas: BMHM; 1600- 1900 m.

SINAN PE: Sin registro.

Herbarios peruanos: Ninguno.

Observaciones: Hierba epífita, conocida solamente de la colección tipo, una planta recolectada en 1929, de la cuenca alta del Palcazú, en Pasco. Antiguamente, la localidad oniginal era reconocida en Junín.

\section{Peperomia alismaefolia C. Presl}

\section{DD}

Publicación: Epim. Bot. 6: 582-583. 1851.

Colección tipo: G. Meyen s.n.

Henbarios: PR.

Nombre común: D esconocido.

Registro departamental: Sin datos.

Regiones Ecológicas: Sin datos; altitud desconocida.

SINAN PE: Sin registro.

Herbarios peruanos: Ninguno.

Observaciones: Hierba terrestre, conocida solamente de una localidad no especificada. Esta especie fue recolectada en el siglo XIX y no hay mayor información sobre ella.

Nota del Editor: En la versión on line de este artículo han sido omitidos los mapas del Perú que ilustraban el Registro departamental. Para ubicar las abreviaturas de los departamentos vea al final del artículo. 


\section{Peperomia andina G. Pino}

$$
\text { EN, Bla }
$$

Publicación: Peperomias de Cajamarca. 13, f. 1A. 2004.

Colección tipo: G. Pino 284

Herbarios: USM.

Nombre común: Lápara, munllu-munllu, papa madre.

Registro departamental: CA, LL.

Regiones Ecológicas: MA, PAR; 2700$3500 \mathrm{~m}$.

SINAN PE: Sin registro.

Herbarios peruanos: HAO (1), USM (holotipo citado+5).

Observaciones: Hierba tuberosa, conocida de laderas semixéricas en la cuenca del Marañón. En esta especie, el tallo está transformado a un tubérculo enterrado y estacionalmente produce hojas e inflorescencias; tal vez, por ello pase desapercibida.

\section{Peperomia anisophylla C. DC.}

\section{CR, B lab(iii)}

Publicación: Bot. Jahrb. Syst. 40: 266. 1908.

Colección tipo: A. Weberbauer 72

Henbarios: B, G

Nombre común: D esconocido.

Registro departamental: LI.

Regiones Ecológicas: MA; 2200-2370 m.

SINANPE: Sin registro.

Herbarios peruanos: Ninguno.

Observaciones: Hierba suculenta, conocida solamente de una localidad, la que erróneamente fue citada como Huánuco en Brako \& Zarucchi (1993). El ejemplar tipo fue recolectado en la cuenca alta del Rímac. No ha sido recolectada en más de 100 años. La localidad original ha sido modificada continuamente por construcción vial. A esto se suma condiciones naturales de sequía y aluviones estacionales que podrían afectar las poblaciones de esta especie.

\section{Peperomia apunimacana Trel.}

\section{DD}

Publicación: Field Mus. Nat. Hist., Bot. Ser. 13(2): 22. 1936.

Colección tipo: E.P. Killip \& A.C. Smith 22355

Herbarios: F, US.

Nombre común: D esconocido.

Registro departamental: AY.

Regiones Ecológicas: BMHM; 1500 m.

SINAN PE: Sin registro.

Herbarios peruanos: Ninguno.

Observaciones: Hierba epífita conocida solamente de la colección tipo, una planta recolectada en 1929, de la cuenca del Apurímac.

\section{Peperomia arborigaudens Trel.}

DD

Publicación: Field Mus. Nat. Hist., Bot. Ser. 13(2): 22. 1936

Colección tipo: E.P. Killip \& A.C. Smith 25509

Herbarios: NY, US.

Nombre común: D esconocido.

Registro departamental: JU.

Regiones Ecológicas: BMHM; 1350$1600 \mathrm{~m}$.

SINAN PE: Sin registro.

Herbarios peruanos: Ninguno.

Observaciones: Hierba epífita, conocida solamente de la colección tipo, una planta recolectada en 1929, de una localidad en la cuenca del Perené.

\section{Peperomia arboniseda C. DC. var. arboniseda}

\section{DD}

Publicación:

Colección tipo: A. Weberbauer 1917

Herbarios: B.

Nombre común: D esconocido.

Registro departamental: JU.

Regiones Ecológicas: BMHP; 1000 m.

SINANPE: Sin registro.

Hembarios peruanos: Ninguno.

Observaciones: Hierba epífita, descrita de una planta recolectada en 1902, de la cuenca del Tulumayo.

\section{Peperomia arboriseda C. DC . var. moyobombana}

\section{DD}

Publicación:

Colección tipo: A. Weberbauer 4691

Hemarios: $B$.

Nombre común: D esconocido.

Registro departamental: SM.

Regiones Ecológicas: BMHP; altitud desconocida.

SINAN PE: Sin registro.

Hemarios peruanos: Ninguno.

Observaciones: Hierba, probablemente epífita, recolectada en 1904, de la cuenca del Mayo.

\section{Peperomia arctebaccata Trel.}

\section{DD}

Publicación: Field Mus. Nat. Hist., Bot. Ser. 13(2): 23. 1936.

Colección tipo: C.O. Schunke 471

Hembarios: $F$.

Nombre común: D esconocido.

Registro departamental: JU.

Regiones Ecológicas: BMHP; $1000 \mathrm{~m}$.

SINAN PE: Sin registro.

Hembarios peruanos: Ninguno.

Observaciones: Hierba terrestre, recolectada en la década de 1920, de la cuenca del Tulumayo. La localidad original está ubicada cerca a La Merced y San Ramón, cuyos ambientes naturales han sido modificados desde el siglo XIX. 


\section{Peperomia ancuatispica Trel.}

DD

Publicación: Field Mus. Nat. Hist., Bot. Ser. 13(2): 23. 1936.

Colección tipo: E.P. Killip \& A.C. Smith 25992

Henbarios: US.

Nombre común: D esconocido.

Registro departamental: PA.

Regiones Ecológicas: BMHP; $1100 \mathrm{~m}$.

SINANPE: Sin registro.

Herbarios peruanos: Ninguno.

Observaciones: Hierba terrestre, recolectada de la cuenca del Pichis, en el departamento de Pasco, muy cerca al límite con Junín. Fue reconocida por Brako \& Zarucchi (1993) como de Junín.

\section{Peperomia areolata Trel.}

\section{DD}

Publicación: Field Mus. Nat. Hist., Bot. Ser. 13(2): 23. 1936. 1936.

Colección tipo: E.P. Killip \& A.C. Smith 28660

Herbarios: US.

Nombre común: D esconocido.

Registro departamental: HU, LO, SM.

Regiones Ecológicas: BHA; $150-350 \mathrm{~m}$. SINANPE: Sin registro.

Herbarios peruanos: Ninguno.

Observaciones: Hierba terrestre, conocida, al parecer, de dos localidades, en la cuenca del Huallaga, occidente de la Amazonía peruana.

\section{Peperomia artatiflora Trel.}

Publicación: Field Mus. Nat. Hist., Bot. Ser. 13(2): 23-24. 1936.

Colección tipo: Stevens 47

Hembarios: ILL.

Nombre común: D esconocido.

Registro departamental: JU.

Regiones Ecológicas: MA; altitud desconocida.

SINAN PE: Sin registro.

Herbarios peruanos: Ninguno.

Observaciones: Estetaxón fue considerado por Brako \& Zarucchi (1993) como un endemismo; sin embargo, no ha sido posible evaluarlo, ni asignarle una categoría.

\section{Peperomia asplundii Yunck.}

\section{DD}

Publicación: Amer. J. Bot. 43: 167-168. 1956.

Colección tipo: E. Asplund 12757

Herbarios: NY.

Nombre común: D esconocido.

Registro departamental: HU.

Regiones Ecológicas: BPM; $2750 \mathrm{~m}$.

SINAN PE: Sin registro.

Herbarios peruanos: Ninguno.

Observaciones: Hierba terrestre, conocida sólo de la localidad original, Carpish, la cual alberga varios endemismos. Fue recolectada en 1940.
16. Peperomia balsapuertana Trel.

DD

Publicación: Field Mus. Nat. Hist., Bot. Ser. 13(2): 24. 1936.

Colección tipo: E.P. Killip \& A.C. Smith 28632

Herbarios: US.

Nombre común: D esconocido.

Registro departamental: LO.

Regiones Ecológicas: BHA; 150- 350 m.

SINAN PE: Sin registro.

Herbarios peruanos: Ninguno.

Observaciones: Hierba epífita conocida de la colección tipo, una planta recolectada en 1929, de la cuenca del Huallaga.

\section{Peperomia binispica Trel.}

Publicación: Field Mus. Nat. Hist., Bot. Ser. 13(2): 25. 1936.

Colección tipo: C.O. Schunke 358

Herbarios: F.

Nombre común: D esconocido.

Registro departamental: JU.

Regiones Ecológicas: BMHP; 1200 m.

SINAN PE: Sin registro.

Herbarios peruanos: Ninguno.

Observaciones: Hierba conocida, aparentemente, de la colección tipo, una planta recolectada en la década de 1920, del valle de Chanchamayo.

\section{Peperomia boekei Callejas}

$$
\text { EN, B 1ab(iii) }
$$

Publicación: Brittonia 42(1): 73-75, f. 2. 1990.

Colección tipo: J.D. Boeke 2125

Herbarios: HUA, NY.

Nombre común: D esconocido.

Registro departamental: AM.

Regiones Ecológicas: PAR, BMHM; altitud desconocida.

SINANPE: ZRCC

Herbarios peruanos: USM (isotipo citado).

Observaciones: Hierba terrestre, suculenta, conocida, al parecer, de dos localidades aisladas, entre las cuencas del Utcubamba y Marañón. Una población se halla en la Zona Reservada Cordillera de Colán, donde no ha vuelto a ser registrada desde 1978. O cupa fragmentos de bosque montano y zonas ecotonales con pajonales, ambos ambientes amenazados por incendios intencionales y modificación de ellos.

\section{Pepenomia caducifolia Trel.}

\section{DD}

Publicación: Field Mus. Nat. Hist., Bot. Ser. 13(2): 26. 1936.

Colección tipo: E.P. Killip \& A.C. Smith 22270

Herbarios: US.

Nombre común: D esconocido.

Registro departamental: AY.

Regiones Ecológicas: BPM; 3000 m.

SINANPE: Sin registro.

Henbarios peruanos: Ninguno. 
Observaciones: Hierba terrestre, recolectada en 1929, de la cuenca del Apurímac.

\section{Peperomia calvescens Trel.}

$$
\text { CR, B lab(iii) }
$$

Publicación: Field Mus. Nat. Hist., Bot. Ser. 13(2): 27. 1936.

Colección tipo: J.F. Macbride 4800

Herbarios: F.

Nombre común: D esconocido.

Registro departamental: PA.

Regiones Ecológicas: BMHP; $1050 \mathrm{~m}$.

SINAN PE: Sin registro.

Herbarios peruanos: Ninguno.

Observaciones: Hierba conocida solamente de una localidad en el centro del país, en la cuenca del Pozuzo. D esde la colección de esta planta, en la década de 1920, ha habido una extensa deforestación en la zona por expansión agrícola. La localidad original fue citada para el departamento de Huánuco por Trelease (1936) y Brako \& Zarucchi (1993), pero en realidad se halla hoy ubicada en Pasco.

\section{Peperomia caniana Trel.}

\section{DD}

Publicación: Field Mus. Nat. Hist., Bot. Ser. 13(2): 27. 1936.

Colección tipo: J.F. Macbride 3415

Herbarios: $F$.

Nombre común: D esconocido.

Registro departamental: HU.

Regiones Ecológicas: BMHM; $2550 \mathrm{~m}$.

SINAN PE: Sin registro.

Herbarios peruanos: Ninguno.

Observaciones: Hierba terrestre, recolectada en 1923, de la cuenca del Huallaga.

\section{Peperomia cereoides Pino \& Cieza}

\section{EN, Bla}

Publicación: Cactus \& Succ. J. 75(1): 27,

f. 1-9, pl. 1-2. 2003.

Colección tipo: $\mathrm{G}$. Pino 689

Herbarios: USM.

Nombre común: D esconocido.

Registro departamental: CA.

Regiones Ecológicas: MA; 3070 m.

SINAN PE: Sin registro.

Herbarios penuanos: USM (holotipo).

Observaciones: Hierba conocida aparentemente de una localidad, en la cuenca del Marañón. Esta especie se halla en cultivo en Cajamarca.

\section{Peperomia chrysotricha Miq.}

Publicación: Syst. Piperac. 1631843.

Colección tipo: J. D ombey 933

Herbarios: P.

Nombre común: D esconocido.

Registro departamental: Sin datos.

Regiones Ecológicas: Sin datos; altitud desconocida.

SINANPE: Sin registro.

Herbarios peruanos: Ninguno.
Observaciones: Este taxón fue considerado por Brako \& Zarucchi (1993) como un endemismo; sin embargo, no ha sido posible evaluarlo, ni asignarle una categoría.

\section{Pepenomia ciliatifolia Trel. var. eciliatifolia Trel.}

\section{DD}

Publicación: Field Mus. Nat. Hist., Bot. Ser. 13(2): 31. 1936.

Colección tipo: E.P. Killip \& A.C. Smith 28723

Herbarios: ILL, US.

Nombre común: D esconocido.

Registro departamental: LO.

Regiones Ecológicas: BHA; $135 \mathrm{~m}$.

SINAN PE: Sin registro.

Herbarios peruanos: Ninguno.

Observaciones: Hierba epífita recolectada, aparentemente, una sola vez, en 1929, de la cuenca del Huallaga.

\section{Peperomia ciliatifolia Trel. var. iquitosana Trel.}

\section{DD}

Publicación: Field Mus. Nat. Hist., Bot. Ser. 13(2): 31. 1936.

Colección tipo: E.P. Killip \& A.C. Smith 27167

Herbarios: US.

Nombre común: D esconocido.

Registro departamental: LO.

Regiones Ecológicas: BHA; 100 m.

SINAN PE: Sin registro.

Herbarios peruanos: Ninguno.

Observaciones: Hierba epífita conocida solamente de la colección tipo, una planta recolectada en 1929, de los alrededores de Iquitos.

\section{Peperomia columella Rauh \& Hutchison}

\section{DD}

Publicación: Cact. Succ. J. (Los Angeles) 45: 152. 1973.

Colección tipo: P.C. Hutchison \& J.K. Wright 4015

Herbarios: UC.

Nombre común: D esconocido.

Registro departamental: AM.

Regiones Ecológicas: MDE; 1300—1900 m.

SINANPE: Sin registro.

Herbarios peruanos: Ninguno.

Observaciones: Hierba suculenta, conocida de la cuenca del Utcubamba (Pino, 1998), de laderas semixéricas, rocosas. Fue descrita en 1964, conociéndose de un registro adicional en 1998. Poco se sabe, sin embargo, del tamaño de sus poblaciones.

\section{Peperomia condulilimba C. DC.}

Publicación: Bot. Jahrb. Syst. 40: 261. 1908.

Colección tipo: A. Weberbauer 1197

Herbarios: $B$.

Nombre común: D esconocido.

Registro departamental: PU.

Regiones Ecológicas: BMHP; $1000 \mathrm{~m}$.

SINANPE: Sin registro.

Herbarios peruanos: Ninguno. 
Observaciones: Este taxón fue considerado por Brako \& Zarucchi (1993) como un endemismo; sin embargo, no ha sido posible evaluarlo, ni asignarle una categoría.

\section{Peperomia cotoneasterifolia Trel.}

Publicación: Field Mus. Nat. Hist., Bot. Ser. 13(2): 33. 1936.

Colección tipo: E.P. Killip \& A.C. Smith 24390

Herbarios: US.

Nombre común: D esconocido.

Registro departamental: JU.

Regiones Ecológicas: BMHM; 2700$3200 \mathrm{~m}$.

SINAN PE: Sin registro.

Herbarios peruanos: Ninguno.

Observaciones: Este taxón fue considerado por Brako \& Zarucchi (1993) como un endemismo; sin embargo, no ha sido posible evaluarlo, ni asignarle una categoría.

\section{Peperomia crinigera Trel.}

Publicación: Field Mus. Nat. Hist., Bot. Ser. 13(2): 33-34. 1936.

Colección tipo: Stevens 45

Hemarios: $F$.

Nombre común: D esconocido.

Registro departamental: JU.

Regiones Ecológicas: MA; 2400-3000 m.

SINANPE: Sin registro.

Herbarios peruanos: Ninguno.

Observaciones: Este taxón fue considerado por Brako \& Zarucchi (1993) como un endemismo; sin embargo, no ha sido posible evaluarlo, ni asignarle una categoría.

\section{Peperomia cruciata Trel.}

Publicación: Field Mus. Nat. Hist., Bot. Ser. 13(2): 34. 1936.

Colección tipo: C.O. Schunke 343

Herbarios: $F$.

Nombre común: D esconocido.

Registro departamental: JU.

Regiones Ecológicas: BMHP; 800 m.

SINANPE: Sin registro.

Herbarios peruanos: Ninguno.

Observaciones: Este taxón fue considerado por Brako \& Zarucchi (1993) como un endemismo; sin embargo, no ha sido posible evaluarlo, ni asignarle una categoría.

\section{Peperomia crusculibacca Trel.}

Publicación: Field Mus. Nat. Hist., Bot. Ser. 13(2): 34-35. 1936.

Colección tipo: Stevens 90

Herbarios: F.

Nombre común: D esconocido.

Registro departamental: JU.

Regiones Ecológicas: BPM; altitud desconocida.

SINAN PE: Sin registro.

Herbarios peruanos: Ninguno.
Observaciones: Este taxón fue considerado por Brako \& Zarucchi (1993) como un endemismo; sin embargo, no ha sido posible evaluarlo, ni asignarle una categoría.

\section{Peperomia crystallina Ruiz \& Pav.}

\section{DD}

Publicación: Flora 1: 30. 1798.

Colección tipo: H. Ruiz \& J. Pavón s.n.

Herbarios: MA.

Nombre común: D esconocido.

Registro departamental: LI.

Regiones Ecológicas: Sin datos; altitud desconocida.

SINAN PE: Sin registro.

Hemarios peruanos: Ninguno.

Observaciones: Hierba suculenta, conocida solamente de una localidad. Trelease (1936) comentó sobre la incertidumbre en su relación con otras especies en el género. No se conoce además detalles del hábitat y rango altitudinal.

\section{Peperomia dasystachia Miq.}

\section{DD}

Publicación: London J. Bot. 4: 416. 1845. Colección tipo: A. Mathews 3229

Herbarios: $\mathrm{G}$.

Nombre común: D esconocido.

Registro departamental: AM.

Regiones Ecológicas: Sin datos; altitud desconocida.

SINANPE: Sin registro.

Herbarios peruanos: Ninguno.

Observaciones: Esta especie herbácea fue recolectada en Amazonas, en el siglo XIX. No se conoce con exactitud la localidad, altitud, ni hábitat de esta especie.

\section{Peperomia deceptrix Trel.}

\section{DD}

Publicación: Field Mus. Nat. Hist., Bot. Ser. 13(2): 38. 1936.

Colección tipo: E.P. Killip \& A.C. Smith 29325

Herbanios: F, NY, US

Nombre común: D esconocido.

Registro departamental: LO.

Regiones Ecológicas: BHA; $110 \mathrm{~m}$.

SINAN PE: Sin registro.

Herbarios peruanos: Ninguno.

Observaciones: Hierba epífita, recolectada en 1929, de la cuenca del Itaya, un tributario del Amazonas.

\section{Peperomia deficiens Trel.}

Publicación: Field Mus. Nat. Hist., Bot. Ser. 13(2): 38. 1936.

Colección tipo: L. Williams 5758a

Herbarios: $F$.

Nombre común: D esconocido.

Registro departamental: SM.

Regiones Ecológicas: BHA; 360-900 m.

SINANPE: Sin registro.

Herbarios peruanos: Ninguno. 
Observaciones: Este taxón fue considerado por Brako \& Zarucchi (1993) como un endemismo; sin embargo, no ha sido posible evaluarlo, ni asignarle una categoría.

\section{Peperomia dendroides Trel.}

\section{DD}

Publicación: Field Mus. Nat. Hist., Bot. Ser. 13(2): 38. 1936.

Colección tipo: J.F. Macbride 3640

Herbarios: $F$.

Nombre común: D esconocido.

Registro departamental: HU, JU.

Regiones Ecológicas: BMHM; $2700 \mathrm{~m}$.

SINAN PE: Sin registro.

Herbarios peruanos: Ninguno.

Observaciones: Hierba epífita, descrita de una planta recolectada en 1922, del centro del país, probablemente de un tributario del Tulumayo. Brako \& Zarucchi (1993) no la señalaron como un endemismo. Un ejemplar adicional fue citado por Trelease (1936), procedente de la cuenca del Huallaga. Poco se sabe de sus poblaciones y de su hábitat.

\section{Peperomia dendromorphis Trel.}

Publicación: Field Mus. Nat. Hist., Bot. Ser. 13(2): 39. 1936.

Colección tipo: A. Weberbauer 7800

Herbarios: $F$.

Nombre común: D esconocido.

Registro departamental: CU.

Regiones Ecológicas: BMHM; $3000 \mathrm{~m}$.

SINAN PE: Sin registro.

Herbarios peruanos: Ninguno.

Observaciones: Este taxón fue considerado por Brako \& Zarucchi (1993) como un endemismo; sin embargo, no ha sido posible evaluarlo, ni asignarle una categoría.

\section{Peperomia dependens Ruiz \& Pav.}

Publicación: Flora 1: 33, t. 48. 1798.

Colección tipo: H. Ruiz \& J. Pavón s.n.

Henbarios: G, MA.

Nombre común: D esconocido.

Registro departamental: AM, CA, HU.

Regiones Ecológicas: MDE, BS; $500-$

$1900 \mathrm{~m}$.

SINAN PE: Sin registro.

Herbarios peruanos: HAO (1).

Observaciones: Esta especie se conoce de tres localidades en el norte y centro del país. Información sobre la localidad original es incompleta; Trelease (1936) mencionó Pozuzo, pero el hábitat en ese lugar es muy distinto que las presentes en la cuenca del Marañón.

\section{Peperomia diehliana Trel.}

\section{DD}

Publicación: Field Mus. Nat. Hist., Bot. Ser. 13(2): 39-40 1936.

Colección tipo: A. Diehl 2526

Herbarios: F.

Nombre común: D esconocido.

Registro departamental: CU.

Regiones Ecológicas: Sin datos; altitud desconocida.

SINANPE: Sin registro.

Herbarios peruanos: Ninguno.
Observaciones: Hierba suculenta, conocida solamente de una localidad, probablemente en Cusco. No ha vuelto a ser recolectada en otro lugar, ni se conoce más detalles del hábitat de esta especie.

\section{Pepenomia distractiflora Trel.}

Publicación: Field Mus. Nat. Hist., Bot. Ser. 13(2): 40. 1936.

Colección tipo: Stevens 214

Herbarios: $F$.

Nombre común: D esconocido.

Registro departamental: JU.

Regiones Ecológicas: Sin datos; altitud desconocida.

SINANPE: Sin registro.

Herbarios peruanos: Ninguno.

Observaciones: Este taxón fue considerado por Brako \& Zarucchi (1993) como un endemismo; sin embargo, no ha sido posible evaluarlo, ni asignarle una categoría.

\section{Peperomia dolabella Rauh \& Kimnach}

$$
\text { EN, Bla }
$$

Publicación: Cact. Succ. J. (Los Angeles) 59: 5. 1987.

Colección tipo: R. Kimnach \& S. Linden 2895b

Herbarios: HEID.

Nombre común: Linli-linli.

Registro departamental: CA

Regiones Ecológicas: MA; 2500-3200 m.

SINANPE: Sin registro.

Hemarios penuanos: USM?.

Observaciones: Hierba acaule, diminuta, conocida de la cuenca media del río Cajamarca. Permanece sin hojas durante la estación seca, de junio a setiembre, pasando desapercibida durante esta época. Amenazas potenciales provienen de las actividades agro-pastoriles que modifican el hábitat de esta especie.

\section{Peperomia dolabriformis Kunth var. velutina Trel.}

\section{DD}

Publicación: Field Mus. Nat. Hist., Bot. Ser. 13(2): 40. 1936.

Colección tipo: A. Weberbauer 3797

Hemarios: $B$.

Nombre común: Desconocido.

Registro departamental: CA.

Regiones Ecológicas: D ST; 500-600 m.

SINAN PE: Sin registro.

Herbarios peruanos: Ninguno.

Observaciones: Hierba suculenta, conocida aparentemente, sólo de la colección tipo, una planta recolectada en 1904, de la cuenca del Chicama. Pino (2004) comentó sobre la presencia de la especie en Cajamarca, pero no incluyó esta variedad.

\section{Peperomia drapeta Trel.}

Publicación: Field Mus. Nat. Hist., Bot. Ser. 13(2): 40-41. 1936.

Colección tipo: J.F. Macbride 4122

Herbarios: F.

Nombre común: D esconocido.

Registro departamental: $\mathrm{HU}$.

Regiones Ecológicas: MA; 1950 m.

SINAN PE: Sin registro.

Herbarios peruanos: Ninguno. 
Observaciones: Este taxón fue considerado por Brako \& Zarucchi (1993) como un endemismo; sin embargo, no ha sido posible evaluarlo, ni asignarle una categoría.

44. Peperomia ellipticorhombea C. DC.

DD

Publicación: Prodr. 16(1): 407. 1869.

Colección tipo: A. Mathews 1835

Herbarios: K.

Nombre común: D esconocido.

Registro departamental: HU, SM.

Regiones Ecológicas: Sin datos; altitud desconocida.

SINANPE: Sin registro.

Herbarios peruanos: Ninguno.

Observaciones: Hierba erecta, conocida de tres localidades, todas registradas en el siglo XIX.

\section{Peperomia enckeaefolia Trel.}

\section{DD}

Publicación: Field Mus. Nat. Hist., Bot. Ser. 13(2): 42. 1936.

Colección tipo: E.P. Killip \& A.C. Smith 29201

Herbarios: US.

Nombre común: D esconocido.

Registro departamental: LO.

Regiones Ecológicas: BHA; $150 \mathrm{~m}$.

SINAN PE: Sin registro.

Herbarios peruanos: Ninguno.

Observaciones: Hierba terrestre, conocida solamente de la colección tipo, una planta recolectada en 1929, de una localidad sobre la cuenca del Marañón, en el occidente de Loreto.

46. Peperomia enenyasensis Trel.

Publicación: Field Mus. Nat. Hist., Bot. Ser. 13(2): 42. 1936.

Colección tipo: E.P. Killip \& A.C. Smith 25654

Herbarios: US.

Nombre común: D esconocido.

Registro departamental: PA.

Regiones Ecológicas: BMHM; 1600$1900 \mathrm{~m}$.

SINANPE: Sin registro.

Herbarios peruanos: Ninguno.

Observaciones: Hierba epífita, conocida, al parecer, sólo de la localidad original, donde fue recolectada en 1929. La localidad original fue citada para el departamento de Junín por Trelease (1936) y Brako \& Zarucchi (1993), pero en realidad se halla hoy ubicada en Pasco.

\section{Peperomia erythrocorma Trel.}

\section{DD}

Publicación: Field Mus. Nat. Hist., Bot. Ser. 13(2): 43. 1936.

Colección tipo: J.F. Macbride 4678

Herbarios: $F$.

Nombre común: D esconocido.

Registro departamental: PA.

Regiones Ecológicas: BMHP; $600 \mathrm{~m}$.

SINANPE: Sin registro.

Herbarios peruanos: Ninguno.
Observaciones: Hierba terrestre, descrita de una planta recolectada en Pozuzo, en 1923, hoy en el D epartamento de Pasco.

\section{Peperomia erythrostachya Trel.}

DD

Publicación: Field Mus. Nat. Hist., Bot. Ser. 13(2): 43. 1936.

Colección tipo: J.F. Macbride 4667

Herbarios: F, US.

Nombre común: D esconocido.

Registro departamental: PA.

Regiones Ecológicas: BMHP; $600 \mathrm{~m}$.

SINANPE: Sin registro.

Herbarios peruanos: Ninguno.

Observaciones: Hierba conocida de una localidad, registrada en 1923 en Huánuco, pero la localidad corresponde hoy a Pasco.

\section{Peperomia estrellana Trel.}

\section{DD}

Publicación: Field Mus. Nat. Hist., Bot. Ser. 13(2): 43. 1936.

Colección tipo: E.P. Killip \& A.C. Smith 23064

Herbarios: ILL, US.

Nombre común: D esconocido.

Registro departamental: AY.

Regiones Ecológicas: BHA; 500 m.

SINAN PE: Sin registro.

Herbarios peruanos: Ninguno.

Observaciones: Hierba epífita, conocida, aparentemente, sólo del ejemplar tipo, una planta recolectada en 1929, de la cuenca del Apurímac, una zona que ha sido escasamente herborizada.

\section{Peperomia exiguispica Trel.}

\section{DD}

Publicación: Field Mus. Nat. Hist., Bot. Ser. 13(2): 44. 1936.

Colección tipo: L. Williams 5331

Hemarios: F, ILL.

Nombre común: D esconocido.

Registro departamental: LO.

Regiones Ecológicas: BHA; 155- 210 m.

SINANPE: Sin registro.

Herbarios peruanos: Ninguno.

Observaciones: Hierba epífita, descrita de una planta recolectada en 1929, de la cuenca del Marañón.

\section{Pepenomia exilamenta Trel.}

\section{DD}

Publicación: Field Mus. Nat. Hist., Bot. Ser. 13(2): 44. 1936.

Colección tipo: L. Williams 5722

Hembarios: $F$.

Nombre común: D esconocido.

Registro departamental: SM.

Regiones Ecológicas: BHA; 360-900 m.

SINANPE: Sin registro.

Herbarios peruanos: Ninguno.

Observaciones: Hierba conocida sólo de la localidad original, en la cuenca del Mayo. Fue recolectada en 1929. 


\section{Peperomia exiliramea Trel.}

\section{DD}

Publicación: Field Mus. Nat. Hist., Bot. Ser. 13(2): 44. 1936.

Colección tipo: E.P. Killip \& A.C. Smith 28768

Herbarios: US.

Nombre común: D esconocido.

Registro departamental: LO.

Regiones Ecológicas: BHA; $135 \mathrm{~m}$.

SINANPE: Sin registro.

Herbarios peruanos: Ninguno.

Observaciones: Hierba epífita, conocida de una localidad, sobre la cuenca del Marañón y recolectada en 1929.

\section{Peperomia falsa A.W. Hill}

\section{DD}

Publicación: Ann. Bot. (Oxford) 21: 151, t. 15. 1907.

Colección tipo: A. Weberbauer 451

Herbarios: $F$,

Nombre común: D esconocido.

Registro departamental: PU.

Regiones Ecológicas: PSH; 3700 m.

SINAN PE: Sin registro.

Herbarios peruanos: Ninguno.

Observaciones: Hierba terrestre, acaule, recolectada en 1902, de ambientes rocosos en la puna del sur del país, en la cuenca del Ramis.

\section{Peperomia famelica Trel.}

\section{DD}

Publicación: Field Mus. Nat. Hist., Bot. Ser. 13(2): 45. 1936.

Colección tipo: E.P. Killip \& A.C. Smith 23961

Herbarios: US.

Nombre común: D esconocido.

Registro departamental: JU.

Regiones Ecológicas: BMHP; 800- 1300

$\mathrm{m}$.

SINAN PE: Sin registro.

Herbarios peruanos: Ninguno.

Observaciones: Hierba terrestre, conocida de una planta recolectada en 1929, de la cuenca del Tulumayo.

\section{Peperomia ferreyrae Y unck.}

$$
\text { EN, Bla }
$$

Publicación: Amer. J. Bot. 43: 168. 1956. Colección tipo: R. Ferreyra 7592

Herbarios: US.

Nombre común: Congona amarilla.

Registro departamental: AM.

Regiones Ecológicas: BS; 1500- 2020 m.

SINANPE: Sin registro.

Hemarios peruanos: AMAZ (1), USM (1).

Observaciones: Hierba suculenta, conocida de la cuenca del Utcubamba, donde en la localidad original es escasa, aunque sus poblaciones son mayores en otras partes de la cuenca (Pino, 1998).
56. Pepenomia ficta Trel.

DD

Publicación: Field Mus. Nat. Hist., Bot. Ser. 13(2): 45. 1936.

Colección tipo: E.P. Killip \& A.C. Smith 23989

Herbarios: US.

Nombre común: D esconocido.

Registro departamental: JU.

Regiones Ecológicas: BMHP; 800- 1300

$\mathrm{m}$.

SINAN PE: Sin registro.

Herbarios peruanos: Ninguno.

Observaciones: Hierba terrestre, recolectada en 1929, de la cuenca del Tulumayo.

\section{Peperomia fissicola Trel.}

Publicación: Field Mus. Nat. Hist., Bot. Ser. 13(2): 46. 1936.

Colección tipo: J.F. Macbride 3255

Hemarios: $F$.

Nombre común: D esconocido.

Registro departamental: $\mathrm{HU}$.

Regiones Ecológicas: MA; 2100 m.

SINAN PE: Sin registro.

Herbarios peruanos: Ninguno.

Observaciones: Este taxón fue considerado por Brako \& Zarucchi (1993) como un endemismo; sin embargo, no ha sido posible evaluarlo, ni asignarle una categoría.

\section{Peperomia flabilis Trel.}

\section{DD}

Publicación: Field Mus. Nat. Hist., Bot. Ser. 13(2): 46. 1936.

Colección tipo: L. Williams 2988

Hembarios: $F$.

Nombre común: D esconocido.

Registro departamental: LO.

Regiones Ecológicas: $\mathrm{BHA}$; altitud desconocida.

SINANPE: Sin registro.

Herbarios peruanos: Ninguno.

Observaciones: Hierba terrestre, conocida de la colección tipo, una planta recolectada en 1924, de la cuenca del Amazonas.

\section{Peperomia flavamenta Trel.}

\section{DD}

Publicación: Field Mus. Nat. Hist., Bot. Ser. 13(2): 46. 1936.

Colección tipo: G. Klug 987

Hembarios: F, NY, US.

Nombre común: D esconocido.

Registro departamental: LO.

Regiones Ecológicas: BHA; $100 \mathrm{~m}$.

SINANPE: Sin registro.

Herbarios peruanos: Ninguno.

Observaciones: Hierba repente y suculenta, conocida aparentemente sólo de la colección tipo, una planta recolectada en 1930, de los alrededores de Iquitos. 
60. Peperomia flavescens C. DC . var. lechleri Trel.

DD

Publicación: Field Mus. Nat. Hist., Bot. Ser. 13(2): 47. 1936.

Colección tipo: W. Lechler 2691pp

Herbarios: $\mathrm{K}$.

Nombre común: D esconocido.

Registro departamental: PU.

Regiones Ecológicas: Sin datos; altitud desconocida.

SINAN PE: Sin registro.

Herbarios peruanos: Ninguno.

Observaciones: Hierba recolectada en el siglo XIX, de la cuenca del San Gabán. Se desconoce la procedencia exacta y las características de su hábitat.

61. Peperomia flavescens C. DC. var. markhami Trel.

\section{DD}

Publicación: Field Mus. Nat. Hist., Bot. Ser. 13(2): 47. 1936.

Colección tipo: C.R. Markham 4

Herbarios: K.

Nombre común: D esconocido.

Registro departamental: PU.

Regiones Ecológicas: Sin datos; altitud desconocida.

SINANPE: Sin registro.

Herbarios peruanos: Ninguno.

Observaciones: Hierba conocida solamente de una localidad, probablemente en Puno, sin mayores indicaciones del hábito y altitud. No havuelto a ser recolectada desde inicios del siglo XX. Si la localidad original se ubicara en lacuenca del nóo Tambopataa altitudes intermedias, entonces podńaestarrepresentadaen el ParqueNacional Bahuaja-Sonene.

\section{Peperomia fortipes Trel.}

\section{DD}

Publicación: Field Mus. Nat. Hist., Bot. Ser. 13(2): 48. 1936.

Colección tipo: E.P. Killip 22589

Herbarios: ILL, US

Nombre común: D esconocido.

Registro departamental: AY.

Regiones Ecológicas: BMHP; 750$1000 \mathrm{~m}$.

SINAN PE: Sin registro.

Herbarios peruanos: Ninguno.

Observaciones: Hierba conocida sólo de una localidad, en la cuenca del Apurímac. Fue descrita de una planta recolectada en 1929.

\section{Peperomia fragilissima Trel.}

\section{DD}

Publicación: Field Mus. Nat. Hist., Bot. Ser. 13(2): 48. 1936.

Colección tipo: R. Spruce s.n.

Herbarios: $\mathrm{K}$.

Nombre común: D esconocido.

Registro departamental: LO.

Regiones Ecológicas: BHA; altitud desconocida.

SINANPE: Sin registro.

Herbarios peruanos: Ninguno.

Observaciones: Hierba terrestre, conocida y descrita de una planta recolectada en el siglo XIX, de la cuenca del Huallaga.
64. Pepenomia furcata 0 piz

DD

Publicación: Reliq. Haenk. 1(3): 164. 1828.

Colección tipo: T. Haenke s.n.

Herbarios: PR.

Nombre común: D esconocido.

Registro departamental: HU.

Regiones Ecológicas: Sin datos; altitud desconocida.

SINAN PE: Sin registro.

Herbarios peruanos: Ninguno.

Observaciones: Planta herbácea, descrita de una planta recolectada a fines del siglo XVIII, de una localidad desconocida.

\section{Peperomia fuscispica C. DC.}

\section{DD}

Publicación: Bot. Jahrb. Syst. 40: 260261. 1908

Colección tipo: A. Weberbauer 3627

Herbarios: B; MOL!

Nombre común: D esconocido.

Registro departamental: HU.

Regiones Ecológicas: BMHP; 600— 700 m.

SINANPE: Sin registro.

Herbarios penuanos: MOL (lectotipo).

Observaciones: Hierba epífita, recolectada en 1903. de la cuenca del Monzón. Esta cuenca incluye varios otros endemismos, desafortunadamente no ha sido herborizada en detalle los últimos 50 años.

66. Peperomia gayi C. DC.

\section{DD}

Publicación: Annuaire Conserv. Jard. Bot. Geneve 2: 283. 1898.

Colección tipo: C. G ay 2181

Herbarios: P.

Nombre común: D esconocido.

Registro departamental: Sin datos.

Regiones Ecológicas: Sin datos; altitud desconocida.

SINAN PE: Sin registro.

Hembarios peruanos: Ninguno.

Observaciones: Hierba conocida de la colección original, recolectada en una localidad no precisada, en el siglo XIX.

\section{Peperomia gibbaC. DC.}

\section{DD}

Publicación: Verh. Bot. Vereins Prov. Brandenburg 47: 116. 1905.

Colección tipo: E.H.G. Ule 6322

Herbarios: Sin datos.

Nombre común: D esconocido.

Registro departamental: SM.

Regiones Ecológicas: BHA; altitud desconocida.

SINAN PE: Sin registro.

Herbarios peruanos: Ninguno.

Observaciones: Hierba conocida solamente de una localidad, en la cuenca del Cainarache, un afluente del Huallaga, en la provincia de Lamas, del departamento de San Martín y erróneamente listada como de Loreto en Brako \& Zarucchi (1993). No ha vuelto a ser registrada desde 1902. 


\section{Pepenomia gilberti Trel.}

\section{DD}

Publicación: Field Mus. Nat. Hist., Bot. Ser. 13(2): 50. 1936.

Colección tipo: O.F. Cook \& G.B. Gilbert 740

Herbarios: US.

Nombre común: D esconocido.

Registro departamental: CU.

Regiones Ecológicas: BMHM; $3000 \mathrm{~m}$.

SINANPE: Sin registro.

Hembarios peruanos: Ninguno.

Obsenvaciones: Hierba conocida sólo de la localidad oniginal, en la cuenca del Unubamba. Fue recolectada en 1915, durante la expedición de la Universidad de Yale, a sitios arqueológicos de esa cuenca.

\section{Peperomia glabrirhachis Trel.}

\section{DD}

Publicación: Field Mus. Nat. Hist., Bot. Ser. 13(2): 50. 1936.

Colección tipo: Stevens 211

Hemarios: $F$.

Nombre común: D esconocido.

Registro departamental: HU, JU, PA.

Regiones Ecológicas: BMHM; altitud desconocida.

SINANPE: Sin registro.

Hemarios peruanos: Ninguno.

Observaciones: Hierba cespitosa, conocida de unas pocas colecciones provenientes del centro del país. Esta especie es conocida de ejemplares recolectados hasta 1929, en las cuencas del Tulumayo, Pichis y Palca. Se desconoce el estado actual de sus poblaciones.

\section{Peperomia glareosa Trel.}

\section{DD}

Publicación: Field Mus. Nat. Hist., Bot. Ser. 13(2): 50. 1936.

Colección tipo: Y. Mexia 6236

Herbarios: UC.

Nombre común: D esconocido.

Registro departamental: AM.

Regiones Ecológicas: BHA; $200 \mathrm{~m}$.

SINAN PE: Sin registro.

Herbarios peruanos: Ninguno.

Observaciones: Especie herbácea conocida, aparentemente, sólo de la colección tipo, una planta recolectada en la cuenca del Santiago. Esta localidad fue citada por Trelease (1936) y luego por Brako \& Zarucchi (1993) como ubicada en Loreto.

\section{Peperomia granulatifolia Trel.}

\section{DD}

Publicación: Field Mus. Nat. Hist., Bot. Ser. 13(2): 50. 1936.

Colección tipo: E.P. Killip \& A.C. Smith 26390

Herbarios: US.

Nombre común: D esconocido.

Registro departamental: PA.

Regiones Ecológicas: BHA; $400 \mathrm{~m}$.

SINANPE: Sin registro.

Herbarios peruanos: Ninguno.
Observaciones: Esta especie herbácea se conoce solamente de una localidad, ubicada en la cuenca del Pichis. Esta localidad original fue citada para el departamento de Junín por Trelease (1936) y Brako \& Zarucchi (1993), pero en realidad se halla hoy ubicada en Pasco.

\section{Peperomia guayrapurana Trel.}

\section{DD}

Publicación: Field Mus. Nat. Hist., Bot. Ser. 13(2): 51. 1936.

Colección tipo: R. Spruce 4010

Herbarios: $\mathrm{K}$.

Nombre común: D esconocido.

Registro departamental: SM.

Regiones Ecológicas: BMHP; 330-700 m.

SINAN PE: Sin registro.

Herbarios peruanos: Ninguno.

Observaciones: Hierba terrestre, recolectada en el siglo XIX, de una montaña cerca de Tarapoto, en la cuenca del Mayo. Se desconoce las características de sus poblaciones.

\section{Peperomia guyacana Trel.}

\section{DD}

Publicación: Field Mus. Nat. Hist., Bot. Ser. 13(2): 51- 52. 1936.

Colección tipo: F. Herrera 1464

Herbarios: US.

Nombre común: D esconocido.

Registro departamental: CU.

Regiones Ecológicas: MA; 3000 m.

SINAN PE: Sin registro.

Herbarios peruanos: Ninguno.

Observaciones: Hierba descrita de una planta recolectada en 1927, de la cuenca del Urubamba. Se desconoce las características de sus poblaciones.

\section{Peperomia haenkeana 0 piz}

\section{DD}

Publicación: Reliq. Haenk. 1(3): 162. 1828.

Colección tipo: T. Haenke s.n.

Herbarios:

Nombre común: D esconocido.

Registro departamental: LL.

Regiones Ecológicas: MDE; $2000 \mathrm{~m}$.

SINAN PE: Sin registro.

Henbarios penuanos: HUT (1).

Observaciones: Hierba perenne, descrita de una planta recolectada en una localidad desconocida, en el siglo XVIII. Un ejemplar de La Libertad se atribuye a esta especie. Sin embargo, se desconoce las características de sus poblaciones.

\section{Peperomia hamiltonianifolia Trel.}

\section{DD}

Publicación: Field Mus. Nat. Hist., Bot. Ser. 13(2): 52. 1936.

Colección tipo: C. G ay s.n.

Herbarios: P.

Nombre común: D esconocido.

Registro departamental: Sin datos.

Regiones Ecológicas: Sin datos; altitud desconocida.

SINAN PE: Sin registro.

Henbarios peruanos: Ninguno. 
Observaciones: Hierba terrestre, conocida aparentemente, sólo de la localidad original, de ubicación exacta desconocida y registrada en el siglo XIX.

\section{Peperomia herrerae Trel.}

Publicación: Field Mus. Nat. Hist., Bot. Ser. 13(2): 52- 53. 1936.

Colección tipo: F. Herrera s.n.

Herbarios: US.

Nombre común: D esconocido.

Registro departamental: $\mathrm{CU}$.

Regiones Ecológicas: MA; 3500 m.

SINAN PE: Sin registro.

Herbarios peruanos: Ninguno.

Observaciones: Este taxón fue considerado por Brako \& Zarucchi (1993) como un endemismo; sin embargo, no ha sido posible evaluarlo, ni asignarle una categoría.

\section{Pepenomia heterostachya A. Dietr.}

\section{DD}

Publicación: Syn. Pl. 1: 717. 1831.

Colección tipo: T. Haenke s.n.

Herbarios: PR.

Nombre común: D esconocido.

Registro departamental: HU.

Regiones Ecológicas: Sin datos; altitud desconocida.

SINANPE: Sin registro.

Herbarios peruanos: Ninguno.

Observaciones: Hierba terrestre, suculenta, aparentemente, conocida del ejemplar tipo, una planta recolectada en el siglo XVIII, de procedencia exacta desconocida.

78. Peperomia hispiduliformis Trel. var. ciliosa Yunck.

$$
\text { EN, Bla }
$$

Publicación: Brittonia 13(1): 63. 1961.

Colección tipo: F. Woytkowski 1560

Herbarios: D PU; MOL.

Nombre común: D esconocido.

Registro departamental: HU, PA.

Regiones Ecológicas: $\mathrm{BMHP}, \mathrm{BHA}$; 400- $950 \mathrm{~m}$.

SINANPE: Sin registro.

Herbarios penuanos: MOL (isotipo).

Observaciones: Hierba terrestre, conocida aparentemente de dos localidades, en el centro del país. El ejemplar tipo fue recolectado en 1934, en la cuenca del Monzón, un tributario del Huallaga. Esta especie se conoce también de las laderas de la Cordillera San Matías muy cerca al Parque Nacional Yanachaga-Chemillén.

\section{Peperomia huacahiana Trel.}

Publicación: Field Mus. Nat. Hist., Bot. Ser. 13(2): 53-54. 1936.

Colección tipo: J.F. Macbride 3899

Herbarios: $F$.

Nombre común: D esconocido.

Registro departamental: HU.

Regiones Ecológicas: MA; altitud desconocida.

SINAN PE: Sin registro.

Herbarios peruanos: Ninguno.
Observaciones: Este taxón fue considerado por Brako \& Zarucchi (1993) como un endemismo; sin embargo, no ha sido posible evaluarlo, ni asignarle una categoría.

\section{Peperomia huallagana Trel. var. huallagana}

\author{
Publicación: \\ Colección tipo: J.F. Macbride 4264 \\ Herbarios: $F$. \\ Nombre común: D esconocido. \\ Registro departamental: $\mathrm{HU}$. \\ Regiones Ecológicas: BMHP; $1200 \mathrm{~m}$. \\ SINANPE: Sin registro. \\ Herbarios peruanos: Ninguno.
}

Observaciones: Este taxón fue considerado por Brako \& Zarucchi (1993) como un endemismo; sin embargo, no ha sido posible evaluarlo, ni asignarle una categoría.

\section{Peperomia huallagana Trel. var. compacta Trel.}

Publicación: Field Mus. Nat. Hist., Bot. Ser. 13(2): 54. 1936.

Colección tipo: C.O. Schunke 1774

Herbarios: $F$.

Nombre común: D esconocido.

Registro departamental: JU.

Regiones Ecológicas: BMHP; altitud desconocida.

SINANPE: Sin registro.

Herbarios peruanos: Ninguno.

Observaciones: Este taxón fue considerado por Brako \& Zarucchi (1993) como un endemismo; sin embargo, no ha sido posible evaluarlo, ni asignarle una categoría.

\section{Peperomia huantanaTrel. var. enenyasana Trel.}

DD

Publicación: Field Mus. Nat. Hist., Bot. Ser. 13(2): 55. 1936.

Colección tipo: E.P. Killip \& A.C. Smith 25727

Herbarios: US

Nombre común: Desconocido.

Registro departamental: PA.

Regiones Ecológicas: BMHM; 1600 $1900 \mathrm{~m}$.

SINANPE: Sin registro.

Herbarios peruanos: Ninguno.

Observaciones: Hierba conocida sólo de una planta, recolectada en el antiguo camino de arrieros que unía la cuenca del Tulumayo y Perené con la del Pichis. Trelease (1936) y luego Brako \& Zarucchi (1993) citaron erróneamente Junín. Se desconoce las características de sus poblaciones.

\section{Peperomia hyporhoda Trel.}

Publicación: Field Mus. Nat. Hist., Bot. Ser. 13(2): 55. 1936.

Colección tipo: E.P. Killip \& A.C. Smith 25479

Herbarios: US.

Nombre común: D esconocido.

Registro departamental: JU.

Regiones Ecológicas: BMHM; 1350 $1600 \mathrm{~m}$.

SINAN PE: Sin registro.

Hembarios peruanos: Ninguno. 
Observaciones: Este taxón fue considerado por Brako \& Zarucchi (1993) como un endemismo; sin embargo, no ha sido posible evaluarlo, ni asignarle una categoría.

\section{Peperomia inaequilatera Trel.}

Publicación: Field Mus. Nat. Hist., Bot. Ser. 13(2): 56. 1936.

Colección tipo: J.F. Macbride 3858

Herbarios: $F$.

Nombre común: D esconocido.

Registro departamental: HU.

Regiones Ecológicas: BMHM; $1500 \mathrm{~m}$.

SINAN PE: Sin registro.

Herbarios peruanos: Ninguno.

Observaciones: Este taxón fue considerado por Brako \& Zarucchi (1993) como un endemismo; sin embargo, no ha sido posible evaluarlo, ni asignarle una categoría.

\section{Peperomia induratifolia Trel.}

Publicación: Field Mus. Nat. Hist., Bot. Ser. 13(2): 56. 1936.

Colección tipo: C.O. Schunke 1582

Herbarios: $F$.

Nombre común: D esconocido.

Registro departamental: JU.

Regiones Ecológicas: BMHM; $1500 \mathrm{~m}$.

SINANPE: Sin registro.

Herbarios peruanos: Ninguno.

Observaciones: Este taxón fue considerado por Brako \& Zarucchi (1993) como un endemismo; sin embargo, no ha sido posible evaluarlo, ni asignarle una categoría.

\section{Peperomia lanosa Trel.}

Publicación: Field Mus. Nat. Hist., Bot. Ser. 13(2): 57. 1936.

Colección tipo: J.F. Macbride 3450

Hembarios: $F$.

Nombre común: D esconocido.

Registro departamental: HU.

Regiones Ecológicas: MA; $2500 \mathrm{~m}$.

SINANPE: Sin registro.

Hemarios peruanos: Ninguno.

Observaciones: Este taxón fue considerado por Brako \& Zarucchi (1993) como un endemismo; sin embargo, no ha sido posible evaluarlo, ni asignarle una categoría.

\section{Pepenomia lanuginosa G. Pino}

\section{DD}

Publicación: Peperomias de Cajamarca. 24-26, f. 11 A-I. 2004.

Colección tipo: G. Pino 1215

Herbarios: USM!

Nombre común: Congona roja, pukacongona.

Registro departamental: CA.

Regiones Ecológicas: MDE; 1000— 2080 m.

SINAN PE: Sin registro.

Herbarios penuanos: USM (isotipo+2).
Observaciones: Hierba suculenta, conocida de laderas arenosas 0 calcáreas en la vertiente del Pacífico. Se conoce también de plantas en cultivo, originalmente recolectadas en Cajamarca; sin embargo, se desconoce las características de sus poblaciones.

\section{Peperomia lechleriana Trel.}

\section{DD}

Publicación: Field Mus. Nat. Hist., Bot. Ser. 13(2): 58. 1936.

Colección tipo: W. Lechler 2375

Henbarios: $\mathrm{K}$.

Nombre común: D esconocido.

Registro departamental: PU.

Regiones Ecológicas: $\mathrm{BMHM}$; altitud desconocida.

SINANPE: Sin registro.

Herbarios peruanos: Ninguno.

Observaciones: Hierba terrestre, recolectada en el siglo XIX, de la cuencadel San G abán. Sedesconocelas caracteństicas de suspoblaciones.

\section{Peperomia lepadiphylla Trel.}

\section{DD}

Publicación: Field Mus. Nat. Hist., Bot. Ser. 13(2): 58. 1936.

Colección tipo: J.F. Macbride 3055

Herbarios: $F$.

Nombre común: D esconocido.

Registro departamental: LI.

Regiones Ecológicas: AA; $4500 \mathrm{~m}$.

SINAN PE: Sin registro.

Herbarios peruanos: Ninguno.

Observaciones: Hierba terrestre y una de las pocas piperáceas que alcanza la parte altoandina. Fue descrita de una planta recolectada en 1922, de la cuenca alta del Rímac. No se conoce detalles de su hábitat, ni el tamaño de sus poblaciones.

\section{Peperomia liclicensis Pino \& Klopfenstein}

$$
\text { EN, B1a }
$$

Publicación: Cactus \& Succ. J. 75(1): 31, f. 11-18, pl. 3. 2003.

Colección tipo: G. Pino 694

Herbarios: USM.

Nombre común: D esconocido.

Registro departamental: CA.

Regiones Ecológicas: MA; $2950 \mathrm{~m}$.

SINANPE: Sin registro.

Herbarios penuanos: USM (holotipo).

Observaciones: Hierba terrestre, conocida aparentemente, sólo de la colección tipo, recolectada en 2001, en el nor-occidente del país. Habita laderas pronunciadas que al parecer ha contribuido a su inaccesibilidad y escaso registro.

\section{Peperomia limaensis Trel.}

Publicación: Field Mus. Nat. Hist., Bot. Ser. 13(2): 58. 1936.

Colección tipo: J.F. Macbride 5920

Hembarios: $F$

Nombre común: D esconocido.

Registro departamental: LI.

Regiones Ecológicas: D ST; $150 \mathrm{~m}$.

SINAN PE: Sin registro.

Herbarios peruanos: Ninguno. 
Observaciones: Este taxón fue considerado por Brako \& Zarucchi (1993) como un endemismo; sin embargo, no ha sido posible evaluarlo, ni asignarle una categoría.

\section{Peperomia longipedunculata 0 piz}

Publicación: Reliq. Haenk. 1(3): 164. 1828.

Colección tipo: T. Haenke s.n.

Herbarios: Sin datos.

Nombre común: D esconocido.

Registro departamental: HU.

Regiones Ecológicas: Sin datos; altitud desconocida.

SINANPE: Sin registro.

Herbarios peruanos: Ninguno.

Observaciones: Este taxón fue considerado por Brako \& Zarucchi (1993) como un endemismo; sin embargo, no ha sido posible evaluarlo, ni asignarle una categoría.

93. Peperomia longipila C. DC.

DD

Publicación: Verh. Bot. Vereins Prov. Brandenburg 47: 115. 1905.

Colección tipo: E.H.G. Ule 6407

Herbarios: $F$.

Nombre común: D esconocido.

Registro departamental: SM.

Regiones Ecológicas: BHA; altitud desconocida.

SINAN PE: Sin registro.

Herbarios peruanos: Ninguno.

Observaciones: Esta especie se conoce solamente de una localidad en el departamento de San Martín, la que erróneamente Brako \& Zarucchi (1993) consideraron en Loreto. Se desconoce las características de sus poblaciones.

\section{Peperomia macbrideana Trel.}

Publicación: Field Mus. Nat. Hist., Bot. Ser. 13(2): 59-60. 1936.

Colección tipo: J.F. Macbride 4144

Herbarios: $F$.

Nombre común: D esconocido.

Registro departamental: HU.

Regiones Ecológicas: BMHM; 1950 m.

SINANPE: Sin registro.

Herbarios peruanos: Ninguno.

Observaciones: Este taxón fue considerado por Brako \& Zarucchi (1993) como un endemismo; sin embargo, no ha sido posible evaluarlo, ni asignarle una categoría.

\section{Peperomia macrorhiza Kunth}

$$
\text { EN, Bla }
$$

Publicación: Nov. Gen. Sp. 1: 2. [1816]. 1815. Colección tipo: A. Humboldt \& A. Bonpland s.n.

Herbarios: B (d), P.

Nombre común: Munllu munllu, uma puma, pata de oso.

Registro departamental: CA.

Regiones Ecológicas: MDE, MA;

$1800-2800 \mathrm{~m}$.

SINAN PE: Sin registro.

Hemarios peruanos: USM (1).
Observaciones: Hierba saxícola, acaule, conocida solamente de la cuenca del río Cajamarca. Pino (2004) indica que es abundante en la localidad original. Elárea de presencia podría ser mayor desde que se vende en los mercados de Cajamarca como planta medicinal.

\section{Peperomia macrothyrsa Miq.}

Publicación: London J. Bot. 4: 419. 1845.

Colección tipo: A. Mathews 3228

Herbarios: G.

Nombre común: D esconocido.

Registro departamental: AM.

Regiones Ecológicas: BMHP; 1430 m.

SINANPE: Sin registro.

Herbarios peruanos: Ninguno.

Observaciones: Este taxón fue considerado por Brako \& Zarucchi (1993) como un endemismo; sin embargo, no ha sido posible evaluarlo, ni asignarle una categoría.

\section{Peperomia majalis Trel.}

\section{DD}

Publicación: Field Mus. Nat. Hist., Bot. Ser. 13(2): 60. 1936.

Colección tipo: E.P. Killip \& A.C. Smith 25886

Herbarios: F, US.

Nombre común: D esconocido.

Registro departamental: JU.

Regiones Ecológicas: BMHM; 1700$1900 \mathrm{~m}$.

SINANPE: Sin registro.

Hemarios peruanos: Ninguno.

Observaciones: Hierba epífita, conocida solamente de una localidad en el centro del país, ubicada en la cuenca del río Perené. Fue recolectada en 1929, de una localidad a lo largo de la llamada «Trocha del Pichis». Esta zona ha sido fuertemente afectada por la deforestación asociada con la expansión agrícola. Con excepción del Parque Nacional Yanachaga-Chemillén al norte, no hay en la cuenca del Perené hábitats similares protegidos. Se desconoce, sin embargo, las características de sus poblaciones.

\section{Peperomia maransara Trel.}

\section{DD}

Publicación: Field Mus. Nat. Hist., Bot. Ser. 13(2): 61. 1936.

Colección tipo: O.F. Cook \& G.B. Gilbert 960

Herbarios: US.

Nombre común: Maransara.

Registro departamental: $\mathrm{CU}$.

Regiones Ecológicas: BMHM; 1800 m.

SINAN PE: Sin registro.

Herbarios peruanos: Ninguno.

Observaciones: Hierba conocida solamente de una localidad, en la cuenca del río Urubamba. Parte de esta cuenca ha recibido herborización continua, dada la cercanía al Santuario Histórico de Machu Picchu; sin embargo, no ha sido recolectada en otras localidades cercanas. Se desconocen las características de sus poblaciones. 
99. Peperomia marshalliana Trel.

Publicación: Field Mus. Nat. Hist., Bot. Ser. 13(2): 61. 1936.

Colección tipo: J.F. Macbride

Hembarios: F, US.

Nombre común: D esconocido.

Registro departamental: HU, PA, SM.

Regiones Ecológicas: BHA; $400 \mathrm{~m}$.

SINANPE: Sin registro.

Hemarios peruanos: Ninguno.

Observaciones: Este taxón fue considerado por Brako \& Zarucchi (1993) como un endemismo; sin embargo, no ha sido posible evaluarlo, ni asignarle una categoría. La localidad original fue citada para el departamento de Huánuco por Trelease (1936) y Brako \& Zarucchi (1993), pero en realidad se halla hoy ubicada en Pasco.

100. Peperomia martiana Miq. var. nervosa Yunck.

Publicación: Brittonia 13(1): 63. 1961.

Colección tipo: E.F. Poeppig 1660

Henbarios: W.

Nombre común: D esconocido.

Registro departamental: HU.

Regiones Ecológicas: Sin datos; altitud desconocida.

SINAN PE: Sin registro.

Hembarios peruanos: Ninguno.

Observaciones: Este taxón fue considerado por Brako \& Zarucchi (1993) como un endemismo; sin embargo, no ha sido posible evaluarlo, ni asignarle una categoría.

\section{Peperomia mathewsiana Miq.}

\section{DD}

Publicación: London J. Bot. 4: 423. 1845.

Colección tipo: A. Mathews 1688

Herbarios: Sin datos.

Nombre común: Zacapota.

Registro departamental: HU.

Regiones Ecológicas: Sin datos; altitud desconocida.

SINAN PE: Sin registro.

Herbarios peruanos: Ninguno.

Observaciones: Subarbusto aparentemente conocido solamente del ejemplar tipo, una planta recolectada en el siglo XIX. Se desconoce las características de sus poblaciones.

102. Peperomia megalepis Trel.

Publicación: Field Mus. Nat. Hist., Bot. Ser. 13(2): 62. 1936.

Colección tipo: J.F. Macbride 4275

Herbarios: F, US

Nombre común: D esconocido.

Registro departamental: HU.

Regiones Ecológicas: MA; 2400 m.

SINAN PE: Sin registro.

Herbarios peruanos: Ninguno.

Observaciones: Este taxón fue considerado por Brako \& Zarucchi (1993) como un endemismo; sin embargo, no ha sido posible evaluarlo, ni asignarle una categoría.
103. Pepenomia mencedanaC. DC. var. carpapatanaTrel.

Publicación: Field Mus. Nat. Hist., Bot. Ser. 13(2): 62. 1936.

Colección tipo: E.P. Killip \& A.C. Smith 24485

Herbarios: US.

Nombre común: D esconocido.

Registro departamental: JU.

Regiones Ecológicas: BMHP; 2700$3200 \mathrm{~m}$.

SINAN PE: Sin registro.

Herbarios peruanos: Ninguno.

Observaciones: Este taxón fue considerado por Brako \& Zarucchi (1993) como un endemismo; sin embargo, no ha sido posible evaluarlo, ni asignarle una categoría.

\section{Peperomia metallica Linden \& Rodigas}

\section{NE}

Publicación: Ill. Hort. 39: 79, t. 157. 1892.

Colección tipo: Anónimo

Herbarios: Sin datos.

Nombre común: D esconocido.

Registro departamental: Sin datos.

Regiones Ecológicas: Sin datos; altitud desconocida.

SINAN PE: Sin registro.

Herbarios peruanos: Ninguno.

Observaciones: Hierba suculenta, descrita de una planta en cultivo cuyo origen se atribuye al Perú, desconociéndose detalles de su hábitat y características de sus poblaciones.

\section{Peperomia microlepis Trel.}

Publicación: Field Mus. Nat. Hist., Bot. Ser. 13(2): 63. 1936.

Colección tipo: Stevens 91

Hemanios: F.

Nombre común: D esconocido.

Registro departamental: JU.

Regiones Ecológicas: MA; altitud desconocida.

SINANPE: Sin registro.

Herbarios peruanos: Ninguno.

Observaciones: Este taxón fue considerado por Brako \& Zarucchi (1993) como un endemismo; sin embargo, no ha sido posible evaluarlo, ni asignarle una categoría.

106. Peperomia micromamillata Trel.

Publicación: Field Mus. Nat. Hist., Bot. Ser. 13(2): 63. 1936.

Colección tipo: J.F. Macbride 3872

Hembarios: F, US.

Nombre común: D esconocido.

Registro departamental: HU.

Regiones Ecológicas: MA; $1950 \mathrm{~m}$.

SINAN PE: Sin registro.

Herbarios peruanos: Ninguno.

Observaciones: Este taxón fue considerado por Brako \& Zarucchi (1993) como un endemismo; sin embargo, no ha sido posible evaluarlo, ni asignarle una categoría. 


\section{Peperomia minuta A.W. Hill}

Publicación: Ann. Bot. (Oxford) 21: 159, t. 15. 1907.

Colección tipo: A. Weberbauer 2776

Herbarios: B.

Nombre común: D esconocido.

Registro departamental: AN, CU.

Regiones Ecológicas: AA; 4340-4400

$\mathrm{m}$.

SINAN PE: PNH

Hemarios penuanos: USM ?

Observaciones: Este taxón fue considerado por Brako \& Zarucchi (1993) como un endemismo; sin embargo, no ha sido posible evaluarlo, ni asignarle una categoría.

\section{Peperomia mishuyacana Trel.}

\section{DD}

Publicación: Field Mus. Nat. Hist., Bot. Ser. 13(2): 64. 1936.

Colección tipo: G. Klug 582

Herbarios: F, US.

Nombre común: D esconocido.

Registro departamental: LO.

Regiones Ecológicas: BHA; 100 m.

SINAN PE: Sin registro.

Herbarios penuanos: USM?

Observaciones: Hierba terrestre, conocida dela colección original, una planta recolectada en 1929, de los alrededores de Iquitos. Se desconoce las características de sus poblaciones.

109. Pepenomia modicilimba C. DC.

Publicación: Bot. Jahrb. Syst. 40: 258. 1908.

Colección tipo: A. Weberbauer 1211

Herbarios: B.

Nombre común: D esconocido.

Registro departamental: PU.

Regiones Ecológicas: BMHP; $1000 \mathrm{~m}$.

SINAN PE: Sin registro.

Hembarios peruanos: Ninguno.

Observaciones: Este taxón fue considerado por Brako \& Zarucchi (1993) como un endemismo; sin embargo, no ha sido posible evaluarlo, ni asignarle una categoría.

\section{Peperomia monostachya Ruiz \& Pav.}

Publicación: Flora 1: 33. 1798.

Colección tipo: H. Ruiz \& J. Pavón s.n.

Hemarios: MA.

Nombre común: D esconocido.

Registro departamental: HU.

Regiones Ecológicas: Sin datos; altitud desconocida.

SINAN PE: Sin registro.

Herbarios peruanos: Ninguno.

Observaciones: Este taxón fue considerado por Brako \& Zarucchi (1993) como un endemismo; sin embargo, no ha sido posible evaluarlo, ni asignarle una categoría.
111. Peperomia montana C. DC.

DD

Publicación: Prodr. 16(1): 426. 1869.

Colección tipo: E.F. Poeppig 1519

Herbarios: G.

Nombre común: Desconocido.

Registro departamental: Sin datos.

Regiones Ecológicas: Sin datos; altitud desconocida.

SINANPE: Sin registro.

Herbarios peruanos: Ninguno.

Observaciones: Hierba conocida solamente de una localidad, visitada porPoeppigainicios del siglo XIX. No se conocedetalles delaubicación y hábitat, ni ha vuelto a ser recolectada desde ese entonces.

\section{Peperomia muscigaudensC. DC.}

Publicación: Bot. Jahrb. Syst. 40: 267. 1908.

Colección tipo: A. Weberbauer 736

Herbarios: B, G.

Nombre común: D esconocido.

Registro departamental: PU.

Regiones Ecológicas: BMHM; 2500$3000 \mathrm{~m}$.

SINAN PE: Sin registro.

Herbarios peruanos: Ninguno.

Observaciones: Este taxón fue considerado por Brako \& Zarucchi (1993) como un endemismo; sin embargo, no ha sido posible evaluarlo, ni asignarle una categoría.

\section{Peperomia naevifolia Trel.}

Publicación: Field Mus. Nat. Hist., Bot. Ser. 13(2): 65. 1936.

Colección tipo: E.P. Killip \& A.C. Smith 24278

Hembarios: US.

Nombre común: D esconocido.

Registro departamental: JU.

Regiones Ecológicas: BMHM; 1800 m.

SINAN PE: Sin registro.

Hemarios peruanos: Ninguno.

Observaciones: Este taxón fue considerado por Brako \& Zarucchi (1993) como un endemismo; sin embargo, no ha sido posible evaluarlo, ni asignarle una categonía.

\section{Peperomia naviculaefolia Trel.}

DD

Publicación: Field Mus. Nat. Hist., Bot. Ser. 13(2): 65. 1936.

Colección tipo: J.F. Macbride 3253

Herbarios: $F$.

Nombre común: Desconocido.

Registro departamental: PA.

Regiones Ecológicas: PSH; 3000-4000 m.

SINAN PE: Sin registro.

Herbarios peruanos: Ninguno. 
Observaciones: Hierba conocida sólo de una localidad, la cual se atribuyó al departamento de Junín y a una altitud de $2850 \mathrm{~m}$, describiéndosela como «alpina», pero que hoy está en Pasco. Como otras localidades en la puna, amenazas a las poblaciones silvestres, provienen dela agriculturay minería; sin embargo, se desconocen las características de sus poblaciones.

\section{Peperomia nigricans Trel.}

Publicación: Field Mus. Nat. Hist., Bot. Ser. 13(2): 65-66. 1936

Colección tipo: E.P. Killip \& A.C. Smith 23674

Herbarios: US.

Nombre común: D esconocido.

Registro departamental: JU.

Regiones Ecológicas: BMHP; $700 \mathrm{~m}$.

SINANPE: Sin registro.

Hemarios peruanos: Ninguno.

Observaciones: Este taxón fue considerado por Brako \& Zarucchi (1993) como un endemismo; sin embargo, no ha sido posible evaluarlo, ni asignarle una categoría.

\section{Peperomia nivalis var. compacta Pino \& Cieza}

Publicación: Cactus \& Succ. J. 75(1): 34, f. $19-22, .2003$.

Colección tipo: G. Pino 701

Herbarios: USM.

Nombre común: D esconocido.

Registro departamental: CA.

Regiones Ecológicas: MA; 3190 m.

SINAN PE: Sin registro.

Hemarios peruanos: USM (holotipo).

Observaciones: Este taxón fue descrito posterior a Brako \& Zarucchi (1993); no ha sido posible evaluarlo, ni asignarle una categonía.

\section{Peperomia nonalata Trel.}

Publicación: Field Mus. Nat. Hist., Bot. Ser. 13(2): 66. 1936.

Colección tipo: L. Williams 7708

Herbarios: $F$.

Nombre común: D esconocido.

Registro departamental: SM.

Regiones Ecológicas: BMHM, BMHP; 1350- $1500 \mathrm{~m}$.

SINAN PE: Sin registro.

Hemarios peruanos: Ninguno.

Observaciones: Estetaxón fue considerado por Brako \& Zarucchi (1993) como un endemismo; sin embargo, no ha sido posible evaluarlo, ni asignarle una categoría.

\section{Peperomia nonhispidula Trel.}

\section{CR, B lab(iii)}

Publicación: Field Mus. Nat. Hist., Bot. Ser. 13(2): 67. 1936.

Colección tipo: J.F. Macbride 5967

Hembarios: F, US

Nombre común: D esconocido.

Registro departamental: LI.

Regiones Ecológicas: DST; $60 \mathrm{~m}$.

SINANPE: Sin registro.

Herbarios peruanos: Ninguno.
Observaciones: Hierba conocida sólo de una localidad, ubicada en la parte baja del valle de Lurín. Probablemente asociada a la garúa invernal de la costa y por tanto a la vegetación efímera de lomas. Los valles que forman parte de la vecindad de Lima están afectados por la expansión urbana y probablemente por su porte delicado contribuya a que no se haya vuelto a recolectar desde 1923.

\section{Peperomia obcordata C. Presl}

\section{DD}

Publicación: Abh. Konigl. Bohm. Ges. Wiss., ser. 5, 6: 583. 1851

Colección tipo: G. Meyen s.n.

Henbarios: Sin datos.

Nombre común: D esconocido.

Registro departamental: Sin datos.

Regiones Ecológicas: Sin datos; altitud desconocida.

SINAN PE: Sin registro.

Herbarios peruanos: Ninguno.

Observaciones: La única información que se tiene de esta especie es que fue recolectada en las montañas del Perú, pero sin datos adicionales de la localidad, altitud y hábitat. No ha vuelto a reconfirmarse esta especie.

\section{Peperomia obcondatifolia Trel.}

Publicación: Field Mus. Nat. Hist., Bot. Ser. 13(2): 67. 1936.

Colección tipo: R. Spruce s.n.

Herbarios: $\mathrm{K}$.

Nombre común: D esconocido.

Registro departamental: SM.

Regiones Ecológicas: BMHP; altitud desconocida.

SINAN PE: Sin registro.

Herbarios peruanos: Ninguno.

Observaciones: Este taxón fue considerado por Brako \& Zarucchi (1993) como un endemismo; sin embargo, no ha sido posible evaluarlo, ni asignarle una categoría.

\section{Peperomia obliqua Ruiz \& Pav.}

DD

Publicación: Fl. Peruv. 1: 32, t. 51, f. c. 1798.

Colección tipo: H. Ruiz \& J. Pavón s.n.

Herbarios: MA.

Nombre común: D esconocido.

Registro departamental: HU, PA.

Regiones Ecológicas: MA; altitud desconocida.

SINAN PE: Sin registro.

Herbarios peruanos: Ninguno.

Observaciones: Hierba conocida de por lo menos tres localidades, en el centro del país, en las cuencas del Pozuzo y del Huallga. Los registros fueron realizados en el siglo XVIII yXIX. Se desconoce las características de sus poblaciones. 


\section{Peperomia obruenda Trel.}

Publicación: Field Mus. Nat. Hist., Bot. Ser. 13(2): 68. 1936.

Colección tipo: Stevens 202

Herbarios: F.

Nombre común: D esconocido.

Registro departamental: JU.

Regiones Ecológicas: Sin datos; altitud desconocida.

SINANPE: Sin registro.

Herbarios peruanos: Ninguno.

Observaciones: Este taxón fue considerado por Brako \& Zarucchi (1993) como un endemismo; sin embargo, no ha sido posible evaluarlo, ni asignarle una categoría.

\section{Peperomia ollantaitambona Trel.}

\section{DD}

Publicación: Field Mus. Nat. Hist., Bot. Ser. 13(2): 68. 1936.

Colección tipo: F.W. Pennell 13661

Herbarios: F, PH.

Nombre común: D esconocido.

Registro departamental: CU.

Regiones Ecológicas: MA; 2300-3100 m.

SINAN PE: Sin registro.

Hembarios peruanos: Ninguno.

Observaciones: Hierba suculenta, descrita de una planta recolectada en la cuenca del Urubamba, en los años 1940. Se desconoce las características de sus poblaciones.

\section{Peperomia opiziana A. Dietr.}

\section{DD}

Publicación: Sp. Pl. 1: 162. 1831.

Colección tipo: T. Haenke s.n.

Herbarios: Sin datos.

Nombre común: Desconocido.

Registro departamental: Sin datos.

Regiones Ecológicas: Sin datos; altitud desconocida.

SINANPE: Sin registro.

Herbarios peruanos: Ninguno.

Observaciones: Hierba conocida solamente de una colección, pero sin detalles de la localidad o del hábitat. No ha vuelto a ser recolectada desde fines del siglo XVIII.

125. Peperomia oxyphylla C. DC.

Publicación: Bot. Jahrb. Syst. 40: 260. 1908.

Colección tipo: A. Weberbauer 1854

Herbarios: $B$.

Nombre común: D esconocido.

Registro departamental: JU.

Regiones Ecológicas: BMHP; $1000 \mathrm{~m}$.

SINANPE: Sin registro.

Herbarios peruanos: Ninguno.

Observaciones: Este taxón fue considerado por Brako \& Zarucchi (1993) como un endemismo; sin embargo, no ha sido posible evaluarlo, ni asignarle una categoría.
126. Pepenomia pachiteana Trel.

DD

Publicación: Field Mus. Nat. Hist., Bot. Ser. 13(2): 69. 1936.

Colección tipo: E.P. Killip \& A.C. Smith 26831

Herbarios: ILL, US.

Nombre común: D esconocido.

Registro departamental: $\mathrm{HU}$.

Regiones Ecológicas: BHA; 300 m.

SINANPE: Sin registro.

Herbarios peruanos: Ninguno.

Observaciones: Hierba conocida sólo del ejemplar original, recolectado en 1929, en una localidad citada en la etiqueta como «Lira, on rio Pachitea», pero que probablemente corresponda a Sira. Se desconoce las características de sus poblaciones.

127. Peperomia pakipskiC. DC.

DD

Publicación: Bot. Jahrb. Syst. 40: 258. 1908.

Colección tipo: A. Weberbauer 869

Herbarios: B; MOL!.

Nombre común: D esconocido.

Registro departamental: PU.

Regiones Ecológicas: BMHM; 2000 m.

SINAN PE: Sin registro.

Herbarios penuanos: MOL (lectotipo).

Observaciones: Hierba epífita, descrita de una planta recolectada en1902, en la cuenca alta del Inambari. Se desconoce las características de sus poblaciones.

128. Peperomia palcanaC. DC.

\section{DD}

Publicación: Bot. Jahrb. Syst. 40: 266. 1908.

Colección tipo: A. Weberbauer 1754

Herbarios: B; MOL!

Nombre común: D esconocido.

Registro departamental: JU.

Regiones Ecológicas: MA; 2500-2600 m.

SINANPE: Sin registro.

Herbarios penuanos: MOL (lectotipo).

Observaciones: Hierba de ambientes rocosos, recolectada en 1902, de la cuenca del Palca, un tributario del Tulumayo. Se desconoce las características de sus poblaciones.

\section{Peperomia pampalcana Trel.}

DD

Publicación: Field Mus. Nat. Hist., Bot. Ser. 13(2): 69-70. 1936.

Colección tipo: E.P. Killip \& A.C. Smith 23282

Herbarios: F, NY, US.

Nombre común: D esconocido.

Registro departamental: AY.

Regiones Ecológicas: MA; $3200 \mathrm{~m}$.

SINANPE: Sin registro.

Herbarios peruanos: Ninguno.

Observaciones: Hierba descrita de una planta recolectada en 1929, de matorrales, en la cuenca del Apurímac. Se desconoce las características de sus poblaciones. 


\section{Peperomia parva Trel.}

\section{DD}

Publicación: Field Mus. Nat. Hist., Bot. Ser. 13(2): 70. 1936.

Colección tipo: E.P. Killip \& A.C. Smith 25881

Herbarios: US.

Nombre común: D esconocido.

Registro departamental: JU.

Regiones Ecológicas: BMHM; 1700$1900 \mathrm{~m}$.

SINAN PE: Sin registro.

Herbarios peruanos: Ninguno.

Observaciones: Hierba epífita, descrita de una planta recolectada en 1929, a lo largo del antiguo camino de arrieros que unía la cuenca del Tulumayo y Perené con la de Pichis. Se desconoce las características de sus poblaciones.

\section{Peperomia parvipunctulata Trel.}

Publicación: Field Mus. Nat. Hist., Bot. Ser. 13(2): 70. 1936.

Colección tipo: L. Williams 7145

Henbarios: F.

Nombre común: D esconocido.

Registro departamental: SM.

Regiones Ecológicas: BMHP; $1350-$ $1500 \mathrm{~m}$.

SINAN PE: Sin registro.

Hemarios peruanos: Ninguno.

Observaciones: Este taxón fue considerado por Brako \& Zarucchi (1993) como un endemismo; sin embargo, no ha sido posible evaluarlo, ni asignarle una categoría.

132. Peperomia pavoniana C. DC.

Publicación: Prodr. 16(1):460. 1869.

Colección tipo: J. Pavón s.n.

Herbarios: MA.

Nombre común: D esconocido

Registro departamental: Sin datos.

Regiones Ecológicas: Sin datos; altitud desconocida.

SINANPE: Sin registro.

Herbarios peruanos: Ninguno.

Observaciones: Este taxón fue considerado por Brako \& Zarucchi (1993) como un endemismo; sin embargo, no ha sido posible evaluarlo, ni asignarle una categoría.

133. Peperomia pearcei Trel.

Publicación: Field Mus. Nat. Hist., Bot. Ser. 13(2): 71. 1936.

Colección tipo: R.W. Pearce 166

Hemarios: $\mathrm{K}$.

Nombre común: D esconocido.

Registro departamental: HU.

Regiones Ecológicas: Sin datos; altitud desconocida.

SINANPE: Sin registro.

Hembarios peruanos: Ninguno.

Observaciones: Este taxón fue considerado por Brako \& Zarucchi (1993) como un endemismo; sin embargo, no ha sido posible evaluarlo, ni asignarle una categoría.
134. Peperomia percalvescens Trel.

Publicación: Field Mus. Nat. Hist., Bot. Ser. 13(2): 71- 72. 1936.

Colección tipo: L. Williams 5758

Herbarios: $F$.

Nombre común: D esconocido.

Registro departamental: SM.

Regiones Ecológicas: BMHP, BHA; 360— $900 \mathrm{~m}$.

SINANPE: Sin registro.

Herbarios peruanos: Ninguno.

Observaciones: Este taxón fue considerado por Brako \& Zarucchi (1993) como un endemismo; sin embargo, no ha sido posible evaluarlo, ni asignarle una categoría.

\section{Peperomia pereneana Trel.}

Publicación: Field Mus. Nat. Hist., Bot. Ser. 13(2): 72. 1936.

Colección tipo: E.P. Killip \& A.C. Smith 25413

Herbarios: US

Nombre común: D esconocido.

Registro departamental: JU.

Regiones Ecológicas: BMHP; $680 \mathrm{~m}$.

SINAN PE: Sin registro.

Henbarios peruanos: Ninguno.

Observaciones: Este taxón fue considerado por Brako \& Zarucchi (1993) como un endemismo; sin embargo, no ha sido posible evaluarlo, ni asignarle una categoría.

\section{Peperomia pergamentacea Trel.}

\section{DD}

Publicación: Field Mus. Nat. Hist., Bot. Ser. 13(2): 72. 1936.

Colección tipo: E.P. Killip \& A.C. Smith 26063

Herbarios: NY, US.

Nombre común: D esconocido.

Registro departamental: PA.

Regiones Ecológicas: BMHP; $1100 \mathrm{~m}$.

SINANPE: Sin registro.

Herbarios peruanos: Ninguno.

Observaciones: Hierba conocida de la colección original, una planta recolectada en una localidad ubicada hoy en Pasco, muy cerca del límite con Junín. Se desconoce las caractenísticas de sus poblaciones.

\section{Peperomia perhispidulaC. DC. var. glabrescens Trel.}

Publicación: Field Mus. Nat. Hist., Bot. Ser. 13(2): 72. 1936.

Colección tipo: F.W. Pennell 14076

Herbarios: $\mathrm{F}, \mathrm{PH}$.

Nombre común: D esconocido.

Registro departamental: CU.

Regiones Ecológicas: BMHM; 2000$2300 \mathrm{~m}$.

SINAN PE: Sin registro.

Herbarios peruanos: Ninguno.

Observaciones: Este taxón fue considerado por Brako \& Zarucchi (1993) como un endemismo; sin embargo, no ha sido posible evaluarlo, ni asignarle una categoría 
138. Peperomia pertomentella Trel.

Publicación: Field Mus. Nat. Hist., Bot. Ser. 13(2): 73. 1936.

Colección tipo: L. Williams 6202

Hemarios: $F$.

Nombre común: D esconocido.

Registro departamental: SM.

Regiones Ecológicas: $\mathrm{BMHP}, \mathrm{BHA}$; 360-900 m.

SINANPE: Sin registro.

Herbarios peruanos: Ninguno.

Observaciones: Este taxón fue considerado por Brako \& Zarucchi (1993) como un endemismo; sin embargo, no ha sido posible evaluarlo, ni asignarle una categoría.

\section{Peperomia penviana (Miq.) Dahlst. var. majorA.W.Hill}

\section{DD}

Publicación: Ann. Bot. (Oxford) 21: 151. 1907.

Colección tipo: A.W. Hill s.n.

Herbarios: $F$.

Nombre común: D esconocido.

Registro departamental: CU.

Regiones Ecológicas: MA; 1400 m.

SINANPE: Sin registro.

Herbarios peruanos: USM (1).

Observaciones: Hierba descrita de una planta recolectada en la cuenca del Urubamba. Ejemplares procedentes de la vertiente occidental de Cajamarca, se atribuyen a este taxón, pero no pudieron ser verificadas. Se desconoce las características de sus poblaciones.

\section{Peperomia phyllantha 0 piz}

Publicación: Reliq. Haenk. 1(3): 162. 1828.

Colección tipo: T. Haenke s.n.

Hemarios: Sin datos.

Nombre común: D esconocido.

Registro departamental: Sin datos.

Regiones Ecológicas: Sin datos; altitud desconocida.

SINANPE: Sin registro.

Herbarios peruanos: Ninguno.

Observaciones: Este taxón fue considerado por Brako \& Zarucchi (1993) como un endemismo; sin embargo, no ha sido posible evaluarlo, ni asignarle una categoría.

\section{Peperomia pichisensis Trel.}

Publicación: Field Mus. Nat. Hist., Bot. Ser. 13(2): 74. 1936

Colección tipo: E.P. Killip \& A.C. Smith 25829

Herbarios: US.

Nombre común: D esconocido.

Registro departamental: JU.

Regiones Ecológicas: BMHM; 1700-

$1900 \mathrm{~m}$.

SINANPE: Sin registro.

Herbarios peruanos: Ninguno.

Observaciones: Estetaxón fue considerado por Brako \& Zarucchi (1993) como un endemismo; sin embargo, no ha sido posible evaluarlo, ni asignarle una categoría.
142. Peperomia pilifera Trel.

Publicación: Field Mus. Nat. Hist., Bot. Ser. 13(2): 74. 1936.

Colección tipo: J.F. Macbride 3460

Herbarios: $F$.

Nombre común: D esconocido.

Registro departamental: $\mathrm{HU}$.

Regiones Ecológicas: MA; $2550 \mathrm{~m}$.

SINANPE: Sin registro.

Herbarios peruanos: Ninguno.

Observaciones: Este taxón fue considerado por Brako \& Zarucchi (1993) como un endemismo; sin embargo, no ha sido posible evaluarlo, ni asignarle una categoría.

\section{Peperomia pillahuatana Trel.}

Publicación: Field Mus. Nat. Hist., Bot. Ser. 13(2): 74. 1936.

Colección tipo: F.W. Pennell 14074

Hemarios: $F$.

Nombre común: D esconocido.

Registro departamental: CU.

Regiones Ecológicas: BMHM; 2000$2300 \mathrm{~m}$.

SINANPE: Sin registro.

Herbarios peruanos: Ninguno.

Observaciones: Este taxón fue considerado por Brako \& Zarucchi (1993) como un endemismo; sin embargo, no ha sido posible evaluarlo, ni asignarle una categoría.

\section{Peperomia pinedoana Trel.}

DD

Publicación: Field Mus. Nat. Hist., Bot. Ser. 13(2): 75. 1936.

Colección tipo: E.P. Killip \& A.C. Smith 23620

Herbarios: US.

Nombre común: D esconocido.

Registro departamental: JU.

Regiones Ecológicas: BMHP; 700-900 m.

SINAN PE: Sin registro.

Herbarios peruanos: Ninguno.

Observaciones: Hierba, listada en Brako \& Zarucchi (1993) tanto en Peperomia como en Piper. En este último género fue señalada como un endemismo. El ejemplar tipo fuerecolectado en 1929, deunasubcuenca del Tulumayo. Se desconoce el estado actual de sus poblaciones.

\section{Peperomia playapampana Trel.}

\section{DD}

Publicación: Field Mus. Nat. Hist., Bot. Ser. 13(2): 75. 1936.

Colección tipo: J.F. Macbride 4496

Herbarios: F, ILL.

Nombre común: Desconocido.

Registro departamental: HU.

Regiones Ecológicas: BMHM; $2700 \mathrm{~m}$.

SINAN PE: Sin registro.

Herbarios peruanos: Ninguno.

Observaciones: Hierba conocida solamente de una localidad, en pajonales húmedos dominados por Sphagnum. Se desconoce el estado de sus poblaciones. 
146. Pepenomia pleiomorpha Trel.

\section{DD}

Publicación: Field Mus. Nat. Hist., Bot. Ser. 13(2): 75. 1936.

Colección tipo: E.P. Killip \& A.C. Smith 26426

Herbarios: $F$.

Nombre común: D esconocido.

Registro departamental: PA.

Regiones Ecológicas: BHA; 375 m.

SINAN PE: Sin registro.

Herbarios peruanos: Ninguno.

Observaciones: Hierba epífita, recolectada en 1929, de la cuenca del Pichis. La localidad se halla hoy en el D epartamento de Pasco. Se desconoce el estado de sus poblaciones.

\section{Peperomia plicatifolia Trel.}

\section{DD}

Publicación: Field Mus. Nat. Hist., Bot. Ser. 13(2): 76. 1936.

Colección tipo: W. Lechler 2231

Herbarios: $\mathrm{K}$.

Nombre común: D esconocido.

Registro departamental: PU.

Regiones Ecológicas: Sin datos; altitud desconocida.

SINANPE: Sin registro.

Hemarios peruanos: Ninguno.

Observaciones: Hierba recolectada en el siglo XIX, de la cuenca del San Gabán. Se desconoce el estado actual de sus poblaciones.

148. Peperomia plurispica Trel.

Publicación: Field Mus. Nat. Hist., Bot. Ser. 13(2): 76. 1936.

Colección tipo: J.F. Macbride 3414

Hemarios: $F$.

Nombre común: D esconocido.

Registro departamental: HU.

Regiones Ecológicas: MA; $2550 \mathrm{~m}$.

SINAN PE: Sin registro.

Herbarios peruanos: Ninguno.

Observaciones: Este taxón fue considerado por Brako \& Zarucchi (1993) como un endemismo; sin embargo, no ha sido posible evaluarlo, ni asignarle una categoría.

149. Peperomia polycephala Trel.

Publicación: Field Mus. Nat. Hist., Bot. Ser. 13(2): 76. 1936

Colección tipo: F. Herrera 1460

Herbarios: $F$.

Nombre común: D esconocido.

Registro departamental: CU.

Regiones Ecológicas: MA; altitud desconocida.

SINAN PE: Sin registro.

Herbarios peruanos: Ninguno.

Observaciones: Este taxón fue considerado por Brako \& Zarucchi (1993) como un endemismo; sin embargo, no ha sido posible evaluarlo, ni asignarle una categoría.
150. Peperomia polymorpha Trel.

DD

Publicación: Field Mus. Nat. Hist., Bot. Ser. 13(2): 77. 1936.

Colección tipo: E.P. Killip \& A.C. Smith 22774

Hemarios: F, US.

Nombre común: D esconocido.

Registro departamental: AY.

Regiones Ecológicas: BMHP; 700-900 m.

SINAN PE: Sin registro.

Herbarios peruanos: Ninguno.

Observaciones: Hierba epífita, recolectada en 1929, de la cuenca del Apurímac. Se desconoce el estado actual de sus poblaciones.

\section{Peperomia pontina Trel.}

Publicación: Field Mus. Nat. Hist., Bot. Ser. 13(2): 77. 1936.

Colección tipo: E.P. Killip \& A.C. Smith 25366

Herbarios: F, US.

Nombre común: D esconocido.

Registro departamental: JU.

Regiones Ecológicas: BMHP; $700 \mathrm{~m}$.

SINAN PE: Sin registro.

Herbarios peruanos: Ninguno.

Observaciones: Este taxón fue considerado por Brako \& Zarucchi (1993) como un endemismo; sin embargo, no ha sido posible evaluarlo, ni asignarle una categoría.

152. Peperomia ppucuppucu Trel.

Publicación: J. Wash. Acad. Sci. 16(8): 206.

1926.

Colección tipo: F. Herrera 802

Herbarios: $F$.

Nombre común: D esconocido.

Registro departamental: CU.

Regiones Ecológicas: MA; $2800 \mathrm{~m}$.

SINAN PE: Sin registro.

Herbarios peruanos: Ninguno.

Observaciones: Este taxón fue considerado por Brako \& Zarucchi (1993) como un endemismo; sin embargo, no ha sido posible evaluarlo, ni asignarle una categoría.

153. Peperomia praeruptorum Trel.

Publicación: Field Mus. Nat. Hist., Bot. Ser. 13(2): 78. 1936.

Colección tipo: F.W. Pennell 14033

Hembarios: $F, P H$.

Nombre común: D esconocido.

Registro departamental: CU.

Regiones Ecológicas: BMHM; 2200$2400 \mathrm{~m}$.

SINANPE: Sin registro.

Herbarios peruanos: Ninguno.

Observaciones: Este taxón fue considerado por Brako \& Zarucchi (1993) como un endemismo; sin embargo, no ha sido posible evaluarlo, ni asignarle una categoría. 


\section{Peperomia profissa Trel.}

Publicación: Field Mus. Nat. Hist., Bot. Ser. 13(2): 78. 1936.

Colección tipo: F.L. Stevens 193

Herbarios:

Nombre común: D esconocido.

Registro departamental: JU.

Regiones Ecológicas: Sin datos; altitud desconocida.

SINANPE: Sin registro.

Herbarios peruanos: Ninguno.

Observaciones: Este taxón fue considerado por Brako \& Zarucchi (1993) como un endemismo; sin embargo, no ha sido posible evaluarlo, ni asignarle una categoría.

\section{Peperomia prolifera Yunck.}

Publicación: Brittonia 13(1): 62-63, f. 5. 1961.

Colección tipo: P.C. Hutchison 1546

Herbarios: UC, US,

Nombre común: D esconocido.

Registro departamental: AM.

Regiones Ecológicas: BS; altitud desconocida.

SINAN PE: Sin registro.

Herbarios peruanos: Ninguno.

Observaciones: Este taxón fue considerado por Brako \& Zarucchi (1993) como un endemismo; sin embargo, no ha sido posible evaluarlo, ni asignarle una categoría.

\section{Peperomia pruinosifolia Trel.}

Publicación: Field Mus. Nat. Hist., Bot. Ser. 13(2): 78- 79. 1936

Colección tipo: E.P. Killip \& A.C. Smith 21742

Herbarios: US.

Nombre común: D esconocido.

Registro departamental: LI.

Regiones Ecológicas: MA; 3000-3500

$\mathrm{m}$

SINANPE: Sin registro.

Herbarios peruanos: Ninguno.

Observaciones: Este taxón fue considerado por Brako \& Zarucchi (1993) como un endemismo; sin embargo, no ha sido posible evaluarlo, ni asignarle una categoría.

\section{Peperomia pseudogalapagensis Trel.}

DD

Publicación: Field Mus. Nat. Hist., Bot. Ser. 13(2): 79. 1936

Colección tipo: C. Wilkes, Exped. Expl. US. 5920

Herbarios: GH.

Nombre común: D esconocido.

Registro departamental: LI.

Regiones Ecológicas: D ST; $150 \mathrm{~m}$.

SINANPE: Sin registro.

Herbarios peruanos: Ninguno.
Observaciones: Hierba diminuta, conocida aparentemente de dos colecciones, realizadas ambas, en el centro del país. Fue descrita de una planta recolectada en 1839, un segundo ejemplar es conocido de los alrededores de la ciudad de Lima, de una localidad con ambientes de lomas. Se desconoce el estado actual de sus poblaciones.

158. Peperomia pseudosalicifolia Trel.

Publicación: Field Mus. Nat. Hist., Bot. Ser. 13(2): 79-80. 1936.

Colección tipo: J.F. Macbride 4254

Herbarios: $F$.

Nombre común: D esconocido.

Registro departamental: HU.

Regiones Ecológicas: BMHP; $1200 \mathrm{~m}$.

SINANPE: Sin registro.

Herbarios peruanos: Ninguno.

Observaciones: Este taxón fue considerado por Brako \& Zarucchi (1993) como un endemismo; sin embargo, no ha sido posible evaluarlo, ni asignarle una categoría.

\section{Peperomia puberulaeformis Trel.}

Publicación: Field Mus. Nat. Hist., Bot. Ser. 13(2): 80. 1936.

Colección tipo: E.P. Killip \& A.C. Smith 22981

Herbarios: US.

Nombre común: Desconocido.

Registro departamental: AY.

Regiones Ecológicas: BHA; $400 \mathrm{~m}$.

SINANPE: Sin registro.

Herbarios peruanos: Ninguno.

Observaciones: Este taxón fue considerado por Brako \& Zarucchi (1993) como un endemismo; sin embargo, no ha sido posible evaluarlo, ni asignarle una categoría.

\section{PeperomiapubenulibaccaC.DC.var pubenulibacca}

Publicación:

Colección tipo: A. Weberbauer 2111

Herbarios: $F$.

Nombre común: D esconocido.

Registro departamental: JU.

Regiones Ecológicas: BMHM; 2100 m.

SINAN PE: Sin registro.

Herbarios peruanos: Ninguno.

Observaciones: Este taxón fue considerado por Brako \& Zarucchi (1993) como un endemismo; sin embargo, no ha sido posible evaluarlo, ni asignarle una categoría.

161. Peperomia puberulibacca C. DC. var. atricha Trel.

Publicación: Field Mus. Nat. Hist., Bot. Ser. 13(2): 80. 1936.

Colección tipo: J.F. Macbride 4009

Herbarios: $F$.

Nombre común: D esconocido.

Registro departamental: HU.

Regiones Ecológicas: MA; $2100 \mathrm{~m}$.

SINANPE: Sin registro.

Herbarios peruanos: Ninguno. 
Observaciones: Este taxón fue considerado por Brako \& Zarucchi (1993) como un endemismo; sin embargo, no ha sido posible evaluarlo, ni asignarle una categoría.

\section{Pepenomia puberulipes Trel.}

Publicación: Field Mus. Nat. Hist., Bot. Ser. 13(2): 80. 1936.

Colección tipo: J.F. Macbride 3856

Herbarios: $F$.

Nombre común: D esconocido.

Registro departamental: HU.

Regiones Ecológicas: BMHM; $1500 \mathrm{~m}$.

SINANPE: Sin registro.

Herbarios peruanos: Ninguno.

Observaciones: Este taxón fue considerado por Brako \& Zarucchi (1993) como un endemismo; sin embargo, no ha sido posible evaluarlo, ni asignarle una categoría.

\section{Peperomia pubescentinervis Trel.}

\section{DD}

Publicación: Field Mus. Nat. Hist., Bot. Ser. 13(2): 81. 1936.

Colección tipo: Stevens 127

Herbarios: $F$.

Nombre común: D esconocido.

Registro departamental: HU.

Regiones Ecológicas: Sin datos; altitud desconocida.

SINANPE: Sin registro.

Herbarios peruanos: Ninguno.

Observaciones: Hierba conocida de la misma localidad que otra endémica Peperomia distractiflora, en la cuenca del Tuluamyo. Se desconoce el estado actual de sus poblaciones.

164. Peperomia pubiramea Trel.

Publicación: Field Mus. Nat. Hist., Bot. Ser. 13(2): 81. 1936.

Colección tipo: E.P. Killip \& A.C. Smith 25360

Herbarios: US.

Nombre común: D esconocido.

Registro departamental: JU.

Regiones Ecológicas: BMHP; $700 \mathrm{~m}$.

SINAN PE: Sin registro.

Hembarios peruanos: Ninguno.

Observaciones: Este taxón fue considerado por Brako \& Zarucchi (1993) como un endemismo; sin embargo, no ha sido posible evaluarlo, ni asignarle una categoría.

\section{Peperomia purpurea Ruiz \& Pav.}

Publicación: Flora 1: 32, t. 49. 1798.

Colección tipo: H. Ruiz \& J. Pavón s.n.

Herbarios: MA.

Nombre común: D esconocido.

Registro departamental: HU.

Regiones Ecológicas: Sin datos; altitud desconocida.

SINAN PE: Sin registro.

Herbarios peruanos: Ninguno.
Observaciones: Este taxón fue considerado por Brako \& Zarucchi (1993) como un endemismo; sin embargo, no ha sido posible evaluarlo, ni asignarle una categoría.

166. Peperomia quadricoma Trel.

Publicación: Field Mus. Nat. Hist., Bot. Ser. 13(2): 82- 83. 1936.

Colección tipo: C.O. Schunke 370

Herbarios: $F$

Nombre común: D esconocido.

Registro departamental: JU.

Regiones Ecológicas: BMHM; $1800 \mathrm{~m}$.

SINAN PE: Sin registro.

Herbarios peruanos: Ninguno.

Observaciones: Este taxón fue considerado por Brako \& Zarucchi (1993) como un endemismo; sin embargo, no ha sido posible evaluarlo, ni asignarle una categoría.

\section{Peperomia quaerata Trel.}

Publicación: Field Mus. Nat. Hist., Bot. Ser. 13(2): 83. 1936

Colección tipo: E.P. Killip \& A.C. Smith 23653

Herbarios: US.

Nombre común: D esconocido.

Registro departamental: JU.

Regiones Ecológicas: BMHP; 700-900 m.

SINANPE: Sin registro.

Herbarios peruanos: Ninguno.

Observaciones: Este taxón fue considerado por Brako \& Zarucchi (1993) como un endemismo; sin embargo, no ha sido posible evaluarlo, ni asignarle una categoría.

\section{Peperomia quatrometralis Trel.}

DD

Publicación: Field Mus. Nat. Hist., Bot. Ser. 13(2): 83. 1936

Colección tipo: E.P. Killip \& A.C. Smith 26330

Herbarios: US.

Nombre común: D esconocido.

Registro departamental: PA.

Regiones Ecológicas: BHA; $400 \mathrm{~m}$.

SINANPE: Sin registro.

Henbarios peruanos: Ninguno.

Observaciones: Hierba epífita, descrita de una planta recolectada en 1929, de la cuenca del Pichis. La localidad original es reconocida hoy en el departamento de Pasco y no en Junín. Se desconoce el estado actual de sus poblaciones.

\section{Peperomia quispicanchiana Trel.}

Publicación: Field Mus. Nat. Hist., Bot. Ser. 13(2): 84. 1936

Colección tipo: A. Weberbauer 7802

Herbarios: $F$

Nombre común: D esconocido.

Registro departamental: $\mathrm{CU}$.

Regiones Ecológicas: BMHM; altitud desconocida.

SINANPE: Sin registro.

Herbarios peruanos: Ninguno. 
Observaciones: Este taxón fue considerado por Brako \& Zarucchi (1993) como un endemismo; sin embargo, no ha sido posible evaluarlo, ni asignarle una categoría.

170. Peperomia racemifolia Trel.

Publicación: Field Mus. Nat. Hist., Bot. Ser. 13(2): 84. 1936.

Colección tipo: E.P. Killip \& A.C. Smith 26657

Herbarios: US.

Nombre común: D esconocido.

Registro departamental: PA.

Regiones Ecológicas: BHA; 375 m.

SINANPE: Sin registro.

Hemarios peruanos: Ninguno.

Observaciones: Este taxón fue considerado por Brako \& Zarucchi (1993) como un endemismo; sin embargo, no ha sido posible evaluarlo, ni asignarle una categoría. La localidad original fue citada para el departamento de Junín por Trelease (1936) y Brako \& Zarucchi (1993), pero en realidad se halla hoy ubicada en Pasco.

\section{Peperomia rhodophylla Trel.}

Publicación: Field Mus. Nat. Hist., Bot. Ser. 13(2): 84. 1936.

Colección tipo: F.W. Pennell 13654

Herbarios: F, PH.

Nombre común: D esconocido.

Registro departamental: CU.

Regiones Ecológicas: MA; 2900-3100 m.

SINANPE: Sin registro.

Herbarios peruanos: Ninguno.

Observaciones: Este taxón fue considerado por Brako \& Zarucchi (1993) como un endemismo; sin embargo, no ha sido posible evaluarlo, ni asignarle una categoría.

\section{Pepenomia rhombeifolia Trel.}

\section{DD}

Publicación: Field Mus. Nat. Hist., Bot. Ser. 13(2): 85. 1936.

Colección tipo: E.P. Killip \& A.C. Smith 28866

Herbarios: US.

Nombre común: D esconocido.

Registro departamental: LO.

Regiones Ecológicas: BHA; $135 \mathrm{~m}$.

SINANPE: Sin registro.

Herbarios peruanos: Ninguno.

Observaciones: Hierba conocida de una localidad, en la cuenca del Marañón. Aparentemente, no ha vuelto a ser recolectada desde 1929. Se desconoce el estado actual de sus poblaciones.

\section{Peperomia rhombeoelliptica Trel.}

Publicación: Field Mus. Nat. Hist., Bot. Ser. 13(2): 85. 1936.

Colección tipo: J.F. Macbride 4171

Herbarios: $F$.

Nombre común: D esconocido.

Registro departamental: HU, JU.

Regiones Ecológicas: MA; $1950 \mathrm{~m}$.

SINANPE: Sin registro.

Herbarios peruanos: Ninguno.
Observaciones: Este taxón fue considerado por Brako \& Zarucchi (1993) como un endemismo; sin embargo, no ha sido posible evaluarlo, ni asignarle una categoría.

\section{Peperomia rhombiformis Trel.}

Publicación: Field Mus. Nat. Hist., Bot. Ser. 13(2): 85- 86. 1936.

Colección tipo: L. Williams 6996

Herbarios: $F$.

Nombre común: D esconocido.

Registro departamental: SM.

Regiones Ecológicas: BMHM; 1350 $1500 \mathrm{~m}$.

SINAN PE: Sin registro.

Hembarios peruanos: Ninguno.

Observaciones: Este taxón fue considerado por Brako \& Zarucchi (1993) como un endemismo; sin embargo, no ha sido posible evaluarlo, ni asignarle una categoría.

\section{Peperomia rhombilimba Trel.}

Publicación: Field Mus. Nat. Hist., Bot. Ser. 13(2): 86. 1936.

Colección tipo: E.P. Killip \& A.C. Smith 22564

Hemarios: US.

Nombre común: D esconocido.

Registro departamental: $\mathrm{AY}, \mathrm{HU}$.

Regiones Ecológicas: BMHP; 750-1000 m.

SINANPE: Sin registro.

Hemarios peruanos: Ninguno.

Observaciones: Este taxón fue considerado por Brako \& Zarucchi (1993) como un endemismo; sin embargo, no ha sido posible evaluarlo, ni asignarle una categoría.

\section{Peperomia nosea Trel.}

Publicación: Field Mus. Nat. Hist., Bot. Ser. 13(2): 86. 1936.

Colección tipo: J.F. Macbride 3927

Herbarios: $F$.

Nombre común: D esconocido.

Registro departamental: $\mathrm{HU}$.

Regiones Ecológicas: MA; 2100 m.

SINAN PE: Sin registro.

Herbarios peruanos: Ninguno.

Observaciones: Estetaxón fue considerado por Brako \& Zarucchi (1993) como un endemismo; sin embargo, no ha sido posible evaluarlo, ni asignarle una categoría.

\section{Pepenomia rubea Trel.}

DD

Publicación: Field Mus. Nat. Hist., Bot. Ser. 13(2): 87. 1936.

Colección tipo: L. Williams 837

Herbanios: $F$.

Nombre común: Lancetilla de monte.

Registro departamental: LO.

Regiones Ecológicas: BHA; altitud desconocida.

SINANPE: Sin registro.

Herbarios peruanos: Ninguno. 
Observaciones: Hierba terrestre conocida sólo del tipo, una planta recolectada en 1929, de la cuenca del Nanay. Se desconoce el estado actual de sus poblaciones.

178. Peperomia nubescens C. DC.

Publicación: Bot. Jahrb. Syst. 40: 265. 1908.

Colección tipo: A. Weberbauer 1944

Herbarios: B.

Nombre común: D esconocido.

Registro departamental: JU.

Regiones Ecológicas: BMHP; $1000 \mathrm{~m}$.

SINANPE: Sin registro.

Herbarios peruanos: Ninguno.

Observaciones: Este taxón fue considerado por Brako \& Zarucchi (1993) como un endemismo; sin embargo, no ha sido posible evaluarlo, ni asignarle una categoría.

\section{Peperomia rubrispica Trel.}

Publicación: Field Mus. Nat. Hist., Bot. Ser. 13(2): 88. 1936.

Colección tipo: J.F. Macbride 4667

Herbarios: $F$.

Nombre común: D esconocido.

Registro departamental: PA.

Regiones Ecológicas: BHA; $600 \mathrm{~m}$.

SINANPE: Sin registro.

Herbarios peruanos: Ninguno.

Observaciones: Este taxón fue considerado por Brako \& Zarucchi (1993) como un endemismo; sin embargo, no ha sido posible evaluarlo, ni asignarle una categoría. La localidad original fue citada para el departamento de Huánuco por Trelease (1936) y Brako \& Zarucchi (1993), pero en realidad se halla hoy ubicada en Pasco.

180. Peperomia nufescens C. DC.

\section{DD}

Publicación: Prodr. 16(1): 416. 1869.

Colección tipo: J. Pavón 277

Hemarios: G.

Nombre común: D esconocido.

Registro departamental: LO.

Regiones Ecológicas: BHA; altitud desconocida.

SINAN PE: Sin registro.

Herbarios peruanos: Ninguno.

Observaciones: Hierba terrestre, conocida aparentemente de dos colecciones. El ejemplar tipo fue recolectado en el siglo XVIII, en una localidad desconocida. Un ejemplar adicional fue recolectado en el siglo XIX, probablemente en una localidad sobre el río Amazonas. Se desconoce el estado actual de sus poblaciones.

\section{Peperomia rufescentifolia Trel.}

Publicación: Field Mus. Nat. Hist., Bot. Ser. 13(2): 89. 1936.

Colección tipo: L. Williams 6487

Herbarios: $F$.

Nombre común: D esconocido.

Registro departamental: SM.

Regiones Ecológicas: BMHP; $840 \mathrm{~m}$.

SINAN PE: Sin registro.

Herbarios peruanos: Ninguno.
Observaciones: Este taxón fue considerado por Brako \& Zarucchi (1993) como un endemismo; sin embargo, no ha sido posible evaluarlo, ni asignarle una categoría.

\section{Peperomia rugatifolia Trel. var. rugatifolia}

\author{
Publicación: \\ Colección tipo: E.P. Killip \& A.C. Smith 26183 \\ Herbarios: US. \\ Nombre común: D esconocido. \\ Registro departamental: JU. \\ Regiones Ecológicas: BMHP; 625-900 m. \\ SINAN PE: Sin registro. \\ Herbarios peruanos: Ninguno.
}

Observaciones: Este taxón fue considerado por Brako \& Zarucchi (1993) como un endemismo; sin embargo, no ha sido posible evaluarlo, ni asignarle una categoría.

183. Peperomia rugatifolia Trel. var. exilispica Trel.

Publicación: Field Mus. Nat. Hist., Bot. Ser. 13(2): 90. 1936.

Colección tipo: C.O. Schunke 1561

Herbarios: $F$.

Nombre común: Desconocido.

Registro departamental: JU.

Regiones Ecológicas: BMHM; 1500 m.

SINANPE: Sin registro.

Herbarios peruanos: Ninguno.

Observaciones: Este taxón fue considerado por Brako \& Zarucchi (1993) como un endemismo; sin embargo, no ha sido posible evaluarlo, ni asignarle una categoría.

\section{Peperomia rupiceda C. DC. ex A.W. Hill}

\section{DD}

Publicación: Ann. Bot. (Oxford) 21: 148, 157, t. 5. 1907.

Colección tipo: A. Weberbauer 145

Herbarios: B.

Nombre común: D esconocido.

Registro departamental: LI.

Regiones Ecológicas: MA; 2370-2830 m.

SINAN PE: Sin registro.

Herbarios peruanos: USM (1).

Observaciones: Hierba acaulescente, tuberífera, conocida sólo de la cuenca del Rímac. Fue descrita de una planta recolectada en 1902 y registrada nuevamente en 1952. Se desconoce el estado actual de sus poblaciones.

\section{Peperomia salicifolia C. DC.}

Publicación: Annuaire Conserv. Jard. Bot. Geneve 2:281. 1898.

Colección tipo: C. Gay s.n.

Henbarios: P.

Nombre común: Desconocido.

Registro departamental: Sin datos.

Regiones Ecológicas: Sin datos; altitud desconocida.

SINANPE: Sin registro.

Herbarios peruanos: Ninguno. 
Observaciones: Este taxón fue considerado por Brako \& Zarucchi (1993) como un endemismo; sin embargo, no ha sido posible evaluarlo, ni asignarle una categoría.

\section{Peperomia salmonicolorTrel. var. salmonicolor}

Publicación:

Colección tipo: L. Williams 7329

Herbarios: $F$.

Nombre común: D esconocido.

Registro departamental: SM.

Regiones Ecológicas: BMHM, BMHP;

$1350-1500 \mathrm{~m}$.

SINANPE: Sin registro.

Herbarios peruanos: Ninguno.

Observaciones: Este taxón fue considerado por Brako \& Zarucchi (1993) como un endemismo; sin embargo, no ha sido posible evaluarlo, ni asignarle una categoría

\section{Peperomia salmonicolorTrel. var. vinidis Trel.}

Publicación: Field Mus. Nat. Hist., Bot. Ser. 13(2): 91. 1936. 1936.

Colección tipo: L. Williams 7258

Herbarios: $F$.

Nombre común: D esconocido.

Registro departamental: SM.

Regiones Ecológicas: BMHM, BMHP; $1350-1500 \mathrm{~m}$.

SINANPE: Sin registro

Herbarios peruanos: Ninguno.

Observaciones: Este taxón fue considerado por Brako \& Zarucchi (1993) como un endemismo; sin embargo, no ha sido posible evaluarlo, ni asignarle una categoría.

\section{Peperomia sanbuenaventuranaTrel.}

Publicación: Field Mus. Nat. Hist., Bot. Ser. 13(2): 91. 1936.

Colección tipo: F.W. Pennell 14566

Hemarios: $\mathrm{PH}$.

Nombre común: D esconocido.

Registro departamental: LI.

Regiones Ecológicas: MA; 2700 m.

SINAN PE: Sin registro.

Herbarios peruanos: Ninguno.

Observaciones: Este taxón fue considerado por Brako \& Zarucchi (1993) como un endemismo; sin embargo, no ha sido posible evaluarlo, ni asignarle una categoría.

\section{Peperomia sandemanii Yunck.}

\section{DD}

Publicación: Amer. J. Bot. 39(9): 636, f. 6. 1952.

Colección tipo: C.A. Sandeman 4586

Herbarios: $\mathrm{K}$.

Nombre común: D esconocido.

Registro departamental: JU.

Regiones Ecológicas: BMHM; $2100 \mathrm{~m}$.

SINANPE: Sin registro.

Herbarios peruanos: Ninguno.
Observaciones: Hierba conocida solamente de una localidad, en Junín. No ha vuelto a ser recolectada desde 1943. Yuncker (1952) citando las notas de Sandeman, señala que esta especie formaba colonias en áreas húmedas. Se desconoce el estado actual de sus poblaciones.

\section{Peperomia sangabanensis Trel.}

Publicación: Field Mus. Nat. Hist., Bot. Ser. 13(2): 91. 1936.

Colección tipo: W. Lechler 2378

Herbarios: $\mathrm{K}$.

Nombre común: D esconocido.

Registro departamental: PU.

Regiones Ecológicas: BMHM; altitud desconocida.

SINAN PE: Sin registro.

Herbarios peruanos: Ninguno.

Observaciones: Este taxón fue considerado por Brako \& Zarucchi (1993) como un endemismo; sin embargo, no ha sido posible evaluarlo, ni asignarle una categoría.

\section{Peperomia sanroqueana Trel.}

Publicación: Field Mus. Nat. Hist., Bot. Ser. 13(2): 91. 1936.

Colección tipo: L. Williams 7260

Herbarios: $F$.

Nombre común: D esconocido.

Registro departamental: SM.

Regiones Ecológicas: BMHM, BMHP; 1350- $1500 \mathrm{~m}$.

SINANPE: Sin registro.

Herbarios peruanos: Ninguno.

Observaciones: Este taxón fue considerado por Brako \& Zarucchi (1993) como un endemismo; sin embargo, no ha sido posible evaluarlo, ni asignarle una categoría.

\section{Peperomia santacruzana Trel.}

\section{DD}

Publicación: Field Mus. Nat. Hist., Bot. Ser. 13(2): 91-92. 1936.

Colección tipo: R.W. Pearce s.n.

Herbarios: K.

Nombre común: D esconocido.

Registro departamental: Sin datos.

Regiones Ecológicas: Sin datos; altitud desconocida.

SINAN PE: Sin registro.

Herbarios peruanos: Ninguno.

Observaciones: Hierba terrestre, descrita por Trelease (1936) de un ejemplar recolectado por Richard Pearce, en 1864, probablemente en el Perú. Por lo menos dos localidades con el nombre «Santa Cruz» existen en el país y que pudieron ser visitadas por este botánico. 
193. Peperomia santiagoana Trel.

\section{DD}

Publicación: Field Mus. Nat. Hist., Bot. Ser. 13(2): 92. 1936.

Colección tipo: Y. Mexia 6146

Herbarios: MO, NY, U, UC, Z.

Nombre común: D esconocido.

Registro departamental: AM.

Regiones Ecológicas: BHA; $200 \mathrm{~m}$.

SINANPE: Sin registro.

Herbarios peruanos: Ninguno.

Observaciones: Hierba conocida solamente de una localidad, en la cuenca del Santiago, Amazonas, localidad cerca del límite con Loreto. Mexia comentó que era localmente frecuente. Se desconoce el estado actual de sus poblaciones.

\section{Peperomia sarcostachya Trel. var. sarcostachya}

\section{DD}

Publicación:

Colección tipo: E.P. Killip \& A.C. Smith 28889

Herbarios: US.

Nombre común: D esconocido.

Registro departamental: LO.

Regiones Ecológicas: BHA; $135 \mathrm{~m}$.

SINANPE: Sin registro.

Hemarios peruanos: Ninguno.

Observaciones: Hierba conocida, al parecer, sólo de la colección tipo, una planta recolectada en 1929, de la cuenca del Marañón. Se desconoce el estado actual de sus poblaciones.

195. Peperomia sarcostachya Trel. var. repens Trel.

Publicación: Field Mus. Nat. Hist., Bot Ser. 13(2): 92. 1936.

Colección tipo: E.P. Killip \& A.C. Smith 25307

Herbarios: US.

Nombre común: D esconocido.

Registro departamental: JU.

Regiones Ecológicas: BMHP; $700 \mathrm{~m}$.

SINANPE: Sin registro.

Hemarios peruanos: Ninguno.

Observaciones: Este taxón fue considerado por Brako \& Zarucchi (1993) como un endemismo; sin embargo, no ha sido posible evaluarlo, ni asignarle una categoría.

196. Peperomia scabiosa Trel.

Publicación: Field Mus. Nat. Hist., Bot. Ser. 13(2): 92- 93. 1936.

Colección tipo: J.F. Macbride 3857

Herbarios: F.

Nombre común: D esconocido.

Registro departamental: HU.

Regiones Ecológicas: BMHM; 1500 m.

SINAN PE: Sin registro.

Herbarios peruanos: Ninguno.

Observaciones: Este taxón fue considerado por Brako \& Zarucchi (1993) como un endemismo; sin embargo, no ha sido posible evaluarlo, ni asignarle una categoría.
197. Peperomia scandens Ruiz \& Pav. var. longispica Trel. DD

Publicación: Field Mus. Nat. Hist., Bot. Ser. 13(2): 93. 1936.

Colección tipo: E.P. Killip \& A.C. Smith 28382

Herbarios: US.

Nombre común: D esconocido.

Registro departamental: LO.

Regiones Ecológicas: BHA; 150-330 m.

SINANPE: Sin registro.

Herbarios peruanos: Ninguno.

Observaciones: Hierba epífita, conocida de la colección tipo, una planta recolectada en 1929, de la cuenca del Huallaga. Se desconoce el estado actual de sus poblaciones.

\section{Peperomia sclemophylla Trel.}

Publicación: Field Mus. Nat. Hist., Bot. Ser. 13(2): 94. 1936.

Colección tipo: L. Williams 6879

Herbarios: $F$.

Nombre común: D esconocido.

Registro departamental: SM.

Regiones Ecológicas: BHA; 360-900 m.

SINAN PE: Sin registro.

Herbarios peruanos: Ninguno.

Observaciones: Este taxón fue considerado por Brako \& Zarucchi (1993) como un endemismo; sin embargo, no ha sido posible evaluarlo, ni asignarle una categoría.

199. Peperomia scutaleifolia Trel.

Publicación: Field Mus. Nat. Hist., Bot. Ser. 13(2): 94. 1936.

Colección tipo: E.P. Killip \& A.C. Smith 25557

Herbarios: US

Nombre común: D esconocido.

Registro departamental: JU.

Regiones Ecológicas: BMHM, BMHP; $1350-1600 \mathrm{~m}$.

SINAN PE: Sin registro.

Hembarios peruanos: Ninguno.

Observaciones: Este taxón fue considerado por Brako \& Zarucchi (1993) como un endemismo; sin embargo, no ha sido posible evaluarlo, ni asignarle una categoría.

200. Peperomia seposita Trel.

Publicación: Field Mus. Nat. Hist., Bot. Ser. 13(2): 96. 1936.

Colección tipo: Stevens 213

Herbarios:

Nombre común: D esconocido.

Registro departamental: JU.

Regiones Ecológicas: Sin datos; altitud desconocida.

SINANPE: Sin registro.

Herbarios peruanos: Ninguno.

Observaciones: Este taxón fue considerado por Brako \& Zarucchi (1993) como un endemismo; sin embargo, no ha sido posible evaluarlo, ni asignarle una categoría 


\section{Peperomia smithii Trel.}

DD

Publicación: Field Mus. Nat. Hist., Bot. Ser. 13(2): 96. 1936.

Colección tipo: E.P. Killip \& A.C. Smith 28115

Herbarios: US.

Nombre común: D esconocido.

Registro departamental: LO.

Regiones Ecológicas: BHA; 135- 150 m.

SINANPE: Sin registro.

Herbarios peruanos: Ninguno.

Observaciones: Hierba epífita, recolectada originalmente en la cuenca del Huallaga, en el occidente de Loreto. Aparentemente, no ha vuelto a ser recolectada desde 1929. Se desconoce el estado actual de sus poblaciones.

\section{Peperomia soukupii Trel.}

Publicación: Field Mus. Nat. Hist., Bot. Ser. 13(2/ 3): 1126. 1936.

Colección tipo: J. Soukup 137

Herbarios: $F$.

Nombre común: D esconocido.

Registro departamental: CU.

Regiones Ecológicas: BMHP; altitud desconocida.

SINAN PE: Sin registro.

Hemarios peruanos: Ninguno.

Observaciones: Este taxón fue considerado por Brako \& Zarucchi (1993) como un endemismo; sin embargo, no ha sido posible evaluarlo, ni asignarle una categoría.

\section{Peperomia spectabilis Miq.}

Publicación: London J. Bot. 4: 417. 1845. Colección tipo: A. Mathews 1635

Hembarios: Sin datos.

Nombre común: D esconocido.

Registro departamental: Sin datos.

Regiones Ecológicas: Sin datos; altitud desconocida.

SINAN PE: Sin registro.

Herbarios peruanos: Ninguno.

Observaciones: Este taxón fue considerado por Brako \& Zarucchi (1993) como un endemismo; sin embargo, no ha sido posible evaluarlo, ni asignarle una categoría.

204. Pepenomia spiculata Trel. var. elliptica Trel.

Publicación: Field Mus. Nat. Hist., Bot. Ser. 13(2): 97. 1936.

Colección tipo: C.O. Schunke 388

Herbarios: $F$.

Nombre común: D esconocido.

Registro departamental: JU.

Regiones Ecológicas: Sin datos; altitud desconocida.

SINAN PE: Sin registro.

Herbarios peruanos: Ninguno.

Observaciones: Este taxón fue considerado por Brako \& Zarucchi (1993) como un endemismo; sin embargo, no ha sido posible evaluarlo, ni asignarle una categoría.
205. Peperomia sprucei C. DC.

Publicación: J. Bot. 4: 133. 1866.

Colección tipo: R. Spruce 4931

Herbarios: $\mathrm{K}$.

Nombre común: D esconocido.

Registro departamental: SM.

Regiones Ecológicas: BMHP; altitud desconocida.

SINAN PE: Sin registro.

Herbarios peruanos: Ninguno.

Observaciones: Este taxón fue considerado por Brako \& Zarucchi (1993) como un endemismo; sin embargo, no ha sido posible evaluarlo, ni asignarle una categoría.

\section{Peperomia strawii Hutchison ex Pino \& Klopfestein \\ EN, Bla}

Publicación: Haseltonia 10: 87-90, f. 16. 2004.

Colección tipo: P.C. Hutchison et al. 16320

Herbarios: UC; USM!.

Nombre común: D esconocido.

Registro departamental: CA, LL.

Regiones Ecológicas: BS; 1470 - 2300 m.

SINANPE: Sin registro.

Herbarios peruanos: USM (holotipo).

Observaciones: Esta especie fue listada en Brako \& Zarucchi (1993); sin embargo, no había sido formalmente descrita hasta 2004. Tanto ladificultad taxonómicadel género, como la escasez de colecciones contribuyeron a lo poco que se sabía de esta especie. Reciente interés en plantas suculentas ha permitido que se adicionen localidades y colectas para esta especie. Probablemente, sea más común en la cuenca del Marañón, en donde están ubicadas las localidades. Por su distribución limitada se la reconoce como en peligro.

\section{Peperomia subdichotoma Trel.}

Publicación: Field Mus. Nat. Hist., Bot. Ser. 13(2): 98. 1936.

Colección tipo: J.F. Macbride 4008

Herbarios: $F$.

Nombre común: Desconocido.

Registro departamental: HU.

Regiones Ecológicas: MA; $2100 \mathrm{~m}$.

SINANPE: Sin registro.

Herbarios peruanos: Ninguno.

Observaciones: Este taxón fue considerado por Brako \& Zarucchi (1993) como un endemismo; sin embargo, no ha sido posible evaluarlo, ni asignarle una categoría.

\section{Peperomia subflaccida Yunck.}

DD

Publicación: Svensk Bot. Tidskr. 51(3): 539. 1957.

Colección tipo: G. Klug 3209

Herbarios: S, US.

Nombre común: Desconocido.

Registro departamental: LO.

Regiones Ecológicas: BMHP; $600-1200 \mathrm{~m}$.

SINANPE: Sin registro.

Herbarios peruanos: Ninguno. 
Observaciones: Hierba terrestre recolectada de una localidad entre las cuencas del Paranapura, un tributario del Huallaga, y del Mayo. Aparentemente, no ha vuelto a ser recolectada desde 1933. Se desconoce el estado actual de sus poblaciones.

\section{Peperomia subsericata Trel.}

Publicación: Field Mus. Nat. Hist., Bot. Ser. 13(2): 98-99. 1936.

Colección tipo: C.O. Schunke A81

Herbarios: $F$.

Nombre común: D esconocido.

Registro departamental: JU, PA, SM.

Regiones Ecológicas: $\mathrm{BMHM}$; altitud desconocida.

SINAN PE: Sin registro.

Hemarios peruanos: Ninguno.

Observaciones: Este taxón fue considerado por Brako \& Zarucchi (1993) como un endemismo; sin embargo, no ha sido posible evaluarlo, ni asignarle una categoría.

\section{Peperomia subvillicaulis Trel.}

Publicación: Field Mus. Nat. Hist., Bot. Ser. 13(2): 99. 1936.

Colección tipo: F.W. Pennell 13990

Herbarios: $\mathrm{F}$, PH.

Nombre común: D esconocido.

Registro departamental: $\mathrm{CU}$.

Regiones Ecológicas: BMHM; 2200$2400 \mathrm{~m}$.

SINAN PE: PNM

Hemarios peruanos: Ninguno.

Observaciones: Este taxón fue considerado por Brako \& Zarucchi (1993) como un endemismo; sin embargo, no ha sido posible evaluarlo, ni asignarle una categoría.

\section{Peperomia sylvaticaC. DC.}

Publicación: Prodr. 16(1): 435. 1869

Colección tipo: E.F. Poeppig s.n.

Herbarios: Sin datos.

Nombre común: D esconocido.

Registro departamental: HU.

Regiones Ecológicas: Sin datos; altitud desconocida.

SINAN PE: Sin registro.

Hemarios peruanos: Ninguno.

Observaciones: Este taxón fue considerado por Brako \& Zarucchi (1993) como un endemismo; sin embargo, no ha sido posible evaluarlo, ni asignarle una categoría.

212. Peperomia tarapotanaC. DC.

Publicación: J. Bot. 4: 137. 1866.

Colección tipo: R. Spruce 4570

Herbarios: $\mathrm{K}$.

Nombre común: D esconocido.

Registro departamental: SM.

Regiones Ecológicas: BMHP; altitud

desconocida.

SINANPE: Sin registro.

Herbarios peruanos: Ninguno.
Observaciones: Este taxón fue considerado por Brako \& Zarucchi (1993) como un endemismo; sin embargo, no ha sido posible evaluarlo, ni asignarle una categoría.

\section{Peperomia tenuiramea C. DC.}

Publicación: Bot. Jahrb. Syst. 40: 263. 1908.

Colección tipo: A. Weberbauer 3656

Hemanios: B; MOL!

Nombre común: D esconocido.

Registro departamental: HU.

Regiones Ecológicas: BMHP; 600- 700 m.

SINAN PE: Sin registro.

Herbarios penuanos: MOL (lectotipo).

Observaciones: Este taxón fue considerado por Brako \& Zarucchi (1993) como un endemismo; sin embargo, no ha sido posible evaluarlo, ni asignarle una categoría.

\section{Peperomia teresitensis Trel.}

Publicación: Field Mus. Nat. Hist., Bot. Ser. 13(2): 100. 1936.

Colección tipo: Stevens 88

Herbarios: Sin datos.

Nombre común: D esconocido.

Registro departamental: JU.

Regiones Ecológicas: Sin datos; altitud desconocida.

SINANPE: Sin registro.

Herbarios peruanos: Ninguno.

Observaciones: Este taxón fue considerado por Brako \& Zarucchi (1993) como un endemismo; sin embargo, no ha sido posible evaluarlo, ni asignarle una categoría.

\section{Peperomia tetrica Trel.}

DD

Publicación: Field Mus. Nat. Hist., Bot. Ser. 13(2): 100. 1936.

Colección tipo: E.P. Killip \& A.C. Smith 28525

Herbarios: US

Nombre común: D esconocido.

Registro departamental: LO.

Regiones Ecológicas: BHA; 350-550 m.

SINANPE: Sin registro.

Herbarios peruanos: Ninguno.

Observaciones: Hierba conocida solamente de la colección tipo, una planta recolectada en 1929, de la cuenca del Huallaga. Se desconoce el estado actual de sus poblaciones.

\section{Peperomia timbuchiana Trel.}

\section{DD}

Publicación: Field Mus. Nat. Hist., Bot. Ser. 13(2): 100-101. 1936

Colección tipo: L. Williams 1163

Herbarios: $F$.

Nombre común: D esconocido.

Registro departamental: LO.

Regiones Ecológicas: BHA; altitud desconocida.

SINANPE: Sin registro.

Herbarios peruanos: Ninguno. 
Observaciones: Hierba diminuta y, probablemente, terrestre conocida sólo de la colección tipo, recolectada en 1924, en la cuenca del Nanay. Se desconoce el estado actual de sus poblaciones.

\section{Peperomia trullaefolia Trel.}

Publicación: Field Mus. Nat. Hist., Bot. Ser. 13(2): 102. 1936

Colección tipo: O.F. Cook \& G.B. Gilbert 401

Herbarios: US.

Nombre común: D esconocido.

Registro departamental: CU, LI.

Regiones Ecológicas: MA; 2600-3000 m.

SINANPE: Sin registro.

Herbarios peruanos: HAO (1).

Observaciones: Este taxón fue considerado por Brako \& Zarucchi (1993) como un endemismo; sin embargo, no ha sido posible evaluarlo, ni asignarle una categoría.

218. Peperomia umbelliformis C. DC.

Publicación: Bot. Jahrb. Syst. 40: 257. 1908.

Colección tipo: A. Weberbauer 1631

Herbarios: B.

Nombre común: D esconocido.

Registro departamental: LI, LL.

Regiones Ecológicas: D ST; 200-800 m.

SINANPE: Sin registro.

Herbarios peruanos: HUT (1).

Observaciones: Este taxón fue considerado por Brako \& Zarucchi (1993) como un endemismo; sin embargo, no ha sido posible evaluarlo, ni asignarle una categoría.

\section{Peperomia umbilicata Ruiz \& Pav.}

Publicación: Fl. Peruv. 1: 30, t. 45, f. b. 1798.

Colección tipo: H. Ruiz \& J. Pavón s.n.

Herbarios: Sin datos.

Nombre común: D esconocido.

Registro departamental: HU, LI.

Regiones Ecológicas: Sin datos; altitud desconocida.

SINANPE: Sin registro.

Herbarios peruanos: Ninguno.

Observaciones: Este taxón fue considerado por Brako \& Zarucchi (1993) como un endemismo; sin embargo, no ha sido posible evaluarlo, ni asignarle una categoría.

220. Peperomia uncatispica Trel.

Publicación: Field Mus. Nat. Hist., Bot. Ser. 13(2): 102-103. 1936

Colección tipo: E.P. Killip \& A.C. Smith 24578

Herbarios: US.

Nombre común: D esconocido.

Registro departamental: JU.

Regiones Ecológicas: BMHM; 1400$1700 \mathrm{~m}$.

SINANPE: Sin registro.

Herbarios peruanos: Ninguno.
Observaciones: Este taxón fue considerado por Brako \& Zarucchi (1993) como un endemismo; sin embargo, no ha sido posible evaluarlo, ni asignarle una categoría.

221. Peperomia undeninervia C. DC.

Publicación: Prodr. 16(1): 441. 1869.

Colección tipo: J. Pavón

Herbarios: G.

Nombre común: D esconocido.

Registro departamental: JU.

Regiones Ecológicas: BHA; altitud desconocida.

SINANPE: Sin registro.

Herbarios peruanos: Ninguno.

Observaciones: Este taxón fue considerado por Brako \& Zarucchi (1993) como un endemismo; sin embargo, no ha sido posible evaluarlo, ni asignarle una categoría.

222. Peperomia vana Trel.

Publicación: Field Mus. Nat. Hist., Bot. Ser. 13(2): 103. 1936

Colección tipo: E.P. Killip \& A.C. Smith 24614

Herbarios: US.

Nombre común: Desconocido.

Registro departamental: JU.

Regiones Ecológicas: BMHM; 1400 $1700 \mathrm{~m}$.

SINANPE: Sin registro.

Herbarios peruanos: Ninguno.

Observaciones: Este taxón fue considerado por Brako \& Zarucchi (1993) como un endemismo; sin embargo, no ha sido posible evaluarlo, ni asignarle una categoría.

\section{Peperomia variculata Trel.}

Publicación: Field Mus. Nat. Hist., Bot. Ser. 13(2): 103. 1936.

Colección tipo: E.P. Killip \& A.C. Smith 26792

Henbarios: US.

Nombre común: D esconocido.

Registro departamental: HU, PA.

Regiones Ecológicas: BHA; 340 m.

SINAN PE: Sin registro.

Herbarios penuanos: USM (1)?.

Observaciones: Este taxón fue considerado por Brako \& Zarucchi (1993) como un endemismo; sin embargo, no ha sido posible evaluarlo, ni asignarle una categoría. La localidad original fue citada para el departamento de Junín por Trelease (1936) y Brako \& Zarucchi (1993), pero en realidad se halla hoy ubicada en Pasco.

224. Peperomia variifolia C. DC.

DD

Publicación: Prodr. 16(1): 462. 1869.

Colección tipo: E.F. Poeppig s.n.

Herbarios: Sin datos.

Nombre común: Desconocido.

Registro departamental: Sin datos.

Regiones Ecológicas: Sin datos; altitud desconocida.

SINANPE: Sin registro.

Herbarios peruanos: Ninguno. 
Observaciones: Planta descrita de un ejemplar recolectado en el siglo XIX, de procedencia desconocida.

\section{Peperomia venticosicarpa Trel.}

\section{DD}

Publicación: Field Mus. Nat. Hist., Bot. Ser. 13(2): 104. 1936.

Colección tipo: E.P. Killip \& A.C. Smith 29800

Herbarios: US.

Nombre común: D esconocido.

Registro departamental: LO.

Regiones Ecológicas: BHA; $110 \mathrm{~m}$.

SINANPE: Sin registro.

Herbarios penuanos: Ninguno.

Observaciones: Hierba conocida de la colección tipo, recolectada en 1929, de la cuenca del Itaya. Se desconoce el estado actual de sus poblaciones.

\section{Peperomia verediana Trel.}

\section{DD}

Publicación: Field Mus. Nat. Hist., Bot. Ser. 13(2): 104. 1936

Colección tipo: L. Williams 2139

Herbarios: $F$.

Nombre común: D esconocido.

Registro departamental: LO.

Regiones Ecológicas: BHA; altitud desconocida.

SINANPE: Sin registro.

Herbarios peruanos: Ninguno.

Observaciones: Hierba descrita de una planta estéril, la cual fue recolectada en 1929, en Caballococha, sobre el ńo Amazonas, muy cerca al límite con Brasil. Se desconoce el estado actual de sus poblaciones.

\section{Peperomia viracochana Trel.}

Publicación: Field Mus. Nat. Hist., Bot. Ser. 13(2): 105. 1936

Colección tipo: O.F. Cook \& G.B. Gilbert 218

Herbarios: US.

Nombre común: D esconocido.

Registro departamental: CU.

Regiones Ecológicas: $\mathrm{PSH} ; 3500 \mathrm{~m}$.

SINAN PE: Sin registro.

Hemarios peruanos: Ninguno.

Observaciones: Este taxón fue considerado por Brako \& Zarucchi (1993) como un endemismo; sin embargo, no ha sido posible evaluarlo, ni asignarle una categoría.

228. Peperomia weberbaueniC. DC.

\section{DD}

Publicación: Bot. Jahrb. Syst. 40: 255256. 1908.

Colección tipo: A. Weberbauer 4306

Herbarios: B, G; MOL!.

Nombre común: Desconocido.

Registro departamental: AM.

Regiones Ecológicas: MDE; $1600 \mathrm{~m}$.

SINAN PE: Sin registro.

Herbarios peruanos: MOL(lectotipo).

Observaciones: Hierba conocida, al parecer, de una localidad, en la cuenca del Utcubamba, donde fue recolectada en 1904. Se desconoce el estado actual de sus poblaciones.
229. Peperomia woytkowskii Yunck.

DD

Publicación: Ann. Missouri Bot. Gard. 53: 384. 1966.

Colección tipo: F. Woytkowski 6390

Herbarios: MO.

Nombre común: D esconocido.

Registro departamental: JU.

Regiones Ecológicas: BMHM; $1600 \mathrm{~m}$.

SINANPE: Sin registro.

Herbarios peruanos: Ninguno.

Observaciones: Hierba conocida de una localidad, en el límite departamental de Junín y Pasco. Fue registrada originalmente en 1961. Se desconoce el estado actual de sus poblaciones.

\section{Peperomia yananoensis Trel. var. yananoensis}

\author{
Publicación: \\ Colección tipo: J.F. Macbride 3741 \\ Herbarios: F. \\ Nombre común: Desconocido. \\ Registro departamental: HU. \\ Regiones Ecológicas: BMHM; 1800 m. \\ SINANPE: Sin registro. \\ Henbarios peruanos: Ninguno.
}

Observaciones: Este taxón fue considerado por Brako \& Zarucchi (1993) como un endemismo; sin embargo, no ha sido posible evaluarlo, ni asignarle una categoría.

\section{Peperomia yananoensis Trel. var. caniana Trel.}

\section{DD}

Publicación: Field Mus. Nat. Hist., Bot. Ser. 13(2): 106. 1936.

Colección tipo: J.F. Macbride 3460

Herbarios: $F$.

Nombre común: D esconocido.

Registro departamental: $\mathrm{HU}$.

Regiones Ecológicas: MA; $2550 \mathrm{~m}$.

SINAN PE: Sin registro.

Herbarios peruanos: Ninguno.

Observaciones: Hierba terrestre, recolectada en 1923, de la cuenca del Huallaga. Se desconoce el estado actual de sus poblaciones.

\section{Peperomia yapasana Trel.}

\section{DD}

Publicación: Field Mus. Nat. Hist., Bot. Ser. 13(2): 106. 1936.

Colección tipo: E.P. Killip \& A.C. Smith 25478

Herbarios: US.

Nombre común: D esconocido.

Registro departamental: JU.

Regiones Ecológicas: BMHM, BMHP; $1350-1600 \mathrm{~m}$

SINANPE: Sin registro.

Herbarios peruanos: Ninguno.

Observaciones: Hierba epífita, descrita de una planta recolectada en 1929, del valle de Chanchamayo. Se desconoce el estado actual de sus poblaciones. 


\section{Piperabditum Trel.}

DD

Publicación: Field Mus. Nat. Hist., Bot. Ser. 13(2): 130. 1936.

Colección tipo: E.P. Killip \& A.C. Smith 27659 Herbarios: US.

Nombre común: D esconocido.

Registro departamental: LO, MD.

Regiones Ecológicas: BHA; $135 \mathrm{~m}$.

SINANPE: Sin registro.

Herbarios peruanos: Ninguno.

Observaciones: Arbusto conocido solamente de una localidad; el ejemplar tipo fue recolectado en la cuenca del Huallaga, en 1929. No ha vuelto a ser recolectada desde entonces. Se desconoce el estado actual de sus poblaciones.

\section{Piperachromatolepis Trel.}

\section{DD}

Publicación: Field Mus. Nat. Hist., Bot. Ser. 13(2): 130. 1936.

Colección tipo: L. Williams 4244

Herbarios: F.

Nombre común: Cordoncillo.

Registro departamental: LO.

Regiones Ecológicas: BHA; 155- 210 m.

SINANPE: Sin registro.

Hembarios peruanos: Ninguno.

Observaciones: Arbusto conocido, al parecer, de dos localidades, en las cuencas del Huallagay del Amazonas. No havuelto a ser recolectado desde 1930. Se desconoce el estado actual de sus poblaciones.

\section{Piperacutifolium Ruiz \& Pav. var. stuebelii Trel.}

\section{DD}

Publicación: Field Mus. Nat. Hist., Bot. Ser. 13(2): 131. 1936.

Colección tipo: A. Stübel 69

Hemarios: B.

Nombre común: D esconocido.

Registro departamental: AM.

Regiones Ecológicas: BMHM; altitud desconocida.

SINAN PE: Sin registro.

Herbarios peruanos: Ninguno.

Observaciones: Arbusto conocido, al parecer, sólo de una localidad en el norte del país, de plantas recolectadas en el siglo XIX. Se desconoce el estado actual de sus poblaciones.

\section{Piper acutulum Trel.}

\section{DD}

Publicación: Field Mus. Nat. Hist., Bot. Ser. 13(2): 131-132. 1936.

Colección tipo: E.P. Killip \& A.C. Smith 26014

Herbarios: US.

Nombre común: D esconocido.

Registro departamental: PA.

Regiones Ecológicas: BMHP; $1100 \mathrm{~m}$.

SINANPE: Sin registro.

Herbarios peruanos: Ninguno.
Observaciones: Árbol conocido, al parecer, sólo de la colección tipo, una planta recolectada entre las cuencas del Perenéy del Palcazú, en 1929. La localidad original fue citada para el departamento de Junín por Trelease (1936) y Brako \& Zarucchi (1993), pero en realidad se halla hoy ubicada en Pasco. Se desconoce el estado actual de sus poblaciones.

\section{Piperadmirabile Yunck.}

\section{DD}

Publicación: Svensk. Bot. Tidskr. 51(3): 532- 533. 1957.

Colección tipo: Y. Mexia 8280

Herbarios: S, UC, US.

Nombre común: Desconocido.

Registro departamental: HU.

Regiones Ecológicas: BMHP; $880 \mathrm{~m}$.

SINAN PE: Sin registro.

Herbarios peruanos: Ninguno.

Observaciones: Especie arbórea conocida sólo de una localidad. El ejemplar tipo fue recolectado en la cuenca del Huallaga, en 1936. No ha vuelto a ser recolectada desde entonces. Se desconoce el estado actual de sus poblaciones.

\section{Piperadreptum Trel.}

\section{EN, Bla}

Publicación: Field Mus. Nat. Hist., Bot. Ser. 13(2): 132. 1936.

Colección tipo: G. Klug 1394

Herbarios: $F$.

Nombre común: D esconocido.

Registro departamental: LO, SM.

Regiones Ecológicas: BHA; 100- $560 \mathrm{~m}$.

SINANPE: Sin registro.

Hembarios peruanos: Ninguno.

Observaciones: Arbusto conocido, al parecer, sólo de dos localidades, una en la cuenca del Huallaga y otra en una subcuenca del Amazonas. El ejemplar tipo fue recolectado en los alrededores de Iquitos, en 1930. Quijano-Abril et al. (2006) la reconocieron como un endemismo que forma parte de un patrón biogeográfico único al Neotrópico.

\section{Piper affictum Trel.}

\section{EN, Bla}

Publicación: Field Mus. Nat. Hist., Bot. Ser. 13(2): 132. 1936.

Colección tipo: E.P. Killip \& A.C. Smith 28581

Herbarios: US.

Nombre común: D esconocido.

Registro departamental: LO, SM.

Regiones Ecológicas: BHA; 150-600 m.

SINAN PE: Sin registro.

Herbarios peruanos: Ninguno.

Observaciones: Esta especie arbustiva se conoce solamente de dos localidades. El ejemplar tipo fue recolectado en los alrededores de Iquitos, en 1929. Una población adicional ha sido recolectada en la cuenca del Huallaga. 


\section{Piperafflictum Trel.}

\section{DD}

Publicación: Field Mus. Nat. Hist., Bot. Ser. 13(2): 132-133. 1936.

Colección tipo: E.F. Poeppig s.n.

Herbarios: W.

Nombre común: Cordoncillo.

Registro departamental: LO.

Regiones Ecológicas: BHA; $100 \mathrm{~m}$.

SINANPE: Sin registro.

Hembarios peruanos: Ninguno.

Observaciones: Arbusto conocido de unas cuatro localidades, en las cuencas del Huallagay Amazonas. El ejemplar tipo fue recolectado en el siglo XIX y, al parecer, no ha vuelto a ser recolectada desde 1929. No fue tratada por Vásquez (1997). Se desconoce el estado actual de sus poblaciones.

\section{Piperalbiciliatum Yunck.}

\section{DD}

Publicación: Brittonia 13(1): 58. 1961. Colección tipo: F. Woytkowski 1377

Herbarios: NY, US; MOL.

Nombre común: D esconocido.

Registro departamental: $\mathrm{HU}$.

Regiones Ecológicas: BHA; $550 \mathrm{~m}$.

SINAN PE: Sin registro.

Henbarios penuanos: MOL (isotipo).

Obsenvaciones: Arbusto conocido, al parecer, de la colección tipo, una planta recolectada en 1954, de la cuenca del Huallaga, en un bosque pantanoso. Se desconoce el estado actual de sus poblaciones.

\section{Piperalbogranulatum Trel.}

\section{CR, B lab(iii)}

Publicación: Field Mus. Nat. Hist., Bot. Ser. 13(2): 133. 1936

Colección tipo: E.P. Killip \& A.C. Smith 28883

Herbarios: US.

Nombre común: D esconocido.

Registro departamental: LO.

Regiones Ecológicas: BHA; 135 m.

SINAN PE: Sin registro.

Hembarios peruanos: Ninguno.

Observaciones: Arbusto conocido, al parecer, sólo de la colección tipo, una planta recolectada en 1929, en la cuenca del Bajo Huallaga. Quijano-Abril et al. (2006) la reconocieron como un endemismo para su análisis biogógrafico. El registro original fue realizado muy cerca de Yurimaguas, por lo que es posible que cambios en los ambientes naturales pueden haberlo afectado.

\section{Piper albopapillatum Trel.}

\section{CR, Blab(iii)}

Publicación: Field Mus. Nat. Hist., Bot. Ser. 13(2): 133. 1936.

Colección tipo: E.P. Killip \& A.C. Smith 24616

Herbarios: US.

Nombre común: D esconocido.

Registro departamental: JU.

Regiones Ecológicas: BMHM; 1400$1700 \mathrm{~m}$.

SINANPE: Sin registro.

Hembarios peruanos: Ninguno.
Observaciones: Arbusto conocido aparentemente sólo de la colección tipo, una planta recolectada en 1929, en el valle de Chanchamayo, cuenca del Tulumayo. La localidad registrada para esa especie ha sido severamente modificada con el crecimiento agrícola cerca a la ciudad de San Ramón; por lo que es posible que la población conocida haya sido afectada.

\section{Piper allardii Y unck.}

DD

Publicación: Amer. J. Bot. 39(9): 635636. 1952.

Colección tipo: H.A. Allard 20425

Hemarios: US.

Nombre común: D esconocido.

Registro departamental: $\mathrm{HU}$.

Regiones Ecológicas: BMHP; $780 \mathrm{~m}$.

SINAN PE: Sin registro.

Herbarios peruanos: Ninguno.

Observaciones: Arbusto conocido al parecer, sólo de la colección tipo, una planta recolectada en la cuenca del Huallaga, en 1949. Fue citada por error porYuncker (1952) y repetido por Brako \& Zarucchi (1993) como procedente del departamento de San Martín, pero, la localidad original, Tingo María, está en Huánuco. Se desconoce detalles del hábitat y localidad precisa de colección.

\section{Piperalveolatum 0 piz}

\section{DD}

Publicación: Reliq. Haenk. 1(3): 155. 1828.

Colección tipo: T. Haenke s.n.

Henbarios: PR.

Nombre común: D esconocido.

Registro departamental: $\mathrm{HU}, \mathrm{CU}$.

Regiones Ecológicas: BMHM; $2400 \mathrm{~m}$.

SINAN PE: Sin registro.

Herbarios peruanos: Ninguno.

Observaciones: Arbusto conocido, al parecer, de dos localidades. La colección tipo fue recolectada en el siglo XVIII, en una localidad no precisada en el centro del país. Trelease (1936) incluyó un ejemplar registrado muy cerca del Parque Nacional Manu, pero no ha sido confirmado. Se desconoce el estado actual de sus poblaciones.

\section{Piper amphitrichum Trel.}

\section{DD}

Publicación: Field Mus. Nat. Hist., Bot. Ser. 13(2): 134. 1936.

Colección tipo: E.P. Killip \& A.C. Smith 24938

Herbarios: NY, US.

Nombre común: D esconocido.

Registro departamental: JU.

Regiones Ecológicas: BMHP; $680 \mathrm{~m}$.

SINAN PE: Sin registro.

Hemarios peruanos: Ninguno.

Observaciones: Arbusto conocido aparentemente sólo de la colección tipo, una planta recolectada en 1929, del valle de Chanchamayo. Esta especie no fue citada por Quijano-Abril et al. (2006). Se desconoce el estado actual de sus poblaciones. 


\section{Piperanastylum Trel.}

\section{DD}

Publicación: Field Mus. Nat. Hist., Bot. Ser. 13(2): 134-135. 1936.

Colección tipo: E.P. Killip \& A.C. Smith 26015

Herbarios: NY, US.

Nombre común: D esconocido.

Registro departamental: PA.

Regiones Ecológicas: BMHP; $1100 \mathrm{~m}$.

SINANPE: Sin registro.

Herbarios peruanos: Ninguno.

Observaciones: Arbusto conocido de la localidad tipo, ubicada muy cercaal límite departamental de Pasco y Junín, entre las cuencas del Pichis y del Perené. Esta especie, no fue citada por QuijanoAbril et al. (2006). Se desconoce el estado actual de sus poblaciones.

\section{Piperanonymum Trel.}

\section{DD}

Publicación: Field Mus. Nat. Hist., Bot. Ser. 13(2): 135. 1936.

Colección tipo: E.F. Poeppig 73

Hembarios: P.

Nombre común: D esconocido.

Registro departamental: Sin datos.

Regiones Ecológicas: Sin datos; altitud desconocida.

SINAN PE: Sin registro.

Herbarios peruanos: Ninguno.

Observaciones: Arbusto conocido solamente de un ejemplar, recolectado en una localidad desconocida, a inicios del siglo XIX. Esta especie no fue citada por Quijano-Abril et al. (2006). Se desconoce el estado actual de sus poblaciones.

\section{Piperapodum Trel.}

\section{DD}

Publicación: Field Mus. Nat. Hist., Bot. Ser. 13(2): 135. 1936.

Colección tipo: J.F. Macbride 3987

Herbarios: F, US.

Nombre común: D esconocido.

Registro departamental: HU.

Regiones Ecológicas: MA; 2100 m.

SINANPE: Sin registro.

Herbarios peruanos: Ninguno.

Observaciones: Árbol conocido de una localidad, en la cuenca de un tributario del Pozuzo, donde fue recolectado en 1923. QuijanoAbril et al. (2006) la reconocieron como un endemismo para su análisis biogeográfico. Se desconoce el estado actual de sus poblaciones.

\section{Piperapunimacanum Trel.}

\section{DD}

Publicación: Field Mus. Nat. Hist., Bot. Ser. 13(2): 135. 1936.

Colección tipo: E.P. Killip \& A.C. Smith 22926

Henbarios: US.

Nombre común: D esconocido.

Registro departamental: $\mathrm{AY}$.

Regiones Ecológicas: BHA; $400 \mathrm{~m}$.

SINANPE: Sin registro.

Herbarios peruanos: Ninguno.
Observaciones: Arbusto conocido de una localidad, en la cuenca baja del Apurímac, donde fue recolectado en 1929. Esta especie no fue citada por Q uijano-Abril et al. (2006). Se desconoce el estado actual de sus poblaciones.

\section{Piperapus Trel.}

Publicación: Field Mus. Nat. Hist., Bot. Ser. 13(2): 136. 1936.

Colección tipo: E.P. Killip \& A.C. Smith 26192

Herbarios: NY, US.

Nombre común: D esconocido.

Registro departamental: JU.

Regiones Ecológicas: BMHP; 625-900 m.

SINANPE: Sin registro.

Herbarios peruanos: Ninguno.

Observaciones: Este taxón fue considerado por Brako \& Zarucchi (1993) como un endemismo; sin embargo, no ha sido posible evaluarlo, ni asignarle una categoría.

\section{Piperaraneatum Trel.}

Publicación: Field Mus. Nat. Hist., Bot. Ser. 13(2): 136. 1936.

Colección tipo: E.P. Killip \& A.C. Smith 25242

Herbarios: NY, US.

Nombre común: D esconocido.

Registro departamental: JU.

Regiones Ecológicas: Sin datos; altitud desconocida.

SINANPE: Sin registro.

Herbarios peruanos: Ninguno.

Observaciones: Este taxón fue considerado por Brako \& Zarucchi (1993) como un endemismo; sin embargo, no ha sido posible evaluarlo, ni asignarle una categoría.

\section{Piperarduum Trel.}

\section{DD}

Publicación: Field Mus. Nat. Hist., Bot. Ser. 13(2): 136. 1936.

Colección tipo: L. Williams 5174

Hembarios: $F$.

Nombre común: D esconocido.

Registro departamental: LO.

Regiones Ecológicas: BHA; 155- 200 m. SINAN PE: Sin registro.

Herbarios peruanos: Ninguno.

Observaciones: Arbusto de sotobosque, conocido de la colección tipo, una planta recolectada en la cuenca del Bajo Huallaga, en 1924. Esta especie no fue citada por Quijano-Abril et al. (2006). Se desconoce el estado actual de sus poblaciones.

254. Piperareolatum (Miq.) C. DC.

Publicación: Prodr. 16(1): 303-304. 1869.

Colección tipo: A. Mathews 3227

Herbarios: $\mathrm{K}$.

Nombre común: D esconocido.

Registro departamental: AM.

Regiones Ecológicas: Sin datos; altitud desconocida.

SINANPE: Sin registro.

Herbarios peruanos: Ninguno. 
Observaciones: Este taxón fue considerado por Brako \& Zarucchi (1993) como un endemismo; sin embargo, no ha sido posible evaluarlo, ni asignarle una categoría.

\section{Piperarrectispicum Trel.}

Publicación: Field Mus. Nat. Hist., Bot. Ser. 13(2): 137. 1936.

Colección tipo: L. Williams 6993

Herbarios: $F$.

Nombre común: D esconocido.

Registro departamental: SM.

Regiones Ecológicas: BMHP; $1350-$ $1500 \mathrm{~m}$.

SINANPE: Sin registro.

Herbarios peruanos: Ninguno.

Observaciones: Este taxón fue considerado por Brako \& Zarucchi (1993) como un endemismo; sin embargo, no ha sido posible evaluarlo, ni asignarle una categoría.

\section{Piper arreptum Trel.}

\section{DD}

Publicación: Field Mus. Nat. Hist., Bot. Ser. 13(2): 137. 1936

Colección tipo: E.P. Killip \& A.C. Smith 26487

Herbarios: US.

Nombre común: D esconocido.

Registro departamental: PA.

Regiones Ecológicas: BHA; 375 m.

SINAN PE: Sin registro.

Herbarios peruanos: Ninguno.

Observaciones: Arbusto conocido de la cuenca del Pichis, donde fue recolectado en 1929, de la cuenca del Pichis. La localidad original fue citada para el departamento de Junín por Trelease (1936) y Brako \& Zarucchi (1993), pero en realidad se halla hoy ubicada en Pasco. Esta especie no fue citada por Quijano-Abril et al. (2006). Se desconoce el estado actual de sus poblaciones.

\section{Piperascendentispicum Trel.}

Publicación: Field Mus. Nat. Hist., Bot. Ser. 13(2): 137. 1936

Colección tipo: E.P. Killip \& A.C. Smith 26724

Herbarios: US

Nombre común: D esconocido.

Registro departamental: PA.

Regiones Ecológicas: BHA; 340 m.

SINAN PE: Sin registro.

Herbarios peruanos: Ninguno.

Observaciones: Arbusto descrito de una planta recolectada en 1929, de la cuenca del Pichis. La localidad original fue citada para el departamento de Junín por Trelease (1936) y Brako \& Zarucchi (1993), pero en realidad se halla hoy ubicada en Pasco. No ha sido posible evaluarlo, ni asignarle una categoría.

\section{Piperasclepiadifolium Trel.}

\section{DD}

Publicación: Field Mus. Nat. Hist., Bot. Ser. 13(2): 138. 1936.

Colección tipo: E.P. Killip \& A.C. Smith 27016

Herbarios: US.

Nombre común: D esconocido.

Registro departamental: LO.

Regiones Ecológicas: BHA; altitud desconocida.

SINANPE: Sin registro.

Herbarios peruanos: Ninguno.

Observaciones: Arbusto conocido sólo de la colección tipo, recolectado en 1929, de los alrededores de Iquitos. Quijano-Abril et al. (2006) la reconocieron como un endemismo para su análisis biogeográfico. Se desconoce el estado actual de sus poblaciones.

\section{Piperasplundii Yunck.}

Publicación: Amer. J. Bot. 43(3): 166, f. 6. 1956.

Colección tipo: E. Asplund 12571

Hembarios: S.

Nombre común: D esconocido.

Registro departamental: HU.

Regiones Ecológicas: BMHP; 1400 m.

SINAN PE: Sin registro.

Herbarios peruanos: Ninguno.

Observaciones: Este taxón fue considerado por Brako \& Zarucchi (1993) como un endemismo; sin embargo, no ha sido posible evaluarlo, ni asignarle una categoría.

\section{Piperasterocarpum Trel.}

\section{DD}

Publicación: Field Mus. Nat. Hist., Bot. Ser. 13(2): 138. 1936.

Colección tipo: Anónimo. s.n.

Henbarios: W.

Nombre común: D esconocido.

Registro departamental: Sin datos.

Regiones Ecológicas: Sin datos; altitud desconocida.

SINANPE: Sin registro.

Herbarios peruanos: Ninguno.

Observaciones: Especie, al parecer, arbustiva, descrita de un ejemplar, presumiblemente recolectado en el Perú. Toda información sobre este único ejemplar es desconocida.

\section{Piper attenuatamentum Trel.}

Publicación: Field Mus. Nat. Hist., Bot. Ser. 13(2): 139. 1936.

Colección tipo: E.P. Killip \& A.C. Smith 26513

Herbarios: US.

Nombre común: D esconocido.

Registro departamental: PA.

Regiones Ecológicas: BHA; 375 m.

SINANPE: Sin registro.

Herbarios peruanos: Ninguno. 
Observaciones: Este taxón fue considerado por Brako \& Zarucchi (1993) como un endemismo; sin embargo, no ha sido posible evaluarlo, ni asignarle una categoría. La localidad original fue citada para el departamento de Junín por Trelease (1936) y Brako \& Zarucchi (1993), pero en realidad se halla hoy ubicada en Pasco.

\section{Piperazupizuanum Trel.}

Publicación: Field Mus. Nat. Hist., Bot. Ser. 13(2): 139-140. 1936.

Colección tipo: E.P. Killip \& A.C. Smith 26094

Herbarios: US.

Nombre común: D esconocido.

Registro departamental: PA.

Regiones Ecológicas: BMHP; 650-900 $\mathrm{m}$.

SINANPE: Sin registro.

Herbarios peruanos: Ninguno.

Observaciones: Este taxón fue considerado por Brako \& Zarucchi (1993) como un endemismo; sin embargo, no ha sido posible evaluarlo, ni asignarle una categoría. La localidad original fue citada para el departamento de Junín por Trelease (1936) y Brako \& Zarucchi (1993), pero en realidad se halla hoy ubicada en Pasco

\section{Piperbalsapuertanum Trel.}

Publicación: Field Mus. Nat. Hist., Bot. Ser. 13(2): 140. 1936.

Colección tipo: E.P. Killip \& A.C. Smith 28394

Herbarios: US.

Nombre común: Desconocido.

Registro departamental: LO.

Regiones Ecológicas: BHA; 150-350 m.

SINAN PE: Sin registro.

Herbarios peruanos: Ninguno.

Observaciones: Este taxón fue considerado por Brako \& Zarucchi (1993) como un endemismo; sin embargo, no ha sido posible evaluarlo, ni asignarle una categoría.

\section{Piperbarbicuspe Trel.}

\section{DD}

Publicación: Field Mus. Nat. Hist., Bot. Ser. 13(2): 140. 1936.

Colección tipo: G. Klug 253

Herbarios: $F$.

Nombre común: D esconocido.

Registro departamental: LO.

Regiones Ecológicas: BHA; $100 \mathrm{~m}$.

SINAN PE: Sin registro.

Herbarios peruanos: Ninguno.

Observaciones: Árbol conocido, al parecer, sólo de la localidad tipo, en una subcuenca del Amazonas. No ha vuelto a ser recolectado desde 1929. Quijano-Abril et al. (2006) la reconocieron como un endemismo para su análisis biogeográfico. Se desconoce el estado actual de sus poblaciones.

\section{Piper banbulantherum Trel.}

Publicación: Field Mus. Nat. Hist., Bot. Ser. 13(2): 140-141. 1936.

Colección tipo: A. Weberbauer 6093

Herbarios: B.

Nombre común: D esconocido.

Registro departamental: PI.

Regiones Ecológicas: MA; $3000 \mathrm{~m}$.

SINANPE: Sin registro.

Herbarios peruanos: Ninguno.

Observaciones: Este taxón fue considerado por Brako \& Zarucchi (1993) como un endemismo; sin embargo, no ha sido posible evaluarlo, ni asignarle una categoría.

\section{Piperbrachytrichum Trel.}

Publicación: Field Mus. Nat. Hist., Bot. Ser. 13(2): 141. 1936.

Colección tipo: E.P. Killip \& A.C. Smith 22652

Herbarios: US.

Nombre común: D esconocido.

Registro departamental: AY.

Regiones Ecológicas: BHA; $500 \mathrm{~m}$.

SINAN PE: Sin registro.

Hemarios peruanos: Ninguno.

Observaciones: Estetaxón fue considerado por Brako \& Zarucchi (1993) como un endemismo; sin embargo, no ha sido posible evaluarlo, ni asignarle una categoría.

\section{Piper brevestrigillosum Trel.}

\section{CR, B lab(iii)}

Publicación: Field Mus. Nat. Hist., Bot. Ser. 13(2): 141. 1936.

Colección tipo: E.P. Killip \& A.C. Smith 22375

Herbarios: US.

Nombre común: Desconocido.

Registro departamental: AY.

Regiones Ecológicas: BMHM; 1500 m.

SINANPE: Sin registro.

Herbarios peruanos: Ninguno.

Observaciones: Arbusto conocido, al parecer, sólo de la localidad original, ubicada en la cuenca del Apurímac, donde fue recolectado en 1929. Quijano-Abril et al. (2006) la reconocieron como un endemismo y formando parte de un patrón biogeográfico único al Neotrópico. La población conocida ocupaba un matorral. Probablemente, la amenaza más importante provenga de los incendios intencionales.

\section{Piper brevipedunculum Trel.}

\section{CR, B lab(iii)}

Publicación: Field Mus. Nat. Hist., Bot. Ser. 13(2): 141-142. 1936.

Colección tipo: E.P. Killip \& A.C. Smith 22677

Herbarios: US.

Nombre común: D esconocido.

Registro departamental: AY.

Regiones Ecológicas: BHA; $500 \mathrm{~m}$.

SINANPE: Sin registro.

Herbarios peruanos: Ninguno. 
Observaciones: Especie arbórea que fue reconocida por Brako \& Zarucchi (1993) en la sinonimia de Piper formosum; sin embargo, Q uijano-Abril et al. (2006) la reconocen como un endemismo. Se conoce sólo de la localidad original, en la cuenca del A purímac y no ha vuelto a ser recolectada desde 1929.

\section{Piperbrongniartii (Miq.) C. DC.}

Publicación: Prodr. 16(1): 327. 1869

Colección tipo: J. D ombey 907

Herbarios: P.

Nombre común: D esconocido.

Registro departamental: HU.

Regiones Ecológicas: Sin datos; altitud desconocida.

SINAN PE: Sin registro.

Herbarios peruanos: Ninguno.

Observaciones: Estetaxón fue considerado por Brako \& Zarucchi (1993) como un endemismo; sin embargo, no ha sido posible evaluarlo, ni asignarle una categoría.

\section{Piper caballocochanum Trel.}

\section{DD}

Publicación: Field Mus. Nat. Hist., Bot. Ser. 13(2): 142. 1936

Colección tipo: L. Williams 2309

Hembarios: $F$.

Nombre común: Cordoncillo.

Registro departamental: LO.

Regiones Ecológicas: BHA; 100-150 m.

SINANPE: Sin registro.

Hemarios peruanos: Ninguno.

Observaciones: Arbusto de sotobosque conocido aparentemente sólo de la colección tipo, una planta recolectada en 1924, de Caballococha, muy cerca al límite con Colombia.

\section{Pipercajamancanum Yunck.}

Publicación: Ann. Missouri Bot. Gard. 53(3): 382. 1966.

Colección tipo: F. Woytkowski 7033

Herbarios: MO.

Nombre común: D esconocido.

Registro departamental: CA.

Regiones Ecológicas: Sin datos; altitud desconocida.

SINANPE: Sin registro.

Hembarios peruanos: Ninguno.

Observaciones: Este taxón fue considerado por Brako \& Zarucchi (1993) como un endemismo; sin embargo, no ha sido posible evaluarlo, ni asignarle una categoría.

\section{Piper calamistratum Trel.}

Publicación: Field Mus. Nat. Hist., Bot. Ser. 13(2): 143. 1936

Colección tipo: G. Klug 206

Herbarios: F.

Nombre común: D esconocido.

Registro departamental: LO.

Regiones Ecológicas: BHA; $100 \mathrm{~m}$.

SINANPE: Sin registro.

Hembarios peruanos: Ninguno.
Observaciones: Este taxón fue considerado por Brako \& Zarucchi (1993) como un endemismo; sin embargo, no ha sido posible evaluarlo, ni asignarle una categoría.

\section{Pipercallcanense Trel.}

Publicación: Field Mus. Nat. Hist., Bot. Ser. 13(2): 143. 1936.

Colección tipo: R.W. Pearce s.n.

Henbarios: $\mathrm{K}$.

Nombre común: D esconocido.

Registro departamental: Sin datos.

Regiones Ecológicas: Sin datos; $2400 \mathrm{~m}$.

SINANPE: Sin registro.

Herbarios peruanos: Ninguno.

Observaciones: Este taxón fue considerado por Brako \& Zarucchi (1993) como un endemismo; sin embargo, no ha sido posible evaluarlo, ni asignarle una categoría.

\section{Piper calvescentinerve Trel.}

Publicación: Field Mus. Nat. Hist., Bot. Ser. 13(2): 144. 1936.

Colección tipo: E.P. Killip \& A.C. Smith 26248

Herbarios: US.

Nombre común: D esconocido.

Registro departamental: PA.

Regiones Ecológicas: BHA; $400 \mathrm{~m}$.

SINANPE: Sin registro.

Herbarios peruanos: Ninguno.

Observaciones: Especie arbórea cuya localidad original fue citada para el departamento de Junín por Trelease (1936) y Brako \& Zarucchi (1993), pero en realidad se halla hoy ubicada en Pasco. No ha sido posible evaluarlo, ni asignarle una categoría.

\section{Piper calvibaccum Trel.}

Publicación: Field Mus. Nat. Hist., Bot. Ser. 13(2): 144. 1936.

Colección tipo: C.O. Schunke 1804

Hembarios: $F$.

Nombre común: D esconocido.

Registro departamental: JU.

Regiones Ecológicas: BMHM, BMHP; $1200-1500 \mathrm{~m}$.

SINANPE: Sin registro.

Herbarios peruanos: Ninguno.

Observaciones: Este taxón fue considerado por Brako \& Zarucchi (1993) como un endemismo; sin embargo, no ha sido posible evaluarlo, ni asignarle una categoría.

276. Pipercamphonifenum C. DC.

Publicación: Annuaire Conserv. Jard. Bot. Geneve 21: 235. 1923.

Colección tipo: Gilg 37

Herbarios: $G$ ?

Nombre común: Desconocido.

Registro departamental: HU.

Regiones Ecológicas: Sin datos; altitud desconocida.

SINANPE: Sin registro.

Herbarios peruanos: Ninguno. 
Observaciones: Este taxón fue considerado por Brako \& Zarucchi (1993) como un endemismo; sin embargo, no ha sido posible evaluarlo, ni asignarle una categoría.

\section{Pipercapillistipes Trel.}

Publicación: Field Mus. Nat. Hist., Bot. Ser. 13(2): 145. 1936.

Colección tipo: E.P. Killip \& A.C. Smith 29607

Herbarios: US.

Nombre común: D esconocido.

Registro departamental: LO.

Regiones Ecológicas: BHA; 110 m.

SINAN PE: Sin registro.

Herbarios peruanos: Ninguno.

Observaciones: Este taxón fue considerado por Brako \& Zarucchi (1993) como un endemismo; sin embargo, no ha sido posible evaluarlo, ni asignarle una categoría

\section{Pipercarrapanum Trel.}

\section{CR, Blab(iii)}

Publicación: Field Mus. Nat. Hist., Bot. Ser. 13(2): 146. 1936

Colección tipo: E.P. Killip \& A.C. Smith 22425

Herbarios: ILL, US.

Nombre común: D esconocido.

Registro departamental: AY.

Regiones Ecológicas: BMHP; $1200 \mathrm{~m}$.

SINANPE: Sin registro.

Herbarios peruanos: Ninguno.

Observaciones: Árbol conocido, al parecer, sólo delalocalidad original, ubicada en la cuenca del Apurímac, donde fue recolectado en 1929. Quijano-Abril et al. (2006) la reconocieron como un endemismo, con un patrón biogeográfico único al Neotrópico.Lapoblación conocidaocupaba una ladera boscosa. Por la altitud y el tipo de vegetación es probable que la amenaza principal sean los incendios intencionales.

\section{Pipercassinoides 0 piz}

Publicación: Reliq. Haenk. 153. 1830.

Colección tipo: T. Haenke s.n.

Herbarios: PR.

Nombre común: D esconocido.

Registro departamental: HU.

Regiones Ecológicas: Sin datos; altitud desconocida.

SINANPE: Sin registro.

Herbarios peruanos: Ninguno.

Observaciones: Este taxón fue considerado por Brako \& Zarucchi (1993) como un endemismo; sin embargo, no ha sido posible evaluarlo, ni asignarle una categoría.

280. PipercelerTrel.

DD

Publicación: Field Mus. Nat. Hist., Bot. Ser. 13(2): 147. 1936

Colección tipo: L. Williams 132

Herbarios: $F$.

Nombre común: D esconocido.

Registro departamental: LO.

Regiones Ecológicas: BHA; 100 m.

SINAN PE: Sin registro

Herbarios peruanos: Ninguno.
Observaciones: Arbusto conocido, al parecer, sólo de la cuenca del Itaya, un tributario del Amazonas, donde fue recolectado en 1930. Quijano-Abril et al. (2006) la reconocieron como un endemismo para su análisis biogeográfico.

\section{Pipercelsum Trel.}

Publicación: Field Mus. Nat. Hist., Bot. Ser. 13(2): 147. 1936.

Colección tipo: E.P. Killip \& A.C. Smith 23907

Henbarios: US.

Nombre común: D esconocido.

Registro departamental: JU, LO

Regiones Ecológicas: BHA; 800-1300 m.

SINANPE: Sin registro.

Herbarios peruanos: Ninguno.

Observaciones: Este taxón fue considerado por Brako \& Zarucchi (1993) como un endemismo; sin embargo, no ha sido posible evaluarlo, ni asignarle una categoría.

\section{Piperchalhuapuquianum Trel.}

DD

Publicación: Field Mus. Nat. Hist., Bot. Ser. 13(2): 147-148. 1936.

Colección tipo: Stevens 104

Herbarios: ILL.

Nombre común: D esconocido.

Registro departamental: $\mathrm{HU}$.

Regiones Ecológicas: Sin datos; altitud desconocida.

SINANPE: Sin registro.

Herbarios peruanos: Ninguno.

Observaciones: Arbusto conocido sólo de la colección tipo, una planta recolectada en 1924, en la cuenca del Tulumayo. Se desconoce el estado actual de sus poblaciones.

283. Piperchanchamayanum Trel.

Publicación: Field Mus. Nat. Hist., Bot. Ser. 13(2): 148. 1936

Colección tipo: C.O. Schunke 1595

Herbarios: $F$.

Nombre común: D esconocido.

Registro departamental: AY, JU.

Regiones Ecológicas: $\mathrm{BMHP}, \mathrm{BHA}$; $500-1200 \mathrm{~m}$.

SINANPE: Sin registro.

Herbarios peruanos: Ninguno.

Observaciones: Este taxón fue considerado por Brako \& Zarucchi (1993) como un endemismo; sin embargo, no ha sido posible evaluarlo, ni asignarle una categoría.

284. Piperchromatolepis Trel.

Publicación: Field Mus. Nat. Hist., Bot. Ser. 13(2): 148. 1936

Colección tipo: L. Williams 536

Herbarios: $F$.

Nombre común: D esconocido.

Registro departamental: LO.

Regiones Ecológicas: BHA; altitud desconocida.

SINANPE: Sin registro.

Herbarios peruanos: Ninguno. 
Observaciones: Este taxón fue considerado por Brako \& Zarucchi (1993) como un endemismo; sin embargo, no ha sido posible evaluarlo, ni asignarle una categoría.

\section{Piperchrysoneurum Trel.}

Publicación: Field Mus. Nat. Hist., Bot. Ser. 13(2): 148- 149. 1936.

Colección tipo: L. Williams 3207

Herbarios: $F$.

Nombre común: D esconocido.

Registro departamental: LO.

Regiones Ecológicas: BHA; $145 \mathrm{~m}$.

SINAN PE: Sin registro.

Herbarios peruanos: Ninguno.

Observaciones: Este taxón fue considerado por Brako \& Zarucchi (1993) como un endemismo; sin embargo, no ha sido posible evaluarlo, ni asignarle una categoría.

\section{Piper churumayu Ruiz \& Pav.}

\section{DD}

Publicación: Flora 1: 35, t. 58. 1798. 1798. Colección tipo: H. Ruiz \& J. Pavón s.n.

Herbarios: MA.

Nombre común: D esconocido.

Registro departamental: JU.

Regiones Ecológicas: MA; altitud desconocida.

SINANPE: Sin registro.

Herbarios peruanos: Ninguno.

Obsenvaciones: Arbusto conocido de la cuenca del Palcay recolectado afines del siglo XVIII.Trelease(1936) consideró queproveníadeHuánuco, pero la localidad oniginal comesponde al departamento de Junín. Se desconoce el estado actual de sus poblaciones.

\section{Piperciniflonis Trel.}

Publicación: Field Mus. Nat. Hist., Bot. Ser. 13(2): 149-150. 1936.

Colección tipo: E.P. Killip \& A.C. Smith 26166

Herbarios: US.

Nombre común: D esconocido.

Registro departamental: JU.

Regiones Ecológicas: BMHP; 625-900 m.

SINAN PE: Sin registro.

Hembarios peruanos: Ninguno.

Observaciones: Este taxón fue considerado por Brako \& Zarucchi (1993) como un endemismo; sin embargo, no ha sido posible evaluarlo, ni asignarle una categoría.

\section{Pipercircumspectantis Trel.}

\section{DD}

Publicación: Field Mus. Nat. Hist., Bot. Ser. 13(2): 150. 1936

Colección tipo: G. Klug 507

Herbarios: US.

Nombre común: D esconocido.

Registro departamental: LO.

Regiones Ecológicas: BHA; 100 m.

SINANPE: Sin registro.

Herbarios peruanos: Ninguno.
Observaciones: Arbusto conocido sólo de la localidad original, en una subcuenca del Amazonas, donde fue registrado en 1929. Brako \& Zarucchi (1993) incluyeron esta especie en la sinonimia de Piper brasiliense; pero Quijano-Abril et al. (2006) la aceptan, criterio que aquí se sigue.

\section{Piper cirratum Trel.}

Publicación: Field Mus. Nat. Hist., Bot. Ser. 13(2): 150. 1936.

Colección tipo: L. Williams 2969

Hemarios: $F$.

Nombre común: D esconocido.

Registro departamental: LO.

Regiones Ecológicas: BHA; altitud desconocida.

SINAN PE: Sin registro.

Herbarios peruanos: Ninguno.

Observaciones: Este taxón fue considerado por Brako \& Zarucchi (1993) como un endemismo; sin embargo, no ha sido posible evaluarlo, ni asignarle una categoría.

\section{Piper cispontinum Trel.}

\section{DD}

Publicación: Field Mus. Nat. Hist., Bot. Ser. 13(2): 150. 1936.

Colección tipo: E.P. Killip \& A.C. Smith 25284

Herbarios: US

Nombre común: D esconocido.

Registro departamental: JU.

Regiones Ecológicas: BMHP; $700 \mathrm{~m}$.

SINAN PE: Sin registro.

Herbarios peruanos: Ninguno.

Observaciones: Arbusto conocido de la cuenca del río Paucartambo, al parecer, no ha vuelto a ser recolectada desde 1929. Esa parte de la cuenca ha sido desde ese entonces muy modificada, por lo que es causa de preocupación para esta especie. Se desconoce el estado actual de sus poblaciones.

\section{Piperclaudicans Trel.}

\section{DD}

Publicación: Field Mus. Nat. Hist., Bot. Ser. 13(2): 151. 1936.

Colección tipo: E.P. Killip \& A.C. Smith 26938

Henbarios: US.

Nombre común: D esconocido.

Registro departamental: LO.

Regiones Ecológicas: BHA; 100 m.

SINANPE: Sin registro.

Herbarios peruanos: Ninguno.

Observaciones: Árbol conocido sólo de la localidad original, en una subcuenca del Amazonas, donde fue registrado en 1929. Brako \& Zarucchi (1993) incluyeron esta especie en la sinonimia de Piper arboreum; pero Quijano-Abril et al. (2006) la aceptan, criterio que aquí se sigue. Se desconoce el estado actual de sus poblaciones. 
292. Piperclaudii C. DC.

DD

Publicación: Annuaire Conserv. Jard. Bot. Geneve 2: 264. 1898.

Colección tipo: C. G ay s.n.

Herbarios: P.

Nombre común: D esconocido.

Registro departamental: Sin datos.

Regiones Ecológicas: Sin datos; altitud desconocida.

SINAN PE: Sin registro.

Herbarios peruanos: Ninguno.

Observaciones: Arbusto conocido sólo de la descripción y del ejemplar tipo, una planta recolectada en el siglo XIX, de procedencia exacta desconocida.

\section{Piper comasense Trel.}

Publicación: Field Mus. Nat. Hist., Bot. Ser. 13(2): 152. 1936.

Colección tipo: A. Weberbauer 6615

Hembarios: F, US; MOL!.

Nombre común: Desconocido.

Registro departamental: JU.

Regiones Ecológicas: BMHM; 2500$2600 \mathrm{~m}$.

SINAN PE: Sin registro.

Herbarios penuanos: MOL (isotipo).

Observaciones: Este taxón fue considerado por Brako \& Zarucchi (1993) como un endemismo; sin embargo, no ha sido posible evaluarlo, ni asignarle una categoría.

\section{Piper conditum Trel. var. angustum Trel.}

Publicación: Field Mus. Nat. Hist., Bot. Ser. 13(2): 152. 1936.

Colección tipo: E.P. Killip \& A.C. Smith 29105

Herbarios: US.

Nombre común: D esconocido.

Registro departamental: LO.

Regiones Ecológicas: BHA; $135 \mathrm{~m}$.

SINAN PE: Sin registro.

Herbarios peruanos: Ninguno.

Observaciones: Estetaxón fue considerado por Brako \& Zarucchi (1993) como un endemismo; sin embargo, no ha sido posible evaluarlo, ni asignarle una categoría.

\section{Piper conispicum Trel.}

Publicación: Field Mus. Nat. Hist., Bot. Ser. 13(2): 153. 1936.

Colección tipo: E.P. Killip \& A.C. Smith 28767

Herbarios: US.

Nombre común: D esconocido.

Registro departamental: HU, LO, SM.

Regiones Ecológicas: BHA; 135- 800 m.

SINAN PE: Sin registro.

Herbarios peruanos: Ninguno.

Observaciones: Este taxón fue considerado por Brako \& Zarucchi (1993) como un endemismo; sin embargo, no ha sido posible evaluarlo, ni asignarle una categoría.
296. Pipercontroversum C. DC.

Publicación: Nomencl. Bot. (ed. 2) 2: 340. 1841.

Colección tipo: T. Haenke 71

Henbarios: W.

Nombre común: D esconocido.

Registro departamental: HU.

Regiones Ecológicas: Sin datos; altitud desconocida.

SINAN PE: Sin registro.

Herbarios peruanos: Ninguno.

Observaciones: Este taxón fue considerado por Brako \& Zarucchi (1993) como un endemismo; sin embargo, no ha sido posible evaluarlo, ni asignarle una categoría.

\section{Piper criniovanium Yunck.}

\section{DD}

Publicación: Caldasia 6: 33, f. 8. 1953.

Colección tipo: R.E. Schultes 6473

Herbarios: US.

Nombre común: D esconocido.

Registro departamental: MD.

Regiones Ecológicas: BHA; altitud desconocida.

SINAN PE: Sin registro.

Hembarios peruanos: Ninguno.

Observaciones: Arbusto conocido solamente de una localidad, vecina a Brasil, cuenca del Tahuamanú. No fue incluida en Brako \& Zarucchi (1993) como un endemismo.

298. Pipercumbasonum C. DC.

Publicación: Verh. Bot. Vereins Prov. Brandenburg 47: 108. 1905.

Colección tipo: E.H.G. Ule 6826

Herbarios: B.

Nombre común: D esconocido.

Registro departamental: LO, SM.

Regiones Ecológicas: $\mathrm{BHA}$; altitud desconocida.

SINAN PE: Sin registro.

Herbarios peruanos: Ninguno.

Observaciones: Este taxón fue considerado por Brako \& Zarucchi (1993) como un endemismo; sin embargo, no ha sido posible evaluarlo, ni asignarle una categoría.

\section{Pipercupreatum Trel.}

\section{DD}

Publicación: Field Mus. Nat. Hist., Bot. Ser. 13(2): 156. 1936.

Colección tipo: E.P. Killip \& A.C. Smith 28509

Herbarios: US.

Nombre común: D esconocido.

Registro departamental: LO.

Regiones Ecológicas: BHA; 350-500 m.

SINANPE: Sin registro.

Herbarios peruanos: Ninguno. 
Observaciones: Árbol conocido, al parecer, sólo de una subcuenca del Bajo Huallaga. No ha vuelto a ser recolectado desde 1929. QuijanoAbril et al. (2006) la reconocieron como un endemismo para su análisis biogeográfico. Se desconoce el estado actual de sus poblaciones.

\section{Pipercurvatum Ruiz \& Pav.}

Publicación: Flora 1: 36, t. 54. 1798. Colección tipo: H. Ruiz \& J. Pavón 1/ 86

Herbarios: MA.

Nombre común: D esconocido.

Registro departamental: HU.

Regiones Ecológicas: BMHP; altitud desconocida.

SINANPE: Sin registro.

Herbarios peruanos: Ninguno.

Observaciones: Este taxón fue considerado por Brako \& Zarucchi (1993) como un endemismo; sin embargo, no ha sido posible evaluarlo, ni asignarle una categoría.

\section{Piperdaedalum Trel.}

Publicación: Field Mus. Nat. Hist., Bot. Ser. 13(2): 156-157. 1936.

Colección tipo: L. Williams 3861

Herbarios: F.

Nombre común: D esconocido.

Registro departamental: LO, SM.

Regiones Ecológicas: BHA; 155- $210 \mathrm{~m}$.

SINANPE: Sin registro.

Herbarios peruanos: Ninguno.

Observaciones: Este taxón fue considerado por Brako \& Zarucchi (1993) como un endemismo; sin embargo, no ha sido posible evaluarlo, ni asignarle una categoría.

302. Piperdasypodum (Miq.) C. DC.

Publicación: Prodr. 16(1): 304. 1869.

Colección tipo: A. Mathews 1702

Herbarios: $\mathrm{K}$.

Nombre común: D esconocido.

Registro departamental: JU, SM.

Regiones Ecológicas: Sin datos; altitud desconocida.

SINANPE: Sin registro.

Herbarios peruanos: Ninguno.

Observaciones: Este taxón fue considerado por Brako \& Zarucchi (1993) como un endemismo; sin embargo, no ha sido posible evaluarlo, ni asignarle una categoría.

\section{Piperdemoratum Trel.}

Publicación: Field Mus. Nat. Hist., Bot. Ser. 13(2): 157- 158. 1936.

Colección tipo: C.O. Schunke 279

Herbarios: $F$.

Nombre común: D esconocido.

Registro departamental: JU.

Regiones Ecológicas: BMHM, BMHP; $1500 \mathrm{~m}$.

SINAN PE: Sin registro.

Herbarios peruanos: Ninguno.
Observaciones: Este taxón fue considerado por Brako \& Zarucchi (1993) como un endemismo; sin embargo, no ha sido posible evaluarlo, ni asignarle una categoría.

\section{Piperdennisii Trel.}

\section{VU, Bla}

Publicación: Field Mus. Nat. Hist., Bot. Ser. 13(2): 158. 1936.

Colección tipo: E.P. Killip et al. 29137

Hemarios: $F, N Y$.

Nombre común: D esconocido.

Registro departamental: AM.

Regiones Ecológicas: BHA; 250-800 m.

SINAN PE: ZRSC.

Hembarios peruanos: Ninguno.

Observaciones: Arbusto conocido de las cuencas del Cenepa, Imaza, Marañón. Especie descrita de una planta recolectada en 1929, cerca del Pongo de Manseriche. Otra poblaciones han sido registradas posteriormente.

\section{Piper desultonium Trel.}

Publicación: Field Mus. Nat. Hist., Bot. Ser. 13(2): 158-159. 1936.

Colección tipo: E.P. Killip \& A.C. Smith 24654

Herbarios: US.

Nombre común: D esconocido.

Registro departamental: JU.

Regiones Ecológicas: BMHM, BMHP; $1400-1700 \mathrm{~m}$.

SINAN PE: Sin registro.

Herbarios peruanos: Ninguno.

Observaciones: Este taxón fue considerado por Brako \& Zarucchi (1993) como un endemismo; sin embargo, no ha sido posible evaluarlo, ni asignarle una categoría.

\section{PiperdimetraleC. DC.}

Publicación: Bot. Jahrb. Syst. 40: 245246. 1908.

Colección tipo: A. Weberbauer 1281

Herbarios: B.

Nombre común: D esconocido.

Registro departamental: PU.

Regiones Ecológicas: BMHM; $1500 \mathrm{~m}$.

SINAN PE: Sin registro.

Herbarios peruanos: Ninguno.

Observaciones: Este taxón fue considerado por Brako \& Zarucchi (1993) como un endemismo; sin embargo, no ha sido posible evaluarlo, ni asignarle una categoría.

\section{Piperdiversipilum Trel.}

\section{DD}

Publicación: Field Mus. Nat. Hist., Bot. Ser. 13(2): 159-160. 1936

Colección tipo: J.F. Macbride 4666

Herbarios: $F$.

Nombre común: D esconocido.

Registro departamental: PA.

Regiones Ecológicas: BMHP; $600 \mathrm{~m}$.

SINANPE: Sin registro.

Herbarios peruanos: Ninguno. 
Observaciones: Subarbusto conocido solamente de una localidad, ubicada en Pasco. El valle del Pozuzo está muy modificado por la ganadería y actividades forestales. Se desconoce el estado actual de sus poblaciones.

\section{Piperdulce Trel.}

Publicación: Field Mus. Nat. Hist., Bot. Ser. 13(2): 160. 1936.

Colección tipo: E.P. Killip \& A.C. Smith 23705

Herbarios: NY, US.

Nombre común: D esconocido.

Registro departamental: HU.

Regiones Ecológicas: BMHP; $700 \mathrm{~m}$.

SINANPE: Sin registro.

Herbarios peruanos: Ninguno.

Observaciones: Este taxón fue considerado por Brako \& Zarucchi (1993) como un endemismo; sin embargo, no ha sido posible evaluarlo, ni asignarle una categoría.

\section{Piperdurvilleanum (Miq.) C. DC.}

Publicación: Field Mus. Nat. Hist., Bot. Ser. 13(2): 160. 1936.

Colección tipo: E.F. Poeppig 3113

Herbarios: W.

Nombre común: D esconocido.

Registro departamental: HU.

Regiones Ecológicas: BMHP; altitud desconocida.

SINANPE: Sin registro.

Herbarios peruanos: Ninguno.

Observaciones: Este taxón fue considerado por Brako \& Zarucchi (1993) como un endemismo; sin embargo, no ha sido posible evaluarlo, ni asignarle una categoría.

\section{Piperecallosum Trel.}

Publicación: Field Mus. Nat. Hist., Bot. Ser. 13(2): 160. 1936.

Colección tipo: A. Mathews 1147

Herbarios: W.

Nombre común: D esconocido.

Registro departamental: JU.

Regiones Ecológicas: BHA; altitud desconocida.

SINAN PE: Sin registro

Herbarios peruanos: Ninguno.

Observaciones: Este taxón fue considerado por Brako \& Zarucchi (1993) como un endemismo; sin embargo, no ha sido posible evaluarlo, ni asignarle una categoría.

311. Piperedurum Trel.

\section{EN, Blab(iii)}

Publicación: Field Mus. Nat. Hist., Bot. Ser. 13(2): 160-161. 1936

Colección tipo: E.P. Killip \& A.C. Smith 22618

Herbarios: NY, US.

Nombre común: D esconocido.

Registro departamental: AY, JU.

Regiones Ecológicas: BMHP; 750—1000 m.

SINANPE: Sin registro.

Herbarios peruanos: Ninguno.
Observaciones: Arbusto conocido de dos localidades, en las cuencas del Apuńmac y Tulumayo. Las poblaciones conocidas fueron registradas en 1929 y desde entonces, al parecer, no han vuelto a ubicarse.

312. Piperelongatum Vahl var. moccomocco Trel.

DD

Publicación: Field Mus. Nat. Hist., Bot. Ser. 13(2): 162. 1936

Colección tipo: F. Herrera 1551

Hembarios: US.

Nombre común: D esconocido.

Registro departamental: CU, HV.

Regiones Ecológicas: BMHM; $2300 \mathrm{~m}$.

SINAN PE: Sin registro.

Hemarios peruanos: Ninguno.

Observaciones: Subarbusto conocido del valle del Urubamba. Este taxón requiere una evaluación taxonómica.

\section{Piper elongatum Vahl var. salviifolium (Miq.) Trel.}

\section{DD}

Publicación: Field Mus. Nat. Hist., Bot. Ser. 13(2): 162. 1936.

Colección tipo: J. D ombey 934

Herbarios: P.

Nombre común: Desconocido.

Registro departamental: HU.

Regiones Ecológicas: Sin datos; altitud desconocida.

SINANPE: Sin registro.

Herbarios peruanos: Ninguno.

Observaciones: Hierba conocida de la colección tipo, una planta recolectada, en el siglo XVIII, probablemente, en la cuenca del Huallaga. Este taxón requiere de una evalución taxonómica.

\section{Piperendlicherianum (Miq.) Trel.}

\section{DD}

Publicación: Field Mus. Nat. Hist., Bot. Ser. 13(2): 162. 1936.

Colección tipo: A. Mathews 1698

Herbarios: $\mathrm{K}$.

Nombre común: D esconocido.

Registro departamental: $\mathrm{HU}$.

Regiones Ecológicas: BMHP; altitud desconocida.

SINAN PE: Sin registro.

Herbarios peruanos: Ninguno.

Observaciones: Arbusto conocido, al parecer, sólo de la colección tipo, una planta recolectada en el siglo XIX, en la cuenca del Huallaga. Se desconoce el estado actual de sus poblaciones.

\section{Piperenenyasense Trel.}

DD

Publicación: Field Mus. Nat. Hist., Bot. Ser. 13(2): 163. 1936.

Colección tipo: E.P. Killip \& A.C. Smith 25646

Herbarios: US.

Nombre común: D esconocido.

Registro departamental: JU.

Regiones Ecológicas: BMHM; 1600$1900 \mathrm{~m}$.

SINANPE: Sin registro.

Herbarios peruanos: Ninguno. 
Observaciones: Arbusto conocido aparentemente sólo de la colección tipo, una planta recolectada en 1929 en la cuenca del Pachitea. La localidad original fue citada para el departamento de Junín por Trelease (1936) y Brako \& Zarucchi (1993), pero en realidad se halla hoy ubicada en Pasco. Se desconoce el estado actual de sus poblaciones.

\section{Piperepunctatum Trel.}

\section{DD}

Publicación: Field Mus. Nat. Hist., Bot. Ser. 13(2): 163. 1936.

Colección tipo: G. Klug 1271

Herbarios: US.

Nombre común: D esconocido.

Registro departamental: LO.

Regiones Ecológicas: BHA; 100 m.

SINAN PE: Sin registro.

Herbarios peruanos: Ninguno.

Observaciones: Arbusto conocido aparentemente sólo de la localidad tipo, en los alrededores de Iquitos, donde fue recolectado en 1930. Quijano-Abril et al. (2006) la reconocieron como un endemismo para su análisis biogógrafico. Se desconoce el estado actual de sus poblaciones.

\section{Piper escaleranum C. DC.}

\section{DD}

Publicación: Verh. Bot. Vereins Prov. Brandenburg 47:115. 1905.

Colección tipo: E.H.G. Ule 6818

Herbarios: B.

Nombre común: D esconocido.

Registro departamental: SM.

Regiones Ecológicas: BMHP; $1200 \mathrm{~m}$.

SINANPE: ACRCE

Herbarios peruanos: Ninguno.

Observaciones: Arbusto conocido sólo de la localdidad original, en Cerro La Escalera, en la cuenca del Mayo y registrada en 1903. Esta localidad ha sido escasamente herborizada y hoy forma parte del Area de Conservación Regional Cerro LaEscalera. Se desconoce el estado actual de sus poblaciones.

\section{Piperevingeri Y unck.}

\section{EN, Blab(iii)}

Publicación: Amer. J. Bot. 43(3): 165, f. 4. 1956.

Colección tipo: E.L. Evinger 448

Hembarios: US.

Nombre común: D esconocido.

Registro departamental: CA.

Regiones Ecológicas: MA; 2200- 2400 m.

SINANPE: PNC

Hemarios penuanos: CPUN (2).

Observaciones: Arbusto conocido, al parecer, sólo del norte del país. La colección tipo fue recolectada en 1953, en la cuenca del Chamaya, en fragmentos de bosque perennifolio. O tros ejemplares han sido recolectados en años posteriores. Amenazas a sus poblaciones están asociadas a deforestación.

\section{Piper excavatum Ruiz \& Pav.}

Publicación: Fl. Peruv. 1:34, t. 54. 1798. Colección tipo: H. Ruiz \& J. Pavón 1/ 76

Herbarios: MA.

Nombre común: D esconocido.

Registro departamental: HU.

Regiones Ecológicas: BMHP; altitud desconocida.

SINAN PE: Sin registro.

Herbarios peruanos: Ninguno.

Observaciones: Este taxón fue considerado por Brako \& Zarucchi (1993) como un endemismo; sin embargo, no ha sido posible evaluarlo, ni asignarle una categoría.

\section{Piper excessum Trel.}

Publicación: Field Mus. Nat. Hist., Bot. Ser. 13(2): 164. 1936.

Colección tipo: E.F. Poeppig 154

Hemanios: W.

Nombre común: D esconocido.

Registro departamental: SM.

Regiones Ecológicas: BHA; altitud desconocida.

SINAN PE: Sin registro.

Herbarios peruanos: Ninguno.

Observaciones: Este taxón fue considerado por Brako \& Zarucchi (1993) como un endemismo; sin embargo, no ha sido posible evaluarlo, ni asignarle una categoría.

\section{Piper factum Trel.}

Publicación: Field Mus. Nat. Hist., Bot. Ser. 13(2): 165. 1936.

Colección tipo: E.P. Killip \& A.C. Smith 27588

Herbarios: US.

Nombre común: D esconocido.

Registro departamental: HU, LO, SM.

Regiones Ecológicas: BHA; 135 m.

SINAN PE: Sin registro.

Herbarios peruanos: Ninguno.

Observaciones: Este taxón fue considerado por Brako \& Zarucchi (1993) como un endemismo; sin embargo, no ha sido posible evaluarlo, ni asignarle una categoría.

\section{Piperfaecatum Trel.}

\section{DD}

Publicación: Field Mus. Nat. Hist., Bot. Ser. 13(2): 165. 1936.

Colección tipo: L. Williams 1593

Herbarios: $F$.

Nombre común: Cordoncillo.

Registro departamental: LO.

Regiones Ecológicas: BHA; $100 \mathrm{~m}$.

SINAN PE: Sin registro.

Herbarios peruanos: Ninguno.

Observaciones: Arbusto conocido solamente de la colección tipo, una planta recolectada en la cuenca del Amazonas, en 1929. Se desconoce el estado actual de sus poblaciones. 


\section{Piper fagifolium Trel.}

\section{DD}

Publicación: Field Mus. Nat. Hist., Bot. Ser. 13(2): 165. 1936.

Colección tipo: L. Williams 4782

Hemarios: $F$.

Nombre común: D esconocido.

Registro departamental: LO.

Regiones Ecológicas: BHA; 155- $210 \mathrm{~m}$.

SINANPE: Sin registro.

Herbarios peruanos: Ninguno.

Observaciones: Arbusto conocido solamente de una localidad en la cuenca del Bajo Huallaga, en pajonales. Se desconoce el estado actual de sus poblaciones.

\section{Piper ferreyrae Yunck.}

DD

Publicación: Amer. J. Bot. 43(3): 165, f. 5. 1956.

Colección tipo: R. Ferreyra 6685

Herbarios: US; MOL!.

Nombre común: D esconocido.

Registro departamental: $\mathrm{HU}$.

Regiones Ecológicas: MA; 3000-3100 m.

SINANPE: Sin registro.

Herbarios peruanos: MOL (isotipo).

Observaciones: Arbusto conocido de una localidad en la cuenca alta del Huallaga. Al parecer, no ha vuelto a ser recolectada desde 1950. Esta parte de la cuenca ha sido escasamente herborizada. Se desconoce el estado actual de sus poblaciones.

\section{Piperferruginispicum Trel.}

\section{DD}

Publicación: Field Mus. Nat. Hist., Bot. Ser. 13(2): 166. 1936

Colección tipo: G. Klug 1421

Herbarios: $F$.

Nombre común: D esconocido.

Registro departamental: LO

Regiones Ecológicas: BHA; $100 \mathrm{~m}$.

SINANPE: Sin registro.

Herbarios peruanos: Ninguno.

Observaciones: Arbusto conocido sólo de la localidad original, en una subcuenca del Amazonas, donde fue registrado en 1930. Brako \& Zarucchi (1993) incluyeron esta especie en la sinonimia de Piper alsum; pero Quijano-Abril et al. (2006) la aceptan, criterio que aquí se sigue. Se desconoce el estado actual de sus poblaciones.

\section{Piper fortalezanum Trel.}

\section{DD}

Publicación: Field Mus. Nat. Hist., Bot. Ser. 13(2): 166. 1936

Colección tipo: L. Williams 4351

Herbarios: $\mathrm{F}$.

Nombre común: Desconocido.

Registro departamental: LO, PA

Regiones Ecológicas: BHA; $155-210 \mathrm{~m}$.

SINANPE: Sin registro.

Herbarios peruanos: Ninguno.

Observaciones: Arbusto conocido de dos localidades, en las cuencas del Huallaga y Pichis. Al parecer, no ha vuelto a ser recolectada desde 1929. Se desconoce el estado actual de sus poblaciones.

\section{Piper fulgentifolium Y unck.}

DD

Publicación: Amer. J. Bot. 39(9): 635, f. 3. 1952.

Colección tipo: C. Sandeman 3419

Herbarios: $\mathrm{K}$.

Nombre común: D esconocido.

Registro departamental: HU.

Regiones Ecológicas: $\mathrm{BHA}$; $450 \mathrm{~m}$.

SINANPE: Sin registro.

Herbarios peruanos: Ninguno.

Observaciones: Arbusto conocido aparentemente sólo de la localidad tipo, una planta recolectada en la cuenca del Pachitea. Se desconoce el estado actual de sus poblaciones.

\section{Piperfulvescenticaule Trel.}

\section{DD}

Publicación: Field Mus. Nat. Hist., Bot. Ser. 13(2): 167. 1936

Colección tipo: E.P. Killip \& A.C. Smith 28574

Herbarios: US.

Nombre común: Desconocido.

Registro departamental: LO.

Regiones Ecológicas: BHA; 150- 350 m.

SINAN PE: Sin registro.

Herbarios peruanos: Ninguno.

Observaciones: Arbusto conocido solamente de la localidad tipo, en la cuenca del Huallaga y recolectado en 1929. Se desconoce el estado actual de sus poblaciones.

\section{Piper fuscispicum Trel.}

Publicación: Field Mus. Nat. Hist., Bot. Ser. 13(2): 167. 1936.

Colección tipo: Y. Mexia 6352a

Hemarios: UC.

Nombre común: Desconocido.

Registro departamental: LO.

Regiones Ecológicas: BHA; altitud desconocida.

SINAN PE: Sin registro.

Herbarios peruanos: Ninguno.

Observaciones: Este taxón fue considerado por Brako \& Zarucchi (1993) como un endemismo; sin embargo, no ha sido posible evaluarlo, ni asignarle una categoría.

\section{Piper gilvescens Trel.}

Publicación: Field Mus. Nat. Hist., Bot. Ser. 13(2): 167. 1936.

Colección tipo: E.P. Killip \& A.C. Smith 26784

Herbarios: US.

Nombre común: D esconocido.

Registro departamental: PA, SM.

Regiones Ecológicas: BHA; 340 m.

SINAN PE: Sin registro.

Herbarios peruanos: Ninguno.

Observaciones: Especie arbustiva cuya localidad original fue citada para el departamento de Junín por Trelease (1936) y Brako \& Zarucchi (1993), pero en realidad se halla hoy ubicada en Pasco. No ha sido posible evaluarla, ni asignarle una categoría. 


\section{Pipergilvibaccum Trel.}

Publicación: Field Mus. Nat. Hist., Bot. Ser. 13(2): 168. 1936.

Colección tipo: L. Williams 2754

Herbarios: $F$.

Nombre común: D esconocido.

Registro departamental: LO.

Regiones Ecológicas: BHA; altitud desconocida.

SINAN PE: Sin registro.

Herbarios peruanos: Ninguno.

Observaciones: Este taxón fue considerado por Brako \& Zarucchi (1993) como un endemismo; sin embargo, no ha sido posible evaluarlo, ni asignarle una categoría.

\section{Piperglabemimicaule Trel.}

\section{DD}

Publicación: Field Mus. Nat. Hist., Bot. Ser. 13(2): 168. 1936.

Colección tipo: E.P. Killip \& A.C. Smith 22624

Hemarios: ILL, US.

Nombre común: D esconocido.

Registro departamental: AY.

Regiones Ecológicas: BHA; 500 m.

SINAN PE: Sin registro.

Herbarios peruanos: Ninguno.

Observaciones: Arbusto conocido sólo de la localidad original, en la cuenca del A purímac, donde no ha vuelto a ser recolectado desde 1929. Se desconoce el estado actual de sus poblaciones.

\section{Piperglabribaccum Trel.}

Publicación: Field Mus. Nat. Hist., Bot. Ser. 13(2): 168. 1936

Colección tipo: J.F. Macbride 5335

Herbarios: $F$.

Nombre común: D esconocido.

Registro departamental: JU.

Regiones Ecológicas: BMHP, BHA; 600 m.

SINANPE: Sin registro.

Herbarios peruanos: Ninguno.

Observaciones: Estetaxón fue considerado por Brako \& Zarucchi (1993) como un endemismo; sin embargo, no ha sido posible evaluarlo, ni asignarle una categoría.

\section{Piper glabrius Trel.}

Publicación: Field Mus. Nat. Hist., Bot. Ser. 13(2): 168. 1936.

Colección tipo: A. Mathews 1705

Herbarios: $\mathrm{K}$.

Nombre común: D esconocido.

Registro departamental: Sin datos.

Regiones Ecológicas: Sin datos; altitud desconocida.

SINAN PE: Sin registro.

Herbarios peruanos: Ninguno.

Observaciones: Este taxón fue considerado por Brako \& Zarucchi (1993) como un endemismo; sin embargo, no ha sido posible evaluarlo, ni asignarle una categoría.
335. Pipergracile Ruiz \& Pav.

Publicación: Fl. Peruv. 1: 35, t. 59. 1798. Colección tipo: H. Ruiz \& J. Pavón s.n.

Herbarios: MA.

Nombre común: D esconocido.

Registro departamental: AM, HU.

Regiones Ecológicas: BMHP; altitud desconocida.

SINAN PE: Sin registro.

Herbarios peruanos: Ninguno.

Observaciones: Este taxón fue considerado por Brako \& Zarucchi (1993) como un endemismo; sin embargo, no ha sido posible evaluarlo, ni asignarle una categoría.

\section{Pipergranuligerum Trel.}

Publicación: Field Mus. Nat. Hist., Bot. Ser. 13(2): 169-170. 1936.

Colección tipo: L. Williams 3459

Hembarios: $F$

Nombre común: D esconocido.

Registro departamental: LO.

Regiones Ecológicas: BHA; altitud desconocida.

SINAN PE: Sin registro.

Herbarios peruanos: Ninguno.

Observaciones: Este taxón fue considerado por Brako \& Zarucchi (1993) como un endemismo; sin embargo, no ha sido posible evaluarlo, ni asignarle una categoría.

\section{Pipergranulosum Ruiz \& Pav.}

Publicación: Fl. Peruv. 1: 38, t. 64. 1798. Colección tipo: H. Ruiz \& J. Pavón 1/ 97

Herbarios: MA.

Nombre común: Cordoncillo.

Registro departamental: HU, JU, SM.

Regiones Ecológicas: BMHP, BHA; altitud desconocida.

SINANPE: Sin registro.

Hembarios peruanos: Ninguno.

Observaciones: Este taxón fue considerado por Brako \& Zarucchi (1993) como un endemismo; sin embargo, no ha sido posible evaluarlo, ni asignarle una categoría.

338. Piper gratum Trel. var. gratum

\author{
Publicación: \\ Colección tipo: E.P. Killip \& A.C. Smith \\ 29785 \\ Herbarios: US. \\ Nombre común: D esconocido. \\ Registro departamental: LO, MD. \\ Regiones Ecológicas: BHA; $110 \mathrm{~m}$. \\ SINAN PE: Sin registro. \\ Herbarios peruanos: Ninguno.
}

Observaciones: Este taxón fue considerado por Brako \& Zarucchi (1993) como un endemismo; sin embargo, no ha sido posible evaluarlo, ni asignarle una categoría. 
Publicación: Field Mus. Nat. Hist., Bot. Ser. 13(2): 170. 1936.

Colección tipo: G. Klug 206

Herbarios: US.

Nombre común: D esconocido.

Registro departamental: LO.

Regiones Ecológicas: BHA; altitud desconocida.

SINANPE: Sin registro.

Herbarios peruanos: Ninguno.

Observaciones: Este taxón fue considerado por Brako \& Zarucchi (1993) como un endemismo; sin embargo, no ha sido posible evaluarlo, ni asignarle una categoría.

\section{Pipergniseocaule Trel.}

Publicación: Field Mus. Nat. Hist., Bot. Ser. 13(2): 170. 1936.

Colección tipo: J.F. Macbride 5723

Herbarios: $F$.

Nombre común: D esconocido.

Registro departamental: JU.

Regiones Ecológicas: BMHP; $1200 \mathrm{~m}$.

SINAN PE: Sin registro.

Herbarios peruanos: Ninguno.

Observaciones: Este taxón fue considerado por Brako \& Zarucchi (1993) como un endemismo; sin embargo, no ha sido posible evaluarlo, ni asignarle una categoría.

\section{Pipergriseum C. DC.}

Publicación: Prodr. 16(1): 281- 282. 1869.

Colección tipo: E.F. Poeppig 1737

Herbarios: W.

Nombre común: D esconocido.

Registro departamental: HU.

Regiones Ecológicas: Sin datos; altitud desconocida.

SINAN PE: Sin registro.

Herbarios peruanos: Ninguno.

Observaciones: Este taxón fue considerado por Brako \& Zarucchi (1993) como un endemismo; sin embargo, no ha sido posible evaluarlo, ni asignarle una categoría.

342. Piper heptandrum (Miq.) C. DC. var. heptandrum

Publicación:

Colección tipo: H. Ruiz s.n.

Herbarios: MA.

Nombre común: Desconocido.

Registro departamental: HU, SM.

Regiones Ecológicas: Sin datos; altitud desconocida.

SINANPE: Sin registro.

Herbarios peruanos: Ninguno.

Observaciones: Arbusto descrito de una planta recolectada en el siglo XIX, en una localidad desconocida. No ha sido posible evaluar este taxón, ni asignarle una categoría.
Publicación: Field Mus. Nat. Hist., Bot. Ser. 13(2): 171. 1936.

Colección tipo: J. Pavón s.n.

Herbarios: Sin datos.

Nombre común: D esconocido.

Registro departamental: LO.

Regiones Ecológicas: BHA; altitud desconocida.

SINANPE: Sin registro.

Herbarios peruanos: Ninguno.

Observaciones: Arbusto descrito de una planta recolectada en el siglo XVIII, de procedencia exacta desconocida. Una coleccción adicional proviene de la cuenca del Ucayali, la que se atribuye a Loreto (Brako \& Zarucchi, 1993). No ha sido posible evaluar este taxón, ni asignarle una categoría.

\section{Piper herrerae Trel.}

Publicación: Field Mus. Nat. Hist., Bot. Ser. 13(2): 171. 1936.

Colección tipo: F. Herrera s.n.

Herbarios: NY.

Nombre común: Desconocido.

Registro departamental: CU.

Regiones Ecológicas: BPM; $3700 \mathrm{~m}$.

SINANPE: Sin registro.

Herbarios peruanos: Ninguno.

Observaciones: Este taxón fue considerado por Brako \& Zarucchi (1993) como un endemismo; sin embargo, no ha sido posible evaluarlo, ni asignarle una categoría.

\section{Piper hookerianum (Miq.) C. DC.}

Publicación: Prodr. 16(1): 292. 1869.

Colección tipo: A. Mathews 3222

Herbarios: $\mathrm{K}$.

Nombre común: D esconocido.

Registro departamental: AM.

Regiones Ecológicas: Sin datos; altitud desconocida.

SINAN PE: Sin registro.

Herbarios peruanos: Ninguno.

Observaciones: Este taxón fue considerado por Brako \& Zarucchi (1993) como un endemismo; sin embargo, no ha sido posible evaluarlo, ni asignarle una categoría.

\section{Piper huacachianum Trel.}

Publicación: Field Mus. Nat. Hist., Bot. Ser. 13(2): 172-173. 1936.

Colección tipo: J.F. Macbride 4167

Herbarios: $F$.

Nombre común: D esconocido.

Registro departamental: HU.

Regiones Ecológicas: MA; $1950 \mathrm{~m}$.

SINAN PE: Sin registro.

Herbarios peruanos: Ninguno.

Observaciones: Este taxón fue considerado por Brako \& Zarucchi (1993) como un endemismo; sin embargo, no ha sido posible evaluarlo, ni asignarle una categoría. 


\section{Piper huacapistanum Trel.}

Publicación: Field Mus. Nat. Hist., Bot. Ser. 13(2): 173. 1936.

Colección tipo: Stevens 77

Herbarios: $F$.

Nombre común: D esconocido.

Registro departamental: JU.

Regiones Ecológicas: BMHM; altitud desconocida.

SINANPE: Sin registro.

Herbarios peruanos: Ninguno.

Observaciones: Este taxón fue considerado por Brako \& Zarucchi (1993) como un endemismo; sin embargo, no ha sido posible evaluarlo, ni asignarle una categoría.

\section{Piper huallaganum Trel.}

Publicación: Field Mus. Nat. Hist., Bot. Ser. 13(2): 173. 1936

Colección tipo: J.F. Macbride 4235

Hembarios: F, US

Nombre común: D esconocido.

Registro departamental: HU.

Regiones Ecológicas: BMHP; $1200 \mathrm{~m}$.

SINAN PE: Sin registro.

Herbarios peruanos: Ninguno.

Observaciones: Este taxón fue considerado por Brako \& Zarucchi (1993) como un endemismo; sin embargo, no ha sido posible evaluarlo, ni asignarle una categoría.

\section{Piperhuantanum Trel.}

\section{DD}

Publicación: Field Mus. Nat. Hist., Bot. Ser. 13(2): 173-174. 1936.

Colección tipo: E.P. Killip \& A.C. Smith 23074

Herbarios: ILL, NY, US.

Nombre común: D esconocido.

Registro departamental: AY, JU.

Regiones Ecológicas: $\mathrm{BMHP}, \mathrm{BHA}$; 500- $700 \mathrm{~m}$.

SINANPE: Sin registro.

Hemarios peruanos: Ninguno.

Observaciones: Árbol o arbusto conocido, al parecer, de dos localidades en la vertiente oriental andina. Fue citado por QuijanoAbril et al. (2006) como endemismo, con un patrón biogeográfico único al Neotrópico. En un sentido amplio, uniendo las variedades propuestas por Trelease, este taxón es conocido en las cuencas del Apurímacy Perené. Brako \& Zarucchi (1993) indicaron su presencia además en los departamentos de Huánuco, San Martín y Ucayali, pero no pudo confirmarse tales registros.

350. Piperillautum Trel.

\section{DD}

Publicación: Field Mus. Nat. Hist., Bot. Ser. 13(2): 174. 1936

Colección tipo: C. Gay 1003

Herbarios: P.

Nombre común: D esconocido.

Registro departamental: Sin datos.

Regiones Ecológicas: Sin datos; altitud desconocida.

SINAN PE: Sin registro.

Herbarios peruanos: Ninguno.
Observaciones: Arbusto conocido aparentemente sólo de la colección tipo, una planta recolectada en el siglo XIX, de procedencia desconocida.

\section{Piperimmite Trel.}

Publicación: Field Mus. Nat. Hist., Bot. Ser. 13(2): 174-175. 1936

Colección tipo: E.P. Killip \& A.C. Smith 23524

Herbarios: US.

Nombre común: D esconocido.

Registro departamental: JU.

Regiones Ecológicas: BMHP; $700 \mathrm{~m}$.

SINANPE: Sin registro.

Herbarios peruanos: Ninguno.

Observaciones: Este taxón fue considerado por Brako \& Zarucchi (1993) como un endemismo; sin embargo, no ha sido posible evaluarlo, ni asignarle una categoría.

\section{Piper incomptum Trel.}

Publicación: Field Mus. Nat. Hist., Bot. Ser. 13(2): 175. 1936.

Colección tipo: C.O. Schunke 1793

Herbarios: $F$.

Nombre común: D esconocido.

Registro departamental: JU.

Regiones Ecológicas: BMHP; $1200 \mathrm{~m}$.

SINAN PE: Sin registro.

Henbarios peruanos: Ninguno.

Observaciones: Este taxón fue considerado por Brako \& Zarucchi (1993) como un endemismo; sin embargo, no ha sido posible evaluarlo, ni asignarle una categoría.

\section{Piper indeconum Kunth}

Publicación: Linnaea 13: 722. 1839.

Colección tipo: E.F. Poeppig 2335b

Herbarios: Sin datos.

Nombre común: D esconocido.

Registro departamental: HU, JU, LO, UC. Regiones Ecológicas: $\mathrm{BMHP}, \mathrm{BHA}$; 200-300 m.

SINAN PE: Sin registro.

Herbarios peruanos: Ninguno.

Observaciones: Este taxón fue considerado por Brako \& Zarucchi (1993) como un endemismo; sin embargo, no ha sido posible evaluarlo, ni asignarle una categoría.

354. Piper indianonum Trel.

\section{DD}

Publicación: Field Mus. Nat. Hist., Bot. Ser. 13(2): 176. 1936.

Colección tipo: Y. Mexia 6396

Herbarios: NY, UC, US.

Nombre común: D esconocido.

Registro departamental: LO.

Regiones Ecológicas: BHA; 110 m.

SINANPE: Sin registro.

Herbarios peruanos: Ninguno. 
Observaciones: Hierba conocida de los alrededores de Iquitos. Q uijano-Abril et al. (2006) la reconocieron como un endemismo, para un análisis biogeográfico del género. Se desconoce el estado actual de sus poblaciones.

\section{Piper indiciflexum Trel.}

Publicación: Field Mus. Nat. Hist., Bot. Ser. 13(2): 176. 1936.

Colección tipo: E.P. Killip \& A.C. Smith 24507

Hemanios: NY, US.

Nombre común: D esconocido.

Registro departamental: JU.

Regiones Ecológicas: BMHM; 1800$2400 \mathrm{~m}$.

SINANPE: Sin registro.

Hembarios peruanos: Ninguno.

Observaciones: Este taxón fue considerado por Brako \& Zarucchi (1993) como un endemismo; sin embargo, no ha sido posible evaluarlo, ni asignarle una categoría.

356. Piper interitum Trel.

\section{DD}

Publicación: Field Mus. Nat. Hist., Bot. Ser. 13(2): 176-177. 1936.

Colección tipo: E.P. Killip \& A.C. Smith 26150

Herbarios: US.

Nombre común: D esconocido.

Registro departamental: JU.

Regiones Ecológicas: BMHP; 625-900 m.

SINANPE: Sin registro.

Herbarios peruanos: Ninguno.

Observaciones: Árbol conocido de la cuenca del Tulumayo. QuijanoAbril et al. (2006) la reconocieron como un endemismo, para un análisis biogeográfico del género. Se desconoceel estado actual de sus poblaciones

\section{Piperintonsum Trel.}

Publicación: Field Mus. Nat. Hist., Bot. Ser. 13(2): 177. 1936.

Colección tipo: J.F. Macbride 5445

Herbarios: $F$.

Nombre común: D esconocido.

Registro departamental: JU, SM.

Regiones Ecológicas: $\mathrm{BMHP}, \mathrm{BHA}$; 360-900 m.

SINANPE: Sin registro.

Herbarios peruanos: Ninguno.

Observaciones: Este taxón fue considerado por Brako \& Zarucchi (1993) como un endemismo; sin embargo, no ha sido posible evaluarlo, ni asignarle una categoría.

\section{Piperiquitosense Trel.}

Publicación: Field Mus. Nat. Hist., Bot. Ser. 13(2): 177. 1936.

Colección tipo: L. Williams 1432

Herbarios: $F$.

Nombre común: D esconocido.

Registro departamental: LO, PA, UC.

Regiones Ecológicas: $\mathrm{BHA}$; altitud desconocida.

SINANPE: Sin registro.

Herbarios penuanos: USM (1)?
Observaciones: Este taxón fue considerado por Brako \& Zarucchi (1993) como un endemismo; sin embargo, no ha sido posible evaluarlo, ni asignarle una categoría.

\section{Piperitayanum Trel. var. itayanum}

\author{
Publicación: \\ Colección tipo: L. Williams 3320 \\ Herbarios: F. \\ Nombre común: D esconocido. \\ Registro departamental: LO, PA. \\ Regiones Ecológicas: $\mathrm{BHA}$; altitud \\ desconocida. \\ SINAN PE: Sin registro. \\ Hemarios peruanos: Ninguno.
}

Observaciones: Este taxón fue considerado por Brako \& Zarucchi (1993) como un endemismo; sin embargo, no ha sido posible evaluarlo, ni asignarle una categoría.

\section{Piperitayanum Trel. var. antoniense Trel.}

Publicación: Field Mus. Nat. Hist., Bot. Ser. 13(2): 178. 1936.

Colección tipo: E.P. Killip \& A.C. Smith 29450

Henbarios: US.

Nombre común: D esconocido.

Registro departamental: LO.

Regiones Ecológicas: BHA; $110 \mathrm{~m}$.

SINAN PE: Sin registro.

Herbarios peruanos: Ninguno.

Observaciones: Este taxón fue considerado por Brako \& Zarucchi (1993) como un endemismo; sin embargo, no ha sido posible evaluarlo, ni asignarle una categoría.

\section{Piperitayanum Trel. var. pichisense Trel.}

Publicación: Field Mus. Nat. Hist., Bot. Ser. 13(2): 178. 1936

Colección tipo: E.P. Killip \& A.C. Smith 26738

Hemanios: US.

Nombre común: Desconocido.

Registro departamental: PA.

Regiones Ecológicas: BHA; $340 \mathrm{~m}$.

SINAN PE: Sin registro.

Herbarios peruanos: Ninguno.

Observaciones: La localidad original fue citada para el departamento de Junín por Trelease (1936) y Brako \& Zarucchi (1993), pero en realidad se halla hoy ubicada en Pasco. No ha sido posible evaluar este taxón, ni asignarle una categoría.

362. Piperitayanum Trel. var. sanjuanum Trel

Publicación: Field Mus. Nat. Hist., Bot. Ser. 13(2): 178. 1936.

Colección tipo: L. Williams 3720

Herbarios: $F$.

Nombre común: Desconocido.

Registro departamental: LO.

Regiones Ecológicas: BHA; $120 \mathrm{~m}$.

SINANPE: Sin registro.

Herbarios peruanos: Ninguno. 
Observaciones: Este taxón fue considerado por Brako \& Zarucchi (1993) como un endemismo; sin embargo, no ha sido posible evaluarlo, ni asignarle una categoría.

363. Piper kanehiranum Trel.

Publicación: Field Mus. Nat. Hist., Bot. Ser. 13(2): 179. 1936

Colección tipo: R. Kanehira 14

Herbarios: $F$.

Nombre común: D esconocido.

Registro departamental: $\mathrm{HU}$.

Regiones Ecológicas: BMHP; altitud desconocida.

SINAN PE: Sin registro.

Herbarios peruanos: Ninguno.

Observaciones: Este taxón fue considerado por Brako \& Zarucchi (1993) como un endemismo; sin embargo, no ha sido posible evaluarlo, ni asignarle una categoría.

\section{Piperkimpitinikianum Trel.}

Publicación: Field Mus. Nat. Hist., Bot. Ser. 13(2): 179. 1936

Colección tipo: E.P. Killip \& A.C. Smith 22847

Hemarios: US.

Nombre común: D esconocido.

Registro departamental: AY.

Regiones Ecológicas: BMHP; 625-900 m.

SINAN PE: Sin registro.

Hemarios peruanos: Ninguno.

Observaciones: Este taxón fue considerado por Brako \& Zarucchi (1993) como un endemismo; sin embargo, no ha sido posible evaluarlo, ni asignarle una categoría.

365. Piper klugianum Trel.

\section{DD}

Publicación: Field Mus. Nat. Hist., Bot. Ser. 13(2): 179. 1936

Colección tipo: G. Klug 1493

Herbarios: F, US.

Nombre común: D esconocido.

Registro departamental: LO.

Regiones Ecológicas: BHA; 100 m.

SINANPE: Sin registro.

Herbarios peruanos: Ninguno.

Observaciones: Arbusto conocido de los alrededores de Iquitos. Quijano-Abril et al. (2006) la reconocieron como un endemismo, para un análisis biogeogáfico del género. Se desconoce el estado actual de sus poblaciones.

366. Piperklugii Yunck.

Publicación: Svensk Bot. Tidskr. 51(3) 529-530. 1957.

Colección tipo: G. Klug 3512

Herbarios: US.

Nombre común: Desconocido.

Registro departamental: SM.

Regiones Ecológicas: BMHP; $1200-$

$1600 \mathrm{~m}$.

SINAN PE: Sin registro.

Herbarios peruanos: Ninguno.
Observaciones: Este taxón fue considerado por Brako \& Zarucchi (1993) como un endemismo; sin embargo, no ha sido posible evaluarlo, ni asignarle una categoría.

\section{Piperlamasense Trel.}

Publicación: Field Mus. Nat. Hist., Bot. Ser. 13(2): 180. 1936.

Colección tipo: L. Williams 6401

Herbarios: $F$

Nombre común: D esconocido.

Registro departamental: SM.

Regiones Ecológicas: BMHP; $840 \mathrm{~m}$.

SINANPE: Sin registro.

Herbarios peruanos: Ninguno.

Observaciones: Este taxón fue considerado por Brako \& Zarucchi (1993) como un endemismo; sin embargo, no ha sido posible evaluarlo, ni asignarle una categoría.

\section{Piperlanosicaule Trel.}

Publicación: Field Mus. Nat. Hist., Bot. Ser. 13(2): 181. 1936.

Colección tipo: E.P. Killip \& A.C. Smith 24723

Herbanios: NY, US.

Nombre común: Desconocido.

Registro departamental: JU, PA.

Regiones Ecológicas: BMHM, BMHP; 1400- $1700 \mathrm{~m}$.

SINANPE: Sin registro.

Herbarios peruanos: Ninguno.

Observaciones: Este taxón fue considerado por Brako \& Zarucchi (1993) como un endemismo; sin embargo, no ha sido posible evaluarlo, ni asignarle una categoría.

\section{Piper lateovatum Trel.}

Publicación: Field Mus. Nat. Hist., Bot. Ser. 13(2): 181. 1936.

Colección tipo: L. Williams 7083

Herbarios: F.

Nombre común: D esconocido.

Registro departamental: SM.

Regiones Ecológicas: BMHP; 1350$1500 \mathrm{~m}$.

SINAN PE: Sin registro.

Henbarios peruanos: Ninguno.

Observaciones: Este taxón fue considerado por Brako \& Zarucchi (1993) como un endemismo; sin embargo, no ha sido posible evaluarlo, ni asignarle una categoría.

370. Piperlauninum Roem. \& Schult.

Publicación: Syst. Veg. 1: 291. 1817 Colección tipo: A. Humboldt \& A. Bonpland 654

Henbarios: $B$

Nombre común: D esconocido.

Registro departamental: LL.

Regiones Ecológicas: Sin datos; altitud desconocida.

SINANPE: Sin registro.

Herbarios peruanos: Ninguno. 
Observaciones: Este taxón fue considerado por Brako \& Zarucchi (1993) como un endemismo; sin embargo, no ha sido posible evaluarlo, ni asignarle una categoría.

371. Piper leticianum C. DC. var. tessmannii Trel.

Publicación: Field Mus. Nat. Hist., Bot. Ser. 13(2): 182. 1936.

Colección tipo: G. Tessmann 3946

Herbarios: B.

Nombre común: D esconocido.

Registro departamental: LO.

Regiones Ecológicas: BHA; altitud desconocida.

SINAN PE: Sin registro.

Herbarios peruanos: Ninguno.

Observaciones: Este taxón fue considerado por Brako \& Zarucchi (1993) como un endemismo; sin embargo, no ha sido posible evaluarlo, ni asignarle una categoría.

372. Piper leucophaeocaule Trel.

Publicación: Field Mus. Nat. Hist., Bot. Ser. 13(2): 183. 1936.

Colección tipo: L. Williams 301

Herbarios: $F$.

Nombre común: D esconocido.

Registro departamental: JU, LO.

Regiones Ecológicas: BMHP; $750 \mathrm{~m}$.

SINAN PE: Sin registro.

Herbarios peruanos: Ninguno.

Observaciones: Este taxón fue considerado por Brako \& Zarucchi (1993) como un endemismo; sin embargo, no ha sido posible evaluarlo, ni asignarle una categoría.

\section{Piper leucophaeum Trel.}

Publicación: Field Mus. Nat. Hist., Bot. Ser. 13(2): 183. 1936

Colección tipo: L. Williams 6086

Herbarios: $F$.

Nombre común: D esconocido.

Registro departamental: SM.

Regiones Ecológicas: BMHP; 750 m.

SINAN PE: Sin registro.

Hembarios peruanos: Ninguno.

Observaciones: Este taxón fue considerado por Brako \& Zarucchi (1993) como un endemismo; sin embargo, no ha sido posible evaluarlo, ni asignarle una categoría.

374. Piper lineatum Ruiz \& Pav. var. cordulatum Trel.

Publicación: Field Mus. Nat. Hist., Bot. Ser. 13(2): 184. 1936.

Colección tipo: A. Mathews 1691

Herbarios: K.

Nombre común: D esconocido.

Registro departamental: JU.

Regiones Ecológicas: Sin datos; altitud desconocida.

SINAN PE: Sin registro.

Herbarios peruanos: Ninguno.
Observaciones: Este taxón fue considerado por Brako \& Zarucchi (1993) como un endemismo; sin embargo, no ha sido posible evaluarlo, ni asignarle una categoría.

\section{Piper llatanum Trel.}

Publicación: Field Mus. Nat. Hist., Bot. Ser. 13(2): 185. 1936.

Colección tipo: J.F. Macbride \& W.

Featherstone 2302

Herbarios: F, US.

Nombre común: D esconocido.

Registro departamental: $\mathrm{HU}$.

Regiones Ecológicas: MA; $2100 \mathrm{~m}$.

SINANPE: Sin registro.

Herbarios peruanos: Ninguno.

Observaciones: Este taxón fue considerado por Brako \& Zarucchi (1993) como un endemismo; sin embargo, no ha sido posible evaluarlo, ni asignarle una categoría.

376. Piperlongeacuminatum Trel.

Publicación: Field Mus. Nat. Hist., Bot. Ser. 13(2): 185. 1936.

Colección tipo: C.O. Schunke A90

Henbarios: US.

Nombre común: D esconocido.

Registro departamental: JU.

Regiones Ecológicas: BMHM, BMHP; $1300-1700 \mathrm{~m}$

SINANPE: Sin registro.

Herbarios peruanos: Ninguno.

Observaciones: Este taxón fue considerado por Brako \& Zarucchi (1993) como un endemismo; sin embargo, no ha sido posible evaluarlo, ni asignarle una categoría.

\section{Piper longestaminatum Trel.}

Publicación: Field Mus. Nat. Hist., Bot. Ser. 13(2): 185-186. 1936.

Colección tipo: E.P. Killip \& A.C. Smith 26011

Herbarios: US.

Nombre común: D esconocido.

Registro departamental: PA.

Regiones Ecológicas: BMHP; $1100 \mathrm{~m}$.

SINANPE: Sin registro.

Herbarios peruanos: Ninguno.

Observaciones: Árbol conocido de una localidad muy cerca al límite departamental entre Junín y Pasco. No ha sido posible evaluarlo, ni asignarle una categoría.

\section{Piperlonetoanum Trel.}

Publicación: Field Mus. Nat. Hist., Bot. Ser. 13(2): 186-187. 1936.

Colección tipo: E.P. Killip \& A.C. Smith 27555

Henbarios: US.

Nombre común: Desconocido.

Registro departamental: LO.

Regiones Ecológicas: BHA; $135 \mathrm{~m}$.

SINANPE: Sin registro.

Hemarios peruanos: Ninguno. 
Observaciones: Este taxón fue considerado por Brako \& Zarucchi (1993) como un endemismo; sin embargo, no ha sido posible evaluarlo, ni asignarle una categoría.

379. Pipermacbrideanum Trel.

Publicación: Field Mus. Nat. Hist., Bot. Ser. 13(2): 187. 1936.

Colección tipo: J.F. Macbride 5516

Herbarios: F, US

Nombre común: D esconocido.

Registro departamental: JU.

Regiones Ecológicas: BMHP; $610 \mathrm{~m}$.

SINAN PE: Sin registro.

Herbarios peruanos: Ninguno.

Observaciones: Este taxón fue considerado por Brako \& Zarucchi (1993) como un endemismo; sin embargo, no ha sido posible evaluarlo, ni asignarle una categoría.

\section{Pipermachupicchuense Trel.}

Publicación: Field Mus. Nat. Hist., Bot. Ser. 13(2): 187. 1936.

Colección tipo: F. Herrera 2006

Herbarios: $F$.

Nombre común: D esconocido.

Registro departamental: CU.

Regiones Ecológicas: BMHM; $2300 \mathrm{~m}$.

SINANPE: Sin registro.

Herbarios peruanos: Ninguno.

Observaciones: Arbusto recolectado en la década de 1920 de las cercanías del Santuario Histórico Machu Picchu en la cuenca del Urubamba. No ha sido posible evaluar esta especie, ni asignarle una categoría.

\section{Piper malifolium Trel. var. malifolium}

Publicación:

Colección tipo: J.F. Macbride 4620

Hembarios: F.

Nombre común: D esconocido.

Registro departamental: PA.

Regiones Ecológicas: BMHP; $600 \mathrm{~m}$.

SINANPE: Sin registro.

Herbarios peruanos: Ninguno.

Observaciones: Este taxón fue considerado por Brako \& Zarucchi (1993) como un endemismo; sin embargo, no ha sido posible evaluarlo, ni asignarle una categoría. La localidad original fue citada para el departamento de Huánuco por Trelease (1936) y Brako \& Zarucchi (1993), pero en realidad se halla hoy ubicada en Pasco.

382. Piper malifolium Trel. var. mercedanum Trel.

Publicación: Field Mus. Nat. Hist., Bot. Ser. 13(2): 188. 1936

Colección tipo: J.F. Macbride 5288

Hemarios: $F$.

Nombre común: D esconocido.

Registro departamental: JU.

Regiones Ecológicas: BMHP; $600 \mathrm{~m}$.

SINAN PE: Sin registro.

Herbarios peruanos: Ninguno.
Observaciones: Este taxón fue considerado por Brako \& Zarucchi (1993) como un endemismo; sin embargo, no ha sido posible evaluarlo, ni asignarle una categoría.

\section{Pipermansericheanum Trel.}

Publicación: Field Mus. Nat. Hist., Bot. Ser. 13(2): 188. 1936.

Colección tipo: G. Tessmann 3883

Herbarios: Sin datos.

Nombre común: D esconocido.

Registro departamental: AM, LO.

Regiones Ecológicas: $\mathrm{BHA}$; altitud desconocida.

SINAN PE: Sin registro.

Herbarios peruanos: Ninguno.

Observaciones: Arbusto descrito de una planta recolectada en la cuenca del Marañón. La localidad original se halla cerca al límite departamental de Loreto y Amazonas. No ha sido posible evaluar esta especie, ni asignarle una categoría.

\section{Piper margaritatum Trel.}

Publicación: Field Mus. Nat. Hist., Bot. Ser. 13(2): 189. 1936.

Colección tipo: L. Williams 7742

Hemarios: $F$

Nombre común: Cordoncillo.

Registro departamental: SM.

Regiones Ecológicas: BMHP; $1350-$ $1500 \mathrm{~m}$.

SINANPE: Sin registro.

Herbarios peruanos: Ninguno.

Observaciones: Este taxón fue considerado por Brako \& Zarucchi (1993) como un endemismo; sin embargo, no ha sido posible evaluarlo, ni asignarle una categoría.

\section{Pipermartinense Trel.}

Publicación: Field Mus. Nat. Hist., Bot. Ser. 13(2): 190. 1936.

Colección tipo: L. Williams 6407

Herbarios: $F$.

Nombre común: D esconocido.

Registro departamental: SM

Regiones Ecológicas: BMHP; $840 \mathrm{~m}$.

SINANPE: Sin registro.

Henbarios peruanos: Ninguno.

Observaciones: Este taxón fue considerado por Brako \& Zarucchi (1993) como un endemismo; sin embargo, no ha sido posible evaluarlo, ni asignarle una categoría.

386. Pipermathewsii C. DC.
Publicación: Prodr. 16(1): 261-262. 1869. Colección tipo: A. Mathews 3224 Henbarios: $\mathrm{K}$.

Nombre común: D esconocido.

Registro departamental: AM.

Regiones Ecológicas: Sin datos; altitud desconocida.

SINAN PE: Sin registro.

Herbarios peruanos: Ninguno. 
Observaciones: Este taxón fue considerado por Brako \& Zarucchi (1993) como un endemismo; sin embargo, no ha sido posible evaluarlo, ni asignarle una categoría.

\section{Pipermazamariense Yunck.}

Publicación: Ann. Missouri Bot. Gard. 53(3): 381. 1966

Colección tipo: F. Woytkowski 5935

Herbarios: MO.

Nombre común: D esconocido.

Registro departamental: JU.

Regiones Ecológicas: BMHP; $800 \mathrm{~m}$.

SINANPE: Sin registro.

Herbarios peruanos: Ninguno.

Observaciones: Este taxón fue considerado por Brako \& Zarucchi (1993) como un endemismo; sin embargo, no ha sido posible evaluarlo, ni asignarle una categoría

\section{Pipermediocre C. DC.}

Publicación: Verh. Bot. Vereins Prov. Brandenburg 47: 104. 1905.

Colección tipo: E.H.G. Ule 6245

Herbarios: $B$

Nombre común: D esconocido.

Registro departamental: LO, SM.

Regiones Ecológicas: $\mathrm{BHA}$; altitud desconocida.

SINANPE: Sin registro.

Herbarios peruanos: Ninguno.

Observaciones: Este taxón fue considerado por Brako \& Zarucchi (1993) como un endemismo; sin embargo, no ha sido posible evaluarlo, ni asignarle una categoría.

\section{Pipermellibracteaum Trel.}

Publicación: Field Mus. Nat. Hist., Bot. Ser. 13(2): 191. 1936.

Colección tipo: J.F. Macbride 4234

Herbarios: $F$.

Nombre común: D esconocido.

Registro departamental: HU.

Regiones Ecológicas: BMHP; $1200 \mathrm{~m}$.

SINAN PE: Sin registro.

Herbarios peruanos: Ninguno.

Observaciones: Este taxón fue considerado por Brako \& Zarucchi (1993) como un endemismo; sin embargo, no ha sido posible evaluarlo, ni asignarle una categoría.

\section{Pipermencedense Trel.}

Publicación: Field Mus. Nat. Hist., Bot. Ser. 13(2): 191-192. 1936.

Colección tipo: E.P. Killip \& A.C. Smith 23731

Hemarios: US.

Nombre común: D esconocido.

Registro departamental: JU.

Regiones Ecológicas: BMHP; $700 \mathrm{~m}$.

SINANPE: Sin registro.

Herbarios peruanos: Ninguno.
Observaciones: Este taxón fue considerado por Brako \& Zarucchi (1993) como un endemismo; sin embargo, no ha sido posible evaluarlo, ni asignarle una categoría.

\section{Piper mikaniaefolium Trel.}

Publicación: Field Mus. Nat. Hist., Bot. Ser. 13(2): 192. 1936

Colección tipo: E.P. Killip \& A.C. Smith 30691

Hembarios: US.

Nombre común: D esconocido.

Registro departamental: LO.

Regiones Ecológicas: BHA; 135-150 m.

SINAN PE: Sin registro.

Hemarios peruanos: Ninguno.

Observaciones: Este taxón fue considerado por Brako \& Zarucchi (1993) como un endemismo; sin embargo, no ha sido posible evaluarlo, ni asignarle una categoría.

\section{Pipermishuyacuense Trel.}

DD

Publicación: Field Mus. Nat. Hist., Bot. Ser. 13(2): 192. 1936.

Colección tipo: E.P. Killip \& A.C. Smith 29903

Herbarios: NY, US.

Nombre común: D esconocido.

Registro departamental: LO.

Regiones Ecológicas: BHA; 100 m.

SINAN PE: Sin registro.

Herbanios peruanos: Ninguno.

Observaciones: Arbusto conocido de los alrededores de Iquitos. Quijano-Abril et al. (2006) la reconocieron como un endemismo, para un análisis biogeográfico del género. Se desconoce el estado actual de sus poblaciones.

\section{Pipermitifolium Trel.}

Publicación: Field Mus. Nat. Hist., Bot. Ser. 13(2): 192-193. 1936.

Colección tipo: J.F. Macbride 5325

Herbarios: $F$.

Nombre común: D esconocido.

Registro departamental: JU.

Regiones Ecológicas: BMHP; $700 \mathrm{~m}$.

SINANPE: Sin registro.

Herbarios peruanos: Ninguno.

Observaciones: Este taxón fue considerado por Brako \& Zarucchi (1993) como un endemismo; sin embargo, no ha sido posible evaluarlo, ni asignarle una categoría.

\section{Piper moccomocco Trel. var. moccomocco}

Publicación:

Colección tipo: F. Herrera 954

Herbarios: B.

Nombre común: D esconocido.

Registro departamental: CU.

Regiones Ecológicas: BMHP; $1250 \mathrm{~m}$.

SINANPE: Sin registro.

Herbarios peruanos: Ninguno. 
Observaciones: Este taxón fue considerado por Brako \& Zarucchi (1993) como un endemismo; sin embargo, no ha sido posible evaluarlo, ni asignarle una categoría.

395. Pipermoccomocco Trel. var. angustum Trel.

Publicación: Field Mus. Nat. Hist., Bot. Ser. 13(2): 193. 1936.

Colección tipo: O.F. Cook \& G.B. Gilbert 1123

Herbarios: US.

Nombre común: D esconocido.

Registro departamental: CU.

Regiones Ecológicas: BMHM; $1800 \mathrm{~m}$.

SINAN PE: Sin registro.

Hembarios peruanos: Ninguno.

Observaciones: Este taxón fue considerado por Brako \& Zarucchi (1993) como un endemismo; sin embargo, no ha sido posible evaluarlo, ni asignarle una categoría.

396. Piper mohomoho C. DC.

Publicación: Bot. Jahrb. Syst. 40: 251252. 1908.

Colección tipo: A. Weberbauer 3839

Herbarios: B.

Nombre común: Mohomoho.

Registro departamental: CA.

Regiones Ecológicas: MA; 2400-2700 m.

SINANPE: Sin registro.

Hembarios peruanos: Ninguno.

Observaciones: Este taxón fue considerado por Brako \& Zarucchi (1993) como un endemismo; sin embargo, no ha sido posible evaluarlo, ni asignarle una categoría.

\section{Pipermonzonense C. DC.}

Publicación: Bot. Jahrb. Syst. 40: 248. 1908.

Colección tipo: A. Weberbauer 3429

Herbarios: B; MOL!

Nombre común: D esconocido.

Registro departamental: HU, LO.

Regiones Ecológicas: BMHP; $900-1000 \mathrm{~m}$

SINAN PE: Sin registro.

Herbarios peruanos: MOL (lectotipo)

Observaciones: Este taxón fue considerado por Brako \& Zarucchi (1993) como un endemismo; sin embargo, no ha sido posible evaluarlo, ni asignarle una categoría.

\section{Pipermoyobambanum Trel.}

Publicación: Field Mus. Nat. Hist., Bot. Ser. 13(2): 194- 195. 1936.

Colección tipo: A. Mathews s.n.

Herbarios: $\mathrm{K}$.

Nombre común: D esconocido.

Registro departamental: AM, SM.

Regiones Ecológicas: Sin datos; altitud desconocida.

SINANPE: Sin registro.

Herbarios peruanos: Ninguno.

Observaciones: Este taxón fue considerado por Brako \& Zarucchi (1993) como un endemismo; sin embargo, no ha sido posible evaluarlo, ni asignarle una categoría.
399. Pipermultimammosum Trel. var. multimammosum

Publicación:

Colección tipo: E.P. Killip \& A.C. Smith 26645

Herbarios: NY, US.

Nombre común: D esconocido.

Registro departamental: LO, PA, SM.

Regiones Ecológicas: BHA; 135-375 m.

SINAN PE: Sin registro.

Herbarios peruanos: Ninguno.

Observaciones: La localidad original fue citada para el departamento de Junín por Trelease (1936) y Brako \& Zarucchi (1993), pero en realidad se halla hoy ubicada en Pasco. No ha sido posible evaluar este taxón, ni asignarle una categoría.

400. Piper munchanum Trel. var. latum Trel.

Publicación: Field Mus. Nat. Hist., Bot. Ser. 13(2): 195. 1936.

Colección tipo: L. Williams 6954

Henbarios: $F$.

Nombre común: D esconocido.

Registro departamental: SM.

Regiones Ecológicas: BMHP; $1350-$ $1500 \mathrm{~m}$.

SINANPE: Sin registro.

Herbarios peruanos: Ninguno.

Observaciones: Este taxón fue considerado por Brako \& Zarucchi (1993) como un endemismo; sin embargo, no ha sido posible evaluarlo, ni asignarle una categoría.

\section{Piper mundum Trel.}

Publicación: Field Mus. Nat. Hist., Bot. Ser. 13(2): 195. 1936

Colección tipo: L. Williams 4758

Hemarios: $F$.

Nombre común: D esconocido.

Registro departamental: LO.

Regiones Ecológicas: BHA; 155- 210 m.

SINAN PE: Sin registro.

Hembarios peruanos: Ninguno.

Observaciones: Este taxón fue considerado por Brako \& Zarucchi (1993) como un endemismo; sin embargo, no ha sido posible evaluarlo, ni asignarle una categoría.

\section{Pipermunyanum Trel.}

Publicación: Field Mus. Nat. Hist., Bot. Ser. 13(2): 195-196. 1936.

Colección tipo: J.F. Macbride

Herbarios: $F$.

Nombre común: D esconocido.

Registro departamental: HU.

Regiones Ecológicas: BMHM; $2400 \mathrm{~m}$.

SINANPE: Sin registro.

Herbarios peruanos: Ninguno.

Observaciones: Este taxón fue considerado por Brako \& Zarucchi (1993) como un endemismo; sin embargo, no ha sido posible evaluarlo, ni asignarle una categoría. 
403. Pipernanayanum Trel.

Publicación: Field Mus. Nat. Hist., Bot. Ser. 13(2): 196. 1936.

Colección tipo: L. Williams 516

Herbarios: F.

Nombre común: D esconocido.

Registro departamental: LO.

Regiones Ecológicas: BHA; altitud desconocida.

SINAN PE: Sin registro.

Herbarios peruanos: Ninguno.

Observaciones: Estetaxón fue considerado por Brako \& Zarucchi (1993) como un endemismo; sin embargo, no ha sido posible evaluarlo, ni asignarle una categoría.

\section{Pipernasutum Trel.}

Publicación: Field Mus. Nat. Hist., Bot. Ser. 13(2): 196. 1936.

Colección tipo: L. Williams 3861

Herbarios: F.

Nombre común: D esconocido.

Registro departamental: LO.

Regiones Ecológicas: BHA; 155- 210 m.

SINAN PE: Sin registro.

Herbarios peruanos: Ninguno.

Observaciones: Este taxón fue considerado por Brako \& Zarucchi (1993) como un endemismo; sin embargo, no ha sido posible evaluarlo, ni asignarle una categoría.

\section{Piperneglectum Trel.}

Publicación: Field Mus. Nat. Hist., Bot. Ser. 13(2): 197. 1936.

Colección tipo: E.F. Poeppig D 1949

Herbarios: W.

Nombre común: D esconocido.

Registro departamental: HU, SM.

Regiones Ecológicas: $\mathrm{BMHP}, \mathrm{BHA}$; altitud desconocida.

SINAN PE: Sin registro.

Herbarios peruanos: Ninguno.

Observaciones: Estetaxón fue considerado por Brako \& Zarucchi (1993) como un endemismo; sin embargo, no ha sido posible evaluarlo, ni asignarle una categoría.

406. Pipernuncupatum Trel.

Publicación: Field Mus. Nat. Hist., Bot. Ser. 13(2): 197. 1936.

Colección tipo: E.P. Killip \& A.C. Smith 25577

Henbarios: NY, US.

Nombre común: D esconocido.

Registro departamental: JU.

Regiones Ecológicas: BMHP; 1350-

$1600 \mathrm{~m}$.

SINAN PE: Sin registro.

Herbarios peruanos: Ninguno.

Observaciones: Este taxón fue considerado por Brako \& Zarucchi (1993) como un endemismo; sin embargo, no ha sido posible evaluarlo, ni asignarle una categoría.

\section{Piperobesum Vahl}

Publicación: Enum. Pl. 1: 321. 1804.

Colección tipo: H. Ruiz \& J. Pavón s.n.

Hemarios: MA.

Nombre común: Desconocido.

Registro departamental: JU.

Regiones Ecológicas: MA; altitud desconocida.

SINANPE: Sin registro.

Herbarios peruanos: Ninguno.

Observaciones: Este taxón fue considerado por Brako \& Zarucchi (1993) como un endemismo; sin embargo, no ha sido posible evaluarlo, ni asignarle una categoría.

\section{Piper oblongatifolium Trel.}

Publicación: Field Mus. Nat. Hist., Bot. Ser. 13(2): 198. 1936.

Colección tipo: E.P. Killip \& A.C. Smith 29153

Herbarios: NY, US.

Nombre común: D esconocido.

Registro departamental: LO.

Regiones Ecológicas: BHA; 150 m.

SINANPE: Sin registro.

Herbarios peruanos: Ninguno.

Observaciones: Este taxón fue considerado por Brako \& Zarucchi (1993) como un endemismo; sin embargo, no ha sido posible evaluarlo, ni asignarle una categoría.

\section{Piperoblongatilimbum Trel.}

Publicación: Field Mus. Nat. Hist., Bot. Ser. 13(2): 198. 1936.

Colección tipo: E.P. Killip \& A.C. Smith 28327

Herbarios: NY, US.

Nombre común: Desconocido.

Registro departamental: LO.

Regiones Ecológicas: BHA; 135-150 m. SINAN PE: Sin registro.

Herbarios peruanos: Ninguno.

Observaciones: Este taxón fue considerado por Brako \& Zarucchi (1993) como un endemismo; sin embargo, no ha sido posible evaluarlo, ni asignarle una categoría.

\section{Piperoblongatum 0 piz}

DD

Publicación: Reliq. Haenk. 153. 1830.

Colección tipo: T. Haenke s.n.

Hembarios: PR?.

Nombre común: D esconocido.

Registro departamental: HU.

Regiones Ecológicas: Sin datos; altitud desconocida.

SINANPE: Sin registro.

Herbarios peruanos: Ninguno.

Observaciones: Arbusto conocido aparentemente sólo de la colección tipo, una planta recolectada en el siglo XVIII. Se desconoce el estado actual de sus poblaciones. 


\section{Piperobovatifolium Trel.}

Publicación: Field Mus. Nat. Hist., Bot. Ser. 13(2): 199. 1936.

Colección tipo: E.P. Killip \& A.C. Smith 28980

Herbarios:

Nombre común: D esconocido.

Registro departamental: LO.

Regiones Ecológicas: BHA; 135- 150 m.

SINAN PE: Sin registro.

Hembarios peruanos: Ninguno.

Observaciones: Este taxón fue considerado por Brako \& Zarucchi (1993) como un endemismo; sin embargo, no ha sido posible evaluarlo, ni asignarle una categoría.

\section{Piperoccultum Trel.}

DD

Publicación: Field Mus. Nat. Hist., Bot. Ser. 13(2): 199, como Peperomia. 1936.

Colección tipo: L. Williams 1406

Herbarios: $F$.

Nombre común: D esconocido.

Registro departamental: LO.

Regiones Ecológicas: BHA; $120 \mathrm{~m}$.

SINAN PE: Sin registro.

Hemarios peruanos: Ninguno.

Observaciones: Arbusto descrito de una planta recolectada en 1929, en las cercanías de Iquitos. Esta especie fue publicada erróneamente como Peperomia, aún cuando estaba incluida en el tratamiento del género Piper. No se conoce el estado actual de sus poblaciones.

\section{Piperoculatispicum Trel.}

Publicación: Field Mus. Nat. Hist., Bot. Ser. 13(2): 200. 1936.

Colección tipo: L. Williams 7954

Herbarios: F.

Nombre común: D esconocido.

Registro departamental: LO.

Regiones Ecológicas: BHA; $120 \mathrm{~m}$.

SINAN PE: Sin registro.

Herbarios peruanos: Ninguno.

Observaciones: Este taxón fue considerado por Brako \& Zarucchi (1993) como un endemismo; sin embargo, no ha sido posible evaluarlo, ni asignarle una categoría.

414. Piperoffensum Trel.

Publicación: Field Mus. Nat. Hist., Bot. Ser. 13(2): 200. 1936

Colección tipo: E.P. Killip \& A.C. Smith 28426

Herbarios: US.

Nombre común: D esconocido.

Registro departamental: LO.

Regiones Ecológicas: BHA; 150- 350 m.

SINAN PE: Sin registro.

Herbarios peruanos: Ninguno.

Observaciones: Este taxón fue considerado por Brako \& Zarucchi (1993) como un endemismo; sin embargo, no ha sido posible evaluarlo, ni asignarle una categoría.

\section{Piperollantaitambanum Trel.}

Publicación: Field Mus. Nat. Hist., Bot. Ser. 13(2): 200. 1936.

Colección tipo: O.F. Cook \& G.B. Gilbert 558

Hemarios: NY.

Nombre común: D esconocido.

Registro departamental: CU.

Regiones Ecológicas: MA; $3000 \mathrm{~m}$.

SINAN PE: Sin registro.

Herbarios peruanos: Ninguno.

Observaciones: Este taxón fue considerado por Brako \& Zarucchi (1993) como un endemismo; sin embargo, no ha sido posible evaluarlo, ni asignarle una categoría.

\section{Piper opizianum Fürnr.}

Publicación: Flora 12: 228. 1829.

Colección tipo: T. Haenke s.n.

Herbarios: PR.

Nombre común: D esconocido.

Registro departamental: Sin datos.

Regiones Ecológicas: Sin datos; altitud desconocida.

SINANPE: Sin registro.

Herbarios peruanos: Ninguno.

Observaciones: Este taxón fue considerado por Brako \& Zarucchi (1993) como un endemismo; sin embargo, no ha sido posible evaluarlo, ni asignarle una categoría.

\section{Piper ornithorhynchum Trel.}

Publicación: Field Mus. Nat. Hist., Bot. Ser. 13(2): 201. 1936.

Colección tipo: E.P. Killip \& A.C. Smith

Herbarios: US.

Nombre común: D esconocido.

Registro departamental: AY.

Regiones Ecológicas: BMHM; altitud desconocida.

SINANPE: Sin registro.

Herbarios peruanos: Ninguno.

Observaciones: Este taxón fue considerado por Brako \& Zarucchi (1993) como un endemismo; sin embargo, no ha sido posible evaluarlo, ni asignarle una categoría.

\section{Piper ostii Trel.}

\section{NT}

Publicación: Field Mus. Nat. Hist., Bot. Ser. 13(2): 201. 1936.

Colección tipo: Y. Mexia 6152

Henbarios: GH, ILL, NY, UC.

Nombre común: D esconocido.

Registro departamental: AM, MD.

Regiones Ecológicas: BHA; $180-250 \mathrm{~m}$. SINANPE: ZRSC

Herbarios peruanos: Ninguno.

Observaciones: Arbusto conocido de varias localidades dispersas y, al parecer, disyuntas en las cuencas del Santiago y Madre de Dios. El ejemplar tipo fue recolectado en 1931, en la cuenca del Santiago. Una de las poblaciones se halla en una reserva particular (Cuzco Amazónico). 


\section{Piperpaganicum Trel.}

\section{DD}

Publicación: Field Mus. Nat. Hist., Bot. Ser. 13(2): 202. 1936.

Colección tipo: E.P. Killip \& A.C. Smith 27432 Herbarios: US.

Nombre común: D esconocido.

Registro departamental: LO.

Regiones Ecológicas: BHA; $100 \mathrm{~m}$.

SINANPE: Sin registro.

Herbarios peruanos: Ninguno.

Observaciones: Arbusto descrito de una planta recolectada en 1929, de una subcuenca del Amazonas. Quijano-Abril et al. (2006) la reconocieron como un endemismo en su análisis biogeográfico. Se desconoce el estado actual de sus poblaciones.

\section{Piper pallididorsum Trel.}

\section{DD}

Publicación: Field Mus. Nat. Hist., Bot. Ser. 13(2): 202. 1936.

Colección tipo: J.F. Macbride \& W. Featherstone 5801

Herbarios: $F$.

Nombre común: D esconocido.

Registro departamental: JU.

Regiones Ecológicas: Sin datos; $1300 \mathrm{~m}$.

SINAN PE: Sin registro.

Herbarios peruanos: Ninguno.

Observaciones: Arbusto conocido de la colección tipo, una planta recolectada en 1922, de la cuenca del Tulumayo. Se desconoce el estado actual de sus poblaciones.

\section{Piperpapillipetiolatum Trel.}

\section{DD}

Publicación: Field Mus. Nat. Hist., Bot. Ser. 13(2): 203. 1936.

Colección tipo: E.P. Killip \& A.C. Smith 27407

Henbarios: US.

Nombre común: D esconocido.

Registro departamental: LO.

Regiones Ecológicas: BHA; $100 \mathrm{~m}$.

SINAN PE: Sin registro.

Herbarios peruanos: Ninguno.

Observaciones: Arbusto conocido sólo de la localidad original, en una subcuenca del Amazonas, donde fue registrado en 1929. Brako \& Zarucchi (1993) incluyeron esta especie en la sinonimia de Piper rusbyi; pero Quijano-Abril et al. (2006) la aceptan, criterio que aquí se sigue. Se desconoce el estado actual de sus poblaciones.

\section{Piperparaisense Trel.}

\section{DD}

Publicación: Field Mus. Nat. Hist., Bot. Ser. 13(2): 203. 1936.

Colección tipo: L. Williams 3207

Herbarios: $F$.

Nombre común: D esconocido.

Registro departamental: LO.

Regiones Ecológicas: BHA; $145 \mathrm{~m}$.

SINAN PE: Sin registro.

Hembarios peruanos: Ninguno.
Observaciones: Arbusto conocido de la colección tipo, una planta recolectada en 1930, de la cuenca del Itaya. Q uijano-Abril et al. (2006) no la incluyeron en su análsis biogeográfico. Se desconoce el estado actual de sus poblaciones.

\section{Piperparalaevigatum Trel.}

\section{DD}

Publicación: Field Mus. Nat. Hist., Bot. Ser. 13(2): 203. 1936.

Colección tipo: E.F. Poeppig 1

Herbarios: Sin datos.

Nombre común: D esconocido.

Registro departamental: LO.

Regiones Ecológicas: Sin datos; altitud desconocida.

SINAN PE: Sin registro.

Herbarios peruanos: Ninguno.

O bservaciones: Especie arbustiva descrita de una planta recolectada en el siglo XIX. Trelease (1936) atribuyó la localidad de origen al departamento de Junín y Brako \& Zarucchi (1993) así lo incluyeron. Sin embargo, la localidad «Mainas alto» probablemente correspondaal occidente de Loreto, que fue herborizada por Poeppig.

\section{Piperparvicondulatum Trel.}

Publicación: Field Mus. Nat. Hist., Bot. Ser. 13(2): 204. 1936.

Colección tipo: C.O. Schunke 319

Hemarios: $F$.

Nombre común: D esconocido.

Registro departamental: JU.

Regiones Ecológicas: BMHM; 1800 m.

SINANPE: Sin registro.

Herbarios peruanos: Ninguno.

Observaciones: Arbusto descrito de una planta recolectada en la década de 1920, en la cuenca del Tulumayo. No ha sido posible evaluar esta especie, ni asignarle una categoría.

\section{Piperpatens 0 piz}

Publicación: Reliq. Haenk. 1(3): 154. 1828.

Colección tipo: T. Haenke s.n.

Hembarios: PR.

Nombre común: D esconocido.

Registro departamental: HU.

Regiones Ecológicas: Sin datos; altitud desconocida.

SINANPE: Sin registro.

Herbarios peruanos: Ninguno.

Observaciones: Especie arbustiva recolectada en el siglo XVIII, de los alrededores de Huánuco. No ha sido posible evaluar esta especie, ni asignarle una categoría.

\section{Piper patentifolium Trel.}

Publicación: Field Mus. Nat. Hist., Bot. Ser. 13(2): 205. 1936.

Colección tipo: Stevens 136

Herbarios: ILL.

Nombre común: D esconocido.

Registro departamental: JU.

Regiones Ecológicas: Sin datos; altitud desconocida.

SINANPE: Sin registro.

Herbarios peruanos: Ninguno. 
Observaciones: Especie a la que se atribuye el hábito de herbácea, descrita de una planta recolectada en 1924, en la cuenca del Tulumayo. No ha sido posible evaluar esta especie, ni asignarle una categoná.

\section{Piperpaucartamboanum Trel.}

Publicación: Field Mus. Nat. Hist., Bot. Ser. 13(2): 205. 1936.

Colección tipo: E.P. Killip \& A.C. Smith 25388

Herbarios: US.

Nombre común: D esconocido.

Registro departamental: JU.

Regiones Ecológicas: BMHP; $700 \mathrm{~m}$.

SINAN PE: Sin registro.

Hemarios peruanos: Ninguno.

Observaciones: Este taxón fue considerado por Brako \& Zarucchi (1993) como un endemismo; sin embargo, no ha sido posible evaluarlo, ni asignarle una categoría.

\section{Piper paulianifolium Trel.}

Publicación: Field Mus. Nat. Hist., Bot. Ser. 13(2): 205. 1936.

Colección tipo: T. Haenke s.n.

Herbarios: PR.

Nombre común: D esconocido.

Registro departamental: Sin datos.

Regiones Ecológicas: Sin datos; altitud desconocida.

SINANPE: Sin registro.

Herbarios peruanos: Ninguno.

Observaciones: Este taxón fue considerado por Brako \& Zarucchi (1993) como un endemismo; sin embargo, no ha sido posible evaluarlo, ni asignarle una categoría.

429. Piperpavonii (Miq.) C. DC.

\section{DD}

Publicación: Prodr. 16(1): 294. 1869.

Colección tipo: A. Mathews 793

Herbarios: $\mathrm{K}$.

Nombre común: D esconocido.

Registro departamental: JU, LO.

Regiones Ecológicas: BMHM; altitud desconocida.

SINAN PE: Sin registro.

Herbarios penuanos: Ninguno.

Observaciones: Arbusto conocido de unas pocas localidades en el centro occidente de la Amazonía peruana. Esta especie fue descrita de una planta, probablemente, recolectada en la cuenca del Huallaga. Trelease (1936) cita dos ejemplares adicionales, uno de ellos procedente de bosques montanos de Junín. No pudo verificarse la presencia en Loreto como mencionan Brako \& Zarucchi (1993).

\section{Piperpebasense Trel.}

Publicación: Field Mus. Nat. Hist., Bot. Ser. 13(2): 206. 1936.

Colección tipo: L. Williams 1746

Herbanios: F.

Nombre común: D esconocido.

Registro departamental: LO.

Regiones Ecológicas: BHA; altitud desconocida.

SINAN PE: Sin registro.
Herbarios peruanos: Ninguno.

Observaciones: Este taxón fue considerado por Brako \& Zarucchi (1993) como un endemismo; sin embargo, no ha sido posible evaluarlo, ni asignarle una categoría.

\section{Piperpenenense Trel.}

\section{EN, Blab(iii)}

Publicación: Field Mus. Nat. Hist., Bot. Ser. 13(2): 207. 1936.

Colección tipo: E.P. Killip \& A.C. Smith 25108

Hemarios: GH, ILL, NY, US.

Nombre común: D esconocido.

Registro departamental: JU, PA.

Regiones Ecológicas: BMHP; $600-700$

$\mathrm{m}$.

SINAN PE: Sin registro.

Herbarios peruanos: Ninguno.

Observaciones: Arbusto conocido, al parecer, de dos localidades, en las cuencas del Perené y del Pichis, registradas en 1929. Brako \& Zarucchi (1993) aceptaron las variedades propuestas por Trelease (1936), pero aquí se acepta este taxón en sentido amplio, tal como lo hicieron Quijano-Abril et al. (2006). Fue registrada en bosques densos, donde es probable que habitaba el sotobosque, pero los cambios ambientales en la zona desde entonces, podría constituir temas de preocupación.

\section{Piperpernignicans Trel.}

Publicación: Field Mus. Nat. Hist., Bot. Ser. 13(2): 207. 1936.

Colección tipo: E.P. Killip \& A.C. Smith 29976

Herbarios: US.

Nombre común: D esconocido.

Registro departamental: LO.

Regiones Ecológicas: BHA; $100 \mathrm{~m}$.

SINAN PE: Sin registro.

Herbarios peruanos: Ninguno.

Observaciones: Quijano-Abril et al. (2006) la reconocieron como un endemismo que forma parte de un patrón biogeográfico único al Neotrópico.

\section{Piperperpunctulatum Trel.}

Publicación: Field Mus. Nat. Hist., Bot. Ser. 13(2): 207. 1936.

Colección tipo: E.P. Killip \& A.C. Smith 28090

Herbarios: US.

Nombre común: D esconocido.

Registro departamental: LO.

Regiones Ecológicas: BHA; 135-150 m.

SINAN PE: Sin registro.

Herbarios peruanos: Ninguno.

Observaciones: Este taxón fue considerado por Brako \& Zarucchi (1993) como un endemismo; sin embargo, no ha sido posible evaluarlo, ni asignarle una categoría. 


\section{Piperperpurgatum Trel.}

Publicación: Field Mus. Nat. Hist., Bot. Ser. 13(2): 208. 1936.

Colección tipo: E.P. Killip \& A.C. Smith 29455

Herbarios: ILL, NY, US.

Nombre común: D esconocido.

Registro departamental: LO.

Regiones Ecológicas: BHA; 110 m.

SINANPE: Sin registro.

Herbarios peruanos: Ninguno.

Observaciones: Este taxón fue considerado por Brako \& Zarucchi (1993) como un endemismo; sin embargo, no ha sido posible evaluarlo, ni asignarle una categoría.

\section{Piperpilosissimum Yunck.}

Publicación: Ann. Missouri Bot. Gard. 53: 383. 1965.

Colección tipo: F. Woytkowski 6999

Hemarios: MO.

Nombre común: D esconocido.

Registro departamental: CA.

Regiones Ecológicas: Sin datos; altitud desconocida.

SINANPE: Sin registro.

Herbarios peruanos: Ninguno.

Observaciones: Este taxón fue considerado por Brako \& Zarucchi (1993) como un endemismo; sin embargo, no ha sido posible evaluarlo, ni asignarle una categoría.

\section{Piper planipes Trel.}

\section{EN, Blab(iii)}

Publicación: Field Mus. Nat. Hist., Bot. Ser. 13(2): 210. 1936.

Colección tipo: E.P. Killip \& A.C. Smith 24928

Herbarios: ILL, NY, US.

Nombre común: D esconocido.

Registro departamental: JU.

Regiones Ecológicas: $\mathrm{BMHP}, \mathrm{BHA}$; 680- $1700 \mathrm{~m}$.

SINAN PE: Sin registro.

Herbarios peruanos: Ninguno.

Obsenvaciones: Especie arbórea o arbustiva conocida sólo de las cuencas del Tulumayo y Perené, donde fue registrada en 1929. Brako \& Zarucchi(1993) aceptaron las variedades propuestas porTrelease (1936), pero aquí se acepta este taxón en sentido amplio, tal como lo hicieron Quijano-Abril et al. (2006). Los cambios ambientales en el rango altitudinal de esas cuencas son de preocupación.

437. Piperpolitaereum Trel. var. politaereum

Publicación:

Colección tipo: E.P. Killip \& A.C. Smith 24545

Herbarios: US.

Nombre común: Desconocido.

Registro departamental: JU, LO.

Regiones Ecológicas: BMHP; $1400-$ $1700 \mathrm{~m}$.

SINANPE: Sin registro.

Herbarios peruanos: Ninguno.
Observaciones: Este taxón fue considerado por Brako \& Zarucchi (1993) como un endemismo; sin embargo, no ha sido posible evaluarlo, ni asignarle una categoría.

\section{Piperpolitaereum Trel. var. elongatum Trel.}

Publicación: Field Mus. Nat. Hist., Bot. Ser. 13(2): 211. 1936.

Colección tipo: E.P. Killip \& A.C. Smith 29587

Herbarios: US.

Nombre común: Desconocido.

Registro departamental: LO.

Regiones Ecológicas: BHA; $110 \mathrm{~m}$.

SINAN PE: Sin registro.

Hembarios peruanos: Ninguno.

Observaciones: Este taxón fue considerado por Brako \& Zarucchi (1993) como un endemismo; sin embargo, no ha sido posible evaluarlo, ni asignarle una categoría.

\section{Piperpolitaeneum Trel. var. mucronatum Trel.}

Publicación: Field Mus. Nat. Hist., Bot. Ser. 13(2): 211. 1936.

Colección tipo: E.P. Killip \& A.C. Smith 29460

Herbarios: US.

Nombre común: Desconocido.

Registro departamental: LO.

Regiones Ecológicas: BHA; $110 \mathrm{~m}$.

SINANPE: Sin registro.

Herbarios peruanos: Ninguno.

Observaciones: Este taxón fue considerado por Brako \& Zarucchi (1993) como un endemismo; sin embargo, no ha sido posible evaluarlo, ni asignarle una categoría.

440. Piper politum C. DC. var. politum

\author{
Publicación: \\ Colección tipo: R. Spruce 4137 \\ Herbarios: G, $K$. \\ Nombre común: Desconocido. \\ Registro departamental: LO, SM. \\ Regiones Ecológicas: BHA; altitud \\ desconocida. \\ SINANPE: Sin registro. \\ Herbarios peruanos: Ninguno.
}

Observaciones: Este taxón fue considerado por Brako \& Zarucchi (1993) como un endemismo; sin embargo, no ha sido posible evaluarlo, ni asignarle una categoría.

441. Piper politum C. DC. var, pallidibracteum Trel.

Publicación: Field Mus. Nat. Hist., Bot. Ser. 13(2): 212. 1936.

Colección tipo: L. Williams 7639

Herbarios: F.

Nombre común: Cordoncillo.

Registro departamental: SM.

Regiones Ecológicas: $\mathrm{BMHM}, \mathrm{BMHP}$; 1350- $1500 \mathrm{~m}$.

SINANPE: Sin registro.

Herbarios peruanos: Ninguno. 
Observaciones: Este taxón fue considerado por Brako \& Zarucchi (1993) como un endemismo; sin embargo, no ha sido posible evaluarlo, ni asignarle una categoría.

\section{Piper ponganum Trel.}

Publicación: Field Mus. Nat. Hist., Bot. Ser. 13(2): 12. 1936.

Colección tipo: Y. Mexia 6123

Herbarios: UC.

Nombre común: D esconocido.

Registro departamental: AM.

Regiones Ecológicas: BHA; 220 m.

SINAN PE: Sin registro.

Herbarios peruanos: Ninguno.

Observaciones: Arbusto conocido de la colección tipo, la cual proviene del Pongo de Manseriche, localizado en el departamento de Amazonas, muy cerca al límite departamental con Loreto.

\section{Piperpontis Trel.}

\section{CR, B lab(iii)}

Publicación: Field Mus. Nat. Hist., Bot. Ser. 13(2): 212. 1936.

Colección tipo: E.P. Killip \& A.C. Smith 25294

Herbarios: ILL, NY, US.

Nombre común: D esconocido.

Registro departamental: JU.

Regiones Ecológicas: BMHP; $700 \mathrm{~m}$.

SINANPE: Sin registro.

Hemarios peruanos: Ninguno.

Observaciones: Arbusto conocido sólo de la localidad original, en la cuenca del Paucartambo, donde fue recolectado en 1929. Q uijanoAbril et al. (2006) la reconocieron como un endemismo,con un patrón biogeográfico único al Neotrópico. En la cuenca conocida y ala altitud registrada se han producido muchos cambios ambientales desde su primer registro, por lo que estos son causa de preocupación.

\section{Piper porveninicola Trel.}

Publicación: Field Mus. Nat. Hist., Bot. Ser. 13(2): 213. 1936.

Colección tipo: E.P. Killip \& A.C. Smith 25940

Herbarios: US.

Nombre común: D esconocido.

Registro departamental: JU.

Regiones Ecológicas: BMHM; 1500$1900 \mathrm{~m}$.

SINANPE: Sin registro.

Herbarios peruanos: Ninguno.

Observaciones: Este taxón fue considerado por Brako \& Zarucchi (1993) como un endemismo; sin embargo, no ha sido posible evaluarlo, ni asignarle una categoría.

\section{Piper positum Trel.}

Publicación: Field Mus. Nat. Hist., Bot. Ser. 13(2): 213. 1936

Colección tipo: E.P. Killip \& A.C. Smith 29256

Herbarios: US.

Nombre común: D esconocido.

Registro departamental: LO, MD.

Regiones Ecológicas: BHA; $135 \mathrm{~m}$.

SINAN PE: Sin registro.

Herbarios peruanos: Ninguno.
Observaciones: Este taxón fue considerado por Brako \& Zarucchi (1993) como un endemismo; sin embargo, no ha sido posible evaluarlo, ni asignarle una categoría.

\section{Piperposusanum Trel.}

Publicación: Field Mus. Nat. Hist., Bot. Ser. 13(2): 213. 1936.

Colección tipo: J.F. Macbride \& W. Featherstone 4609

Hembarios: $F$.

Nombre común: D esconocido.

Registro departamental: PA.

Regiones Ecológicas: BMHP, BHA; $600 \mathrm{~m}$. SINAN PE: Sin registro.

Herbarios peruanos: Ninguno.

Observaciones: Arbusto conocido de la colección tipo, una planta recolectada en 1923, en la cuenca del Pozuzo, hoy en departamento de Pasco y no en Huánuco como fue señalado por Brako \& Zarucchi (1993). No hasido posible evaluar esta especie, ni asignanle una categoní.

\section{Piperpothophyllum Trel.}

Publicación: Field Mus. Nat. Hist., Bot. Ser. 13(2): 214. 1936.

Colección tipo: L. Williams 2998

Hembarios: $F$.

Nombre común: D esconocido.

Registro departamental: LO.

Regiones Ecológicas: BHA; altitud desconocida.

SINAN PE: Sin registro.

Herbarios peruanos: Ninguno.

Observaciones: Este taxón fue considerado por Brako \& Zarucchi (1993) como un endemismo; sin embargo, no ha sido posible evaluarlo, ni asignarle una categoría.

\section{Piper procerum Trel.}

Publicación: Field Mus. Nat. Hist., Bot. Ser. 13(2): 214. 1936.

Colección tipo: E.P. Killip \& A.C. Smith 24636

Herbarios: US.

Nombre común: D esconocido.

Registro departamental: JU.

Regiones Ecológicas: BMHM, BMHP; 1400-1700 m.

SINAN PE: Sin registro.

Herbarios peruanos: Ninguno.

Observaciones: Este taxón fue considerado por Brako \& Zarucchi (1993) como un endemismo; sin embargo, no ha sido posible evaluarlo, ni asignarle una categoría.

449. Piperpseudobarbatum C. DC.

\section{DD}

Publicación: Bot. Jahrb. Syst. 40: 249— 250. 1908.

Colección tipo: A. Weberbauer 3738

Henbarios: B, G; MOL!.

Nombre común: D esconocido.

Registro departamental: AN.

Regiones Ecológicas: MA; $2700 \mathrm{~m}$.

SINAN PE: Sin registro.

Herbarios penuanos: MOL (lectotipo). 
Observaciones: Arbusto conocido, al parecer, sólo de la localidad original, en la cuenca del Puccha, un afluente del alto Marañón. Esa localidad es reconocida con vacíos de información botánica; además, sus ambientes naturales se encuentran entre los más amenazados por la tala paraleña, incendios intencionales y ampliación de las áreas cultivadas. Al parecer, no ha vuelto a ser recolectada desde 1903 (Cano, com. pers.).

450. Piperpseudocallosum Trel.

Publicación: Field Mus. Nat. Hist., Bot. Ser. 13(2): 215. 1936.

Colección tipo: J.F. Macbride \& W. Featherstone 4103

Herbarios: $F$.

Nombre común: D esconocido.

Registro departamental: HU.

Regiones Ecológicas: BMHM; 1950-

$2400 \mathrm{~m}$.

SINANPE: Sin registro.

Herbarios peruanos: Ninguno.

Observaciones: Arbusto conocido de dos poblaciones en la cuenca del Huallaga. No hasido posibleevaluar estaespecie, niasignarleunacategona.

\section{Piperpseudoflexuosum Trel.}

DD

Publicación: Field Mus. Nat. Hist., Bot. Ser. 13(2): 216. 1936.

Colección tipo: E.F. Poeppig s.n.

Herbarios: W.

Nombre común: D esconocido.

Registro departamental: Sin datos.

Regiones Ecológicas: Sin datos; altitud desconocida.

SINAN PE: Sin registro.

Herbarios peruanos: Ninguno.

Observaciones: Esta especie arbustiva es conocida del ejemplar tipo recolectado en el siglo XIX, en el Perú, pero cuya procedencia exacta se desconoce.

452. Piperpseudomatico Trel.

Publicación: Field Mus. Nat. Hist., Bot. Ser. 13(2): 217. 1936.

Colección tipo: J.F. Macbride \& W. Featherstone 1488

Herbarios: F.

Nombre común: D esconocido.

Registro departamental: HU, JU.

Regiones Ecológicas: BMHM; $2700 \mathrm{~m}$.

SINANPE: Sin registro.

Herbarios peruanos: Ninguno.

Observaciones: Este taxón fue considerado por Brako \& Zarucchi (1993) como un endemismo; sin embargo, no ha sido posible evaluarlo, ni asignarle una categoría.

453. Piperpseudomollicomum C. DC. var. dichotomum C. DC.

Publicación: Prodr. 16(1): 279. 1869.

Colección tipo: E.F. Poeppig s.n.

Herbarios: W.

Nombre común: D esconocido.

Registro departamental: Sin datos.

Regiones Ecológicas: Sin datos; altitud

desconocida.

SINANPE: Sin registro.

Herbarios peruanos: Ninguno.
Observaciones: Este taxón fue considerado por Brako \& Zarucchi (1993) como un endemismo; sin embargo, no ha sido posible evaluarlo, ni asignarle una categoría.

\section{Piperpseudomunchanum Trel.}

Publicación: Field Mus. Nat. Hist., Bot. Ser. 13(2): 217. 1936.

Colección tipo: R. Spruce 4341

Herbarios: K.

Nombre común: D esconocido.

Registro departamental: SM.

Regiones Ecológicas: Sin datos; altitud desconocida.

SINANPE: Sin registro.

Hembarios peruanos: Ninguno.

Observaciones: Este taxón fue considerado por Brako \& Zarucchi (1993) como un endemismo; sin embargo, no ha sido posible evaluarlo, ni asignarle una categoría.

\section{Piperpubenulescens Trel.}

Publicación: Field Mus. Nat. Hist., Bot. Ser. 13(2): 218. 1936.

Colección tipo: E.P. Killip \& A.C. Smith 29057

Hemanios: US.

Nombre común: Desconocido.

Registro departamental: AM, HU, LO, MD.

Regiones Ecológicas: BHA; $135 \mathrm{~m}$.

SINANPE: Sin registro.

Hemarios peruanos: Ninguno.

Observaciones: Este taxón fue considerado por Brako \& Zarucchi (1993) como un endemismo; sin embargo, no ha sido posible evaluarlo, ni asignarle una categoría.

456. Piper puberuliciliatum Yunck.

Publicación: Brittonia 13(1): 58, f. 1.

1961.

Colección tipo: F. Woytkowski 1249

Hembarios: NY, US; MOL!.

Nombre común: D esconocido.

Registro departamental: HU.

Regiones Ecológicas: BHA; $520 \mathrm{~m}$.

SINAN PE: Sin registro.

Herbarios penuanos: MOL (isotipo).

Observaciones: Estetaxón fue considerado por Brako \& Zarucchi (1993) como un endemismo; sin embargo, no ha sido posible evaluarlo, ni asignarle una categoría.

457. Piper pubibaccum C. DC.

Publicación: Bot. Jahrb. Syst. 40: 251. 1908.

Colección tipo: A. Weberbauer 3581

Herbarios: B; MOL!.

Nombre común: Desconocido.

Registro departamental: HU, JU.

Regiones Ecológicas: BMHP; $600-700$

$\mathrm{m}$.

SINANPE: Sin registro.

Herbarios penuanos: MOL (lectotipo). 
Observaciones: Este taxón fue considerado por Brako \& Zarucchi (1993) como un endemismo; sin embargo, no ha sido posible evaluarlo, ni asignarle una categoría.

458. Piper pullispicum Trel.

\section{DD}

Publicación: Field Mus. Nat. Hist., Bot. Ser. 13(2): 218. 1936.

Colección tipo: Y. Mexia 6352

Herbarios: UC.

Nombre común: D esconocido.

Registro departamental: AM.

Regiones Ecológicas: BHA; $280 \mathrm{~m}$.

SINAN PE: Sin registro.

Herbarios peruanos: Ninguno.

Observaciones: Arbusto conocido de la colección tipo, la cual proviene del Pongo de Manseriche, localizado en el departamento de Amazonas, muy cerca al límite con Loreto. Se desconoce el estado actual de sus poblaciones.

\section{Piper puniceum Trel.}

Publicación: Field Mus. Nat. Hist., Bot.

Ser. 13(2): 219. 1936.

Colección tipo: Schunke 236

Herbarios: $F$.

Nombre común: D esconocido.

Registro departamental: JU.

Regiones Ecológicas: BMHM; $1500 \mathrm{~m}$.

SINAN PE: Sin registro.

Hemarios peruanos: Ninguno.

Observaciones: Este taxón fue considerado por Brako \& Zarucchi (1993) como un endemismo; sin embargo, no ha sido posible evaluarlo, ni asignarle una categoría.

\section{Piperpygmaeum Yunck.}

Publicación: Svensk Bot. Tidskr. 51(3): 530. 1957.

Colección tipo: G. Klug 3177

Hemarios: S, US.

Nombre común: D esconocido.

Registro departamental: LO.

Regiones Ecológicas: BMHP; 600—1200 m.

SINAN PE: Sin registro.

Herbarios peruanos: Ninguno.

Observaciones: Este taxón fue considerado por Brako \& Zarucchi (1993) como un endemismo; sin embargo, no ha sido posible evaluarlo, ni asignarle una categoría.

\section{Piperquiminianum Trel.}

Publicación: Field Mus. Nat. Hist., Bot. Ser. 13(2): 219. 1936.

Colección tipo: E.P. Killip \& A.C. Smith 23904

Herbarios: US.

Nombre común: D esconocido.

Registro departamental: JU.

Regiones Ecológicas: BMHP; 800— $1300 \mathrm{~m}$.

SINANPE: Sin registro.

Herbarios peruanos: Ninguno.
Observaciones: Este taxón fue considerado por Brako \& Zarucchi (1993) como un endemismo; sin embargo, no ha sido posible evaluarlo, ni asignarle una categoría.

462. Piperrasile Trel.

Publicación: Field Mus. Nat. Hist., Bot. Ser. 13(2): 220. 1936.

Colección tipo: E.P. Killip \& A.C. Smith 26404

Herbarios: US.

Nombre común: D esconocido.

Registro departamental: PA.

Regiones Ecológicas: BHA; 375 m.

SINANPE: Sin registro.

Herbarios peruanos: Ninguno.

Observaciones: Arbusto conocido de la colección tipo, recolectada en 1929, de la cuenca del Pichis, cerca de la Cordillera San MatíasSan Carlos. Esta localidad se reconocía en Junín (Trelease, 1936; Brako \& Zarucchi, 1993). No ha sido posible evaluar esta especie, ni asignarle una catergoría.

\section{Piper recensitum Trel.}

Publicación: Field Mus. Nat. Hist., Bot. Ser. 13(2): 220. 1936.

Colección tipo: E.P. Killip \& A.C. Smith 28810

Herbarios: US.

Nombre común: D esconocido.

Registro departamental: LO.

Regiones Ecológicas: BHA; $135 \mathrm{~m}$.

SINAN PE: Sin registro.

Herbarios peruanos: Ninguno.

Observaciones: Este taxón fue considerado por Brako \& Zarucchi (1993) como un endemismo; sin embargo, no ha sido posible evaluarlo, ni asignarle una categoría.

\section{Piper recreoense Trel.}

Publicación: Field Mus. Nat. Hist., Bot. Ser. 13(2): 220. 1936.

Colección tipo: L. Williams 3928

Henbarios: $F$.

Nombre común: D esconocido.

Registro departamental: $\mathrm{LO}$.

Regiones Ecológicas: BHA; 155-210 m.

SINAN PE: Sin registro.

Herbarios peruanos: Ninguno.

Observaciones: Este taxón fue considerado por Brako \& Zarucchi (1993) como un endemismo; sin embargo, no ha sido posible evaluarlo, ni asignarle una categoría.

465. Piperredactum Trel.

Publicación: Field Mus. Nat. Hist., Bot. Ser. 13(2): 221. 1936.

Colección tipo: A. Mathews s.n.

Herbarios: K.

Nombre común: D esconocido.

Registro departamental: AM.

Regiones Ecológicas: Sin datos; altitud desconocida.

SINANPE: Sin registro.

Herbarios peruanos: Ninguno. 
Observaciones: Este taxón fue considerado por Brako \& Zarucchi (1993) como un endemismo; sin embargo, no ha sido posible evaluarlo, ni asignarle una categoría.

\section{Piper reductipes Trel. var. reductipes}

Publicación:

Colección tipo: L. Williams 2700

Herbarios: F.

Nombre común: D esconocido.

Registro departamental: LO.

Regiones Ecológicas: BHA; altitud desconocida.

SINANPE: Sin registro.

Herbarios peruanos: Ninguno.

Observaciones: Este taxón fue considerado por Brako \& Zarucchi (1993) como un endemismo; sin embargo, no ha sido posible evaluarlo, ni asignarle una categoría.

\section{Piper reductipes Trel. var. amplum Trel.}

Publicación: Field Mus. Nat. Hist., Bot. Ser. 13(2): 221. 1936.

Colección tipo: L. Williams 2971

Herbarios: $F$.

Nombre común: D esconocido.

Registro departamental: LO.

Regiones Ecológicas: BHA; altitud desconocida.

SINANPE: Sin registro.

Herbarios peruanos: Ninguno.

Observaciones: Este taxón fue considerado por Brako \& Zarucchi (1993) como un endemismo; sin embargo, no ha sido posible evaluarlo, ni asignarle una categoría.

\section{Piperreductipes Trel. var. stenostachys Trel.}

Publicación: Field Mus. Nat. Hist., Bot. Ser. 13(2): 221. 1936

Colección tipo: L. Williams 2578

Herbarios: $F$.

Nombre común: D esconocido.

Registro departamental: LO.

Regiones Ecológicas: BHA; altitud desconocida.

SINAN PE: Sin registro.

Herbarios penuanos: Ninguno.

Observaciones: Este taxón fue considerado por Brako \& Zarucchi (1993) como un endemismo; sin embargo, no ha sido posible evaluarlo, ni asignarle una categoría.

\section{Piperrelaxatum Trel.}

Publicación: Field Mus. Nat. Hist., Bot. Ser. 13(2): 222. 1936

Colección tipo: E.P. Killip \& A.C. Smith 28385

Herbarios: US.

Nombre común: D esconocido.

Registro departamental: LO.

Regiones Ecológicas: BHA; 150- 350 m.

SINANPE: Sin registro.

Herbarios peruanos: Ninguno.
Observaciones: Este taxón fue considerado por Brako \& Zarucchi (1993) como un endemismo; sin embargo, no ha sido posible evaluarlo, ni asignarle una categoría.

\section{Piperresalutatum Trel.}

Publicación: Field Mus. Nat. Hist., Bot. Ser. 13(2): 222. 1936

Colección tipo: E.P. Killip \& A.C. Smith 26024

Herbarios: US.

Nombre común: D esconocido.

Registro departamental: JU.

Regiones Ecológicas: BHA; $110 \mathrm{~m}$.

SINANPE: Sin registro.

Herbarios peruanos: Ninguno.

Observaciones: No ha sido posible evaluar esta especie, ni asignarle una categoría. La localidad original fue citada para el departamento de Junín por Trelease (1936) y Brako \& Zarucchi (1993), pero en realidad se halla hoy ubicada en Pasco.

\section{Piper restio Trel.}

Publicación: Field Mus. Nat. Hist., Bot. Ser. 13(2): 222. 1936.

Colección tipo: J.F. Macbride \& W. Featherstone 4689

Hembarios: $F$.

Nombre común: D esconocido.

Registro departamental: PA.

Regiones Ecológicas: BMHP; $600 \mathrm{~m}$.

SINAN PE: Sin registro.

Herbarios peruanos: Ninguno.

Observaciones: Especie descrita de una planta recolectada en 1923, en la cuenca del Pozuzo, hoy en Pasco, pero citada en Brako \& Zarucchi (1993) como de Huánuco. No ha sido posible evaluarla, ni asignarle una categoría.

\section{Piper restrictum Trel.}

Publicación: Field Mus. Nat. Hist., Bot. Ser. 13(2): 223. 1936.

Colección tipo: E.P. Killip \& A.C. Smith 26737

Herbarios: US.

Nombre común: Desconocido.

Registro departamental: JU.

Regiones Ecológicas: BHA; 340 m.

SINANPE: Sin registro.

Herbarios peruanos: Ninguno.

Observaciones: Este taxón fue considerado por Brako \& Zarucchi (1993) como un endemismo; sin embargo, no ha sido posible evaluarlo, ni asignarle una categoría.

\section{Piperreticulatum L. var. santarosanum Trel.}

Publicación: Field Mus. Nat. Hist., Bot. Ser. 13(2): 223. 1936.

Colección tipo: L. Williams 4793

Herbarios: $F$.

Nombre común: Desconocido.

Registro departamental: LO.

Regiones Ecológicas: BHA; 150- 210 m.

SINANPE: Sin registro.

Herbarios peruanos: Ninguno. 
Observaciones: Este taxón fue considerado por Brako \& Zarucchi (1993) como un endemismo; sin embargo, no ha sido posible evaluarlo, ni asignarle una categoría.

\section{Piper hinostachyum Trel.}

\section{DD}

Publicación: Field Mus. Nat. Hist., Bot. Ser. 13(2): 224. 1936.

Colección tipo: E.P. Killip \& A.C. Smith 23461

Hemarios: ILL, US.

Nombre común: D esconocido.

Registro departamental: JU.

Regiones Ecológicas: BMHP; altitud desconocida.

SINANPE: Sin registro.

Hembarios peruanos: Ninguno.

Observaciones: Arbusto conocido de la cuenca del Tulumayo y registrado sólo en 1929. Sedesconoceel estado actual desus poblaciones.

\section{Piperriojanum Trel.}

Publicación: Field Mus. Nat. Hist., Bot. Ser. 13(2): 224. 1936

Colección tipo: L. Williams 7600

Herbarios: $F$.

Nombre común: D esconocido.

Registro departamental: AM, HU, JU, SM. Regiones Ecológicas: BPM; 2700-3300 m.

SINANPE: Sin registro.

Herbarios peruanos: Ninguno.

Observaciones: Arbusto descrito de una planta recolectada en 1930, en la cuenca del Mayo. No ha sido posible evaluar esta especie, ni asignarle una categoría

\section{Piper roqueanum Trel.}

Publicación: Field Mus. Nat. Hist., Bot Ser. 13(2): 224. 1936.

Colección tipo: J. Schunke V. 5158

Herbarios: NY.

Nombre común: D esconocido.

Registro departamental: AM, HU, SM. Regiones Ecológicas: BMHP; $1350-$ $1500 \mathrm{~m}$.

SINAN PE: Sin registro.

Herbarios peruanos: Ninguno.

Observaciones: Este taxón fue considerado por Brako \& Zarucchi (1993) como un endemismo; sin embargo, no ha sido posible evaluarlo, ni asignarle una categoría.

\section{Piper rubiginosum Trel.}

\section{DD}

Publicación: Field Mus. Nat. Hist., Bot. Ser. 13(2): 224. 1936

Colección tipo: E.P. Killip \& A.C. Smith 26292

Herbarios: US.

Nombre común: D esconocido.

Registro departamental: PA.

Regiones Ecológicas: BHA; $400 \mathrm{~m}$.

SINANPE: Sin registro.

Herbarios peruanos: Ninguno.
Observaciones: Arbusto de sotobosque, descrita de una planta recolectada en 1929, en la cuenca del Pichis. Esta localidad era antes considerada en Junín, pero hoy es parte de Pasco. Se desconoce el estado actual de sus poblaciones.

\section{Piper rubribaccum Trel.}

Publicación: Field Mus. Nat. Hist., Bot. Ser. 13(2): 225. 1936.

Colección tipo: J.F. Macbride \& W. Featherstone 4565

Herbarios: $F$.

Nombre común: D esconocido.

Registro departamental: PA.

Regiones Ecológicas: BMHP; $600 \mathrm{~m}$.

SINAN PE: Sin registro.

Hemarios peruanos: Ninguno.

Observaciones: Especie arbustiva conocida solamente del ejemplar tipo, una planta recolectada en la cuenca del Pozuzo, hoy en Pasco y no Huánuco. No ha sido posible evaluarla, ni asignarle una categonía.

\section{Piperrugosibaccum Trel.}

Publicación: Field Mus. Nat. Hist., Bot. Ser. 13(2): 225. 1936.

Colección tipo: G. Klug 193

Herbarios: NY.

Nombre común: D esconocido.

Registro departamental: LO.

Regiones Ecológicas: BHA; altitud desconocida.

SINAN PE: Sin registro.

Herbarios peruanos: Ninguno.

Observaciones: Este taxón fue considerado por Brako \& Zarucchi (1993) como un endemismo; sin embargo, no ha sido posible evaluarlo, ni asignarle una categoría.

480. Piper rugosilimbum Trel.

DD

Publicación: Field Mus. Nat. Hist., Bot. Ser. 13(2): 225. 1936.

Colección tipo: G. Klug 193

Herbarios: US

Nombre común: D esconocido.

Registro departamental: LO.

Regiones Ecológicas: BHA; $100 \mathrm{~m}$.

SINAN PE: Sin registro.

Herbarios peruanos: Ninguno.

Observaciones: Arbusto reconocido por Quijano-Abril et al. (2006) como un endemismo, para un análisis biogeográfico del género. No ha vuelto a ser recolectado desde 1929. Se desconoce el estado actual de sus poblaciones.

\section{Piper sagittiferTrel.}

Publicación: Field Mus. Nat. Hist., Bot. Ser. 13(2): 226. 1936.

Colección tipo: L. Williams 1605

Hembarios: $F$.

Nombre común: D esconocido.

Registro departamental: LO, MD.

Regiones Ecológicas: BHA; altitud desconocida.

SINANPE: Sin registro.

Herbarios peruanos: Ninguno. 
Observaciones: Este taxón fue considerado por Brako \& Zarucchi (1993) como un endemismo; sin embargo, no ha sido posible evaluarlo, ni asignarle una categoría.

482. Pipersandianum C. DC.

Publicación: Bot. Jahrb. Syst. 40: 247. 1908.

Colección tipo: A. Weberbauer 727

Herbarios: B, G; MOL!.

Nombre común: D esconocido.

Registro departamental: PU.

Regiones Ecológicas: BMHM; $2400 \mathrm{~m}$.

SINANPE: Sin registro.

Herbarios peruanos: MOL (lectotipo).

Observaciones: Estetaxón fue considerado por Brako \& Zarucchi (1993) como un endemismo; sin embargo, no ha sido posible evaluarlo, ni asignarle una categoría.

483. Pipersangonianum C. DC.

Publicación: Candollea 1: 140. 1923.

Colección tipo: W. Lechler 2527

Hemarios: Sin datos.

Nombre común: D esconocido.

Registro departamental: LO, PU.

Regiones Ecológicas: Sin datos; altitud desconocida.

SINANPE: Sin registro.

Herbarios peruanos: Ninguno.

Observaciones: Estetaxón fue considerado por Brako \& Zarucchi (1993) como un endemismo; sin embargo, no ha sido posible evaluarlo, ni asignarle una categoría.

484. Pipersanguineispicum Trel.

\section{DD}

Publicación: Field Mus. Nat. Hist., Bot. Ser. 13(2): 226. 1936.

Colección tipo: E.P. Killip \& A.C. Smith 27135

Henbarios: US.

Nombre común: D esconocido.

Registro departamental: LO.

Regiones Ecológicas: BHA; $100 \mathrm{~m}$.

SINANPE: Sin registro.

Herbarios peruanos: Ninguno.

Observaciones: Árbol conocido sólo de la localidad original, en una subcuenca del Amazonas, registrado en 1929. Brako \& Zarucchi (1993) incluyeron esta especie en la sinonimia de Piper obliquum, pero Q uijano-Abril et al. (2006) la aceptan, criterio con el que concordamos. Se desconoce el estado actual de sus poblaciones.

\section{Piper sannicolasense Trel.}

\section{DD}

Publicación: Field Mus. Nat. Hist., Bot. Ser. 13(2): 227. 1936.

Colección tipo: E.P. Killip \& A.C. Smith 26009

Henbarios: US.

Nombre común: D esconocido.

Registro departamental: JU.

Regiones Ecológicas: BMHP; $1100 \mathrm{~m}$.

SINAN PE: Sin registro.

Herbarios peruanos: Ninguno.
Observaciones: Arbusto descrito de una planta recolectada en 1929, en el antiguo camino de arrieros entre las cuencas del Tulumayo y el Pichis. Trelease (1936) y Brako \& Zarucchi (1993) citaron erróneamente Loreto para referirse a la ubicación de la localidad tipo.

486. Pipersanramonense Trel.

Publicación: Field Mus. Nat. Hist., Bot. Ser. 13(2): 227. 1936.

Colección tipo: E.P. Killip \& A.C. Smith 24585

Herbarios: US.

Nombre común: D esconocido.

Registro departamental: JU.

Regiones Ecológicas: BMHM, BMHP; 1400- $1700 \mathrm{~m}$.

SINAN PE: Sin registro.

Herbarios peruanos: Ninguno.

Observaciones: Este taxón fue considerado por Brako \& Zarucchi (1993) como un endemismo; sin embargo, no ha sido posible evaluarlo, ni asignarle una categoría.

\section{Pipersanroqueanum Trel.}

Publicación: Field Mus. Nat. Hist., Bot. Ser. 13(2): 227. 1936.

Colección tipo: L. Williams 7402

Herbarios: US.

Nombre común: D esconocido.

Registro departamental: LO, SM.

Regiones Ecológicas: $\mathrm{BMHP}, \mathrm{BHA}$; $100-1500 \mathrm{~m}$.

SINAN PE: Sin registro.

Herbarios peruanos: Ninguno.

Observaciones: Este taxón fue considerado por Brako \& Zarucchi (1993) como un endemismo; sin embargo, no ha sido posible evaluarlo, ni asignarle una categoría.

488. Pipersantaritanum Trel.

Publicación: Field Mus. Nat. Hist., Bot. Ser. 13(2): 227. 1936.

Colección tipo: F. Herrera 1551

Hemarios: ILL.

Nombre común: D esconocido.

Registro departamental: CU.

Regiones Ecológicas: BMHM; 2300 m.

SINAN PE: Sin registro.

Herbarios peruanos: Ninguno.

Observaciones: Este taxón fue considerado por Brako \& Zarucchi (1993) como un endemismo; sin embargo, no ha sido posible evaluarlo, ni asignarle una categoría.

489. Pipersapotoanum Trel.

Publicación: Field Mus. Nat. Hist., Bot. Ser. 13(2): 228. 1936.

Colección tipo: L. Williams 4816

Herbarios: $F$.

Nombre común: Desconocido.

Registro departamental: LO.

Regiones Ecológicas: BHA; 160- $210 \mathrm{~m}$.

SINANPE: Sin registro.

Herbarios peruanos: Ninguno. 
Observaciones: Arbusto conocido sólo de la localidad tipo. No ha sido posible evaluar esta especie, ni asignarle una categoría.

\section{Pipersapotoyacuense Trel.}

Publicación: Field Mus. Nat. Hist., Bot. Ser. 13(2): 228. 1936.

Colección tipo: L. Williams 4923

Hembarios: $F$.

Nombre común: D esconocido.

Registro departamental: LO.

Regiones Ecológicas: BHA; 145- $210 \mathrm{~m}$.

SINANPE: Sin registro.

Herbarios peruanos: Ninguno.

Observaciones: Arbusto conocido sólo de la localidad tipo. No ha sido posible evaluar esta especie, ni asignarle una categoría.

\section{Pipersatisfactum Trel.}

Publicación: Field Mus. Nat. Hist., Bot. Ser. 13(2): 228. 1936

Colección tipo: E.P. Killip \& A.C. Smith 26245

Herbarios: US.

Nombre común: D esconocido.

Registro departamental: PA.

Regiones Ecológicas: BHA; $400 \mathrm{~m}$.

SINAN PE: Sin registro.

Hemarios peruanos: Ninguno.

Observaciones: Arbusto descrito de una planta procedente de la cuenca del Pichis en Pasco, pero citada en Brako \& Zarucchi (1993) como procedente de Junín. No ha sido posible evaluar esta especie, ni asignarle una categoría.

\section{Piper scabiosifolium Trel.}

Publicación: Field Mus. Nat. Hist., Bot. Ser. 13(2): 229. 1936.

Colección tipo: E.P. Killip \& A.C. Smith 27730

Herbarios: Sin datos.

Nombre común: D esconocido.

Registro departamental: LO.

Regiones Ecológicas: BHA; 135 m.

SINAN PE: Sin registro.

Herbarios peruanos: Ninguno.

Observaciones: Este taxón fue considerado por Brako \& Zarucchi (1993) como un endemismo; sin embargo, no ha sido posible evaluarlo, ni asignarle una categoría.

\section{Piper scabricaule Trel.}

\section{CR, B lab(iii)}

Publicación: Field Mus. Nat. Hist., Bot. Ser. 13(2): 233. 1936

Colección tipo: E.P. Killip \& A.C. Smith 25299

Herbarios: ILL, NY, US.

Nombre común: D esconocido.

Registro departamental: JU.

Regiones Ecológicas: BMHP; altitud desconocida.

SINANPE: Sin registro.

Herbarios peruanos: Ninguno.

Observaciones: Arbusto recolectado en 1929, de la cuenca del Paucartambo. Brako \& Zarucchi (1993) incluyeron esta especie en la sinonimia de Piper hispidum, pero Quijano-Abril et al. (2006) la aceptan, criterio con el que concordamos. Al igual que para otras especies en el valle del Chanchamayo, cambios en los ambientes naturales son motivo de preocupación.
494. Piperscabridulicaule Trel.

Publicación: Field Mus. Nat. Hist., Bot. Ser. 13(2): 229-230. 1936.

Colección tipo: Y. Mexia 6106

Hemarios: NY, UC.

Nombre común: D esconocido.

Registro departamental: AM.

Regiones Ecológicas: BHA; altitud desconocida.

SINANPE: Sin registro.

Hemarios peruanos: Ninguno.

Observaciones: Arbusto recolectado en 1931, dela desembocadura del Santiago, localizada en el departamento de Amazonas, muy cerca al límite con Loreto. No ha sido posible evaluar esta especie, ni asignarle una categoría.

\section{Piperscalariforme Trel.}

Publicación: Field Mus. Nat. Hist., Bot. Ser. 13(2): 230. 1936.

Colección tipo: L. Williams 2057

Henbarios: $F$.

Nombre común: D esconocido.

Registro departamental: LO.

Regiones Ecológicas: BHA; altitud desconocida.

SINAN PE: Sin registro.

Herbarios peruanos: Ninguno.

Observaciones: Este taxón fue considerado por Brako \& Zarucchi (1993) como un endemismo; sin embargo, no ha sido posible evaluarlo, ni asignarle una categoría.

\section{Piperscapispicum Trel.}

\section{DD}

Publicación: Field Mus. Nat. Hist., Bot. Ser. 13(2): 230. 1936.

Colección tipo: G. Klug 1420

Herbarios: US.

Nombre común: D esconocido.

Registro departamental: LO.

Regiones Ecológicas: BHA; $100 \mathrm{~m}$.

SINAN PE: Sin registro.

Herbarios peruanos: Ninguno.

Observaciones: Arbusto conocido sólo de una subcuenca del Amazonas, donde fue registrado en 1930. Brako \& Zarucchi (1993) incluyeron esta especie en la sinonimia de Piper pavonii; pero Q uijanoAbril et al. (2006) la aceptan, criterio que aquí se sigue. Se desconoce el estado actual de sus poblaciones.

\section{Piperschunkeanum Trel.}

Publicación: Field Mus. Nat. Hist., Bot. Ser. 13(2): 230. 1936.

Colección tipo: C.O. Schunke 275

Hembarios: $F$.

Nombre común: D esconocido.

Registro departamental: JU.

Regiones Ecológicas: BMHP; 1200 m.

SINAN PE: Sin registro.

Herbarios peruanos: Ninguno.

Observaciones: Este taxón fue considerado por Brako \& Zarucchi (1993) como un endemismo; sin embargo, no ha sido posible evaluarlo, ni asignarle una categoría. 
Publicación: Bot. Jahrb. Syst. 40: 242243. 1908.

Colección tipo: A. Weberbauer 3557

Herbarios: B, G; MOL!

Nombre común: Desconocido.

Registro departamental: $\mathrm{HU}$.

Regiones Ecológicas: BMHM; $1800 \mathrm{~m}$.

SINANPE: Sin registro.

Herbarios peruanos: MOL (lectotipo).

Observaciones: Este taxón fue considerado por Brako \& Zarucchi (1993) como un endemismo; sin embargo, no ha sido posible evaluarlo, ni asignarle una categoría.

\section{Pipersecundum Ruiz \& Pav.}

Publicación: Fl. Peruv. 1: 36-37, t. 62, f. b. 1798.

Colección tipo: H. Ruiz \& J. Pavón s.n.

Hemarios: Sin datos.

Nombre común: D esconocido.

Registro departamental: HU.

Regiones Ecológicas: Sin datos; altitud desconocida.

SINANPE: Sin registro.

Herbarios peruanos: Ninguno.

Observaciones: Este taxón fue considerado por Brako \& Zarucchi (1993) como un endemismo; sin embargo, no ha sido posible evaluarlo, ni asignarle una categoría.

\section{Piper sellertianum Trel. var. tenuiforme Trel.}

Publicación: Field Mus. Nat. Hist., Bot. Ser. 13(2): 232. 1936.

Colección tipo: E.F. Poeppig s.n.

Herbarios: W.

Nombre común: D esconocido.

Registro departamental: $\mathrm{HU}$.

Regiones Ecológicas: Sin datos; altitud desconocida.

SINAN PE: Sin registro.

Herbarios peruanos: Ninguno.

Observaciones: Estetaxón fue considerado por Brako \& Zarucchi (1993) como un endemismo; sin embargo, no ha sido posible evaluarlo, ni asignarle una categoría.

\section{Piper semicondulatum Trel.}

Publicación: Field Mus. Nat. Hist., Bot. Ser. 13(2): 232. 1936.

Colección tipo: C.O. Schunke 238

Herbarios: F.

Nombre común: D esconocido.

Registro departamental: JU.

Regiones Ecológicas: BHA; $1200 \mathrm{~m}$.

SINAN PE: Sin registro.

Herbarios peruanos: Ninguno.

Observaciones: Este taxón fue considerado por Brako \& Zarucchi (1993) como un endemismo; sin embargo, no ha sido posible evaluarlo, ni asignarle una categoría.
Publicación: Field Mus. Nat. Hist., Bot. Ser. 13(2): 232. 1936.

Colección tipo: E.P. Killip \& A.C. Smith 25344

Herbarios: US.

Nombre común: D esconocido.

Registro departamental: LO.

Regiones Ecológicas: BMHP; 350— $550 \mathrm{~m}$.

SINAN PE: Sin registro.

Herbarios peruanos: Ninguno.

Observaciones: Este taxón fue considerado por Brako \& Zarucchi (1993) como un endemismo; sin embargo, no ha sido posible evaluarlo, ni asignarle una categoría.

\section{Piper seminitidulum Trel.}

Publicación: Field Mus. Nat. Hist., Bot. Ser. 13(2): 232. 1936.

Colección tipo: J.F. Macbride \& W. Featherstone 5289

Hembarios: $F$.

Nombre común: D esconocido.

Registro departamental: JU.

Regiones Ecológicas: BMHP; $600 \mathrm{~m}$.

SINANPE: Sin registro.

Herbarios peruanos: Ninguno.

Observaciones: Este taxón fue considerado por Brako \& Zarucchi (1993) como un endemismo; sin embargo, no ha sido posible evaluarlo, ni asignarle una categoría.

\section{Piper seniceonervosum Trel.}

Publicación: Field Mus. Nat. Hist., Bot. Ser. 13(2): 233. 1936.

Colección tipo: L. Williams 2928

Henbarios: Sin datos.

Nombre común: D esconocido.

Registro departamental: LO.

Regiones Ecológicas: BHA; altitud desconocida.

SINAN PE: Sin registro.

Herbarios peruanos: Ninguno.

Observaciones: Este taxón fue considerado por Brako \& Zarucchi (1993) como un endemismo; sin embargo, no ha sido posible evaluarlo, ni asignarle una categoría.

\section{Piper serotinum Trel.}

\section{CR, B lab(iii)}

Publicación: Field Mus. Nat. Hist., Bot. Ser. 13(2): 233. 1936.

Colección tipo: E.P. Killip \& A.C. Smith 25344

Hembarios: ILL, NY, US.

Nombre común: D esconocido.

Registro departamental: JU.

Regiones Ecológicas: BMHP; $700 \mathrm{~m}$.

SINANPE: Sin registro.

Herbarios peruanos: Ninguno.

Observaciones: Arbusto conocido sólo de la cuenca del Paucartambo, dondefueregistrado en 1929. Q uijano-Abril etal. (2006) la reconocieron como un endemismo. Al igual que para otras especies en la cuenca, cambios en los ambientes boscosos son motivo de preocupación. 
506. Piper semulatum Yunck.

Publicación: Svensk Bot. Tidskr. 51(3):

535. 1957.

Colección tipo: Y. Mexia 8151

Herbarios: S, UC, US.

Nombre común: D esconocido.

Registro departamental: HU.

Regiones Ecológicas: BMHM; 2000 m.

SINANPE: Sin registro.

Herbarios peruanos: Ninguno.

Observaciones: Este taxón fue considerado por Brako \& Zarucchi (1993) como un endemismo; sin embargo, no ha sido posible evaluarlo, ni asignarle una categoría.

\section{Piper setigerum Trel.}

Publicación: Field Mus. Nat. Hist., Bot. Ser. 13(2): 234. 1936.

Colección tipo: E.P. Killip \& A.C. Smith 26510

Hembarios: US.

Nombre común: D esconocido.

Registro departamental: PA.

Regiones Ecológicas: BHA; 375 m.

SINANPE: Sin registro.

Herbarios peruanos: Ninguno.

Observaciones: Esta especie arbustiva fue descrita de una planta recolectada en 1929, de la cuenca del Pichis en el departamento de Pasco. Brako \& Zarucchi (1993) erróneamente la registraron como de Junín. No ha sido posible evaluarla, ni asignarle una categoría.

\section{Piper setulosum Trel.}

Publicación: Field Mus. Nat. Hist., Bot. Ser. 13(2): 234. 1936

Colección tipo: E.P. Killip \& A.C. Smith 27568

Herbarios:

Nombre común: D esconocido.

Registro departamental: LO.

Regiones Ecológicas: BHA; $135 \mathrm{~m}$.

SINAN PE: Sin registro.

Herbarios peruanos: Ninguno.

Observaciones: Arbusto descrito de una planta recolectada en la cuenca del Huallaga. No ha sido posible evaluar esta especie, ni asignarle una categoría.

\section{Piper sidipilum Trel.}

\section{CR, B lab(iii)}

Publicación: Field Mus. Nat. Hist., Bot. Ser. 13(2): 234. 1936

Colección tipo: E.P. Killip \& A.C. Smith 25160

Hembarios: ILL, NY, US.

Nombre común: D esconocido.

Registro departamental: JU.

Regiones Ecológicas: BMHP; $600 \mathrm{~m}$.

SINANPE: Sin registro.

Hemarios peruanos: Ninguno.

Observaciones: Arbusto conocido sólo de la cuenca del Paucartambo, donde fue registrado en 1929. Brako \& Zarucchi (1993) incluyeron esta especie en la sinonimia de Piper hispidum, pero Q uijano-Abril et al. (2006) la aceptan, con lo que concordamos. Aligual que para otras especies en la cuenca, cambios en los ambientes boscosos son motivo de preocupación.
510. Pipersinuclausum Trel.

Publicación: Field Mus. Nat. Hist., Bot. Ser. 13(2): 235. 1936.

Colección tipo: J.F. Macbride \& W. Featherstone 3564

Hemanios: $F$.

Nombre común: Matico.

Registro departamental: AM, CU, HU.

Regiones Ecológicas: BMHM; 2100$2400 \mathrm{~m}$.

SINAN PE: SHMP

Herbarios peruanos: Ninguno.

Observaciones: Este taxón fue considerado por Brako \& Zarucchi (1993) como un endemismo; sin embargo, no ha sido posible evaluarlo, ni asignarle una categoría.

511. Pipersoledadense Trel. var. angustum Trel.

Publicación: Field Mus. Nat. Hist., Bot. Ser. 13(2): 236. 1936.

Colección tipo: E.P. Killip \& A.C. Smith 29350

Henbarios: US.

Nombre común: D esconocido.

Registro departamental: LO.

Regiones Ecológicas: BHA; $110 \mathrm{~m}$.

SINANPE: Sin registro.

Herbarios peruanos: Ninguno.

Observaciones: Este taxón fue considerado por Brako \& Zarucchi (1993) como un endemismo; sin embargo, no ha sido posible evaluarlo, ni asignarle una categoría.

512. Piper sononium (Miq.) C. DC.

Publicación: Prodr. 16(1): 295. 1869.

Colección tipo: H. Ruiz \& J. Pavón s.n.

Herbarios: MA.

Nombre común: D esconocido.

Registro departamental: $\mathrm{HU}, \mathrm{LO}, \mathrm{SM}$.

Regiones Ecológicas: $\mathrm{BMHP}, \mathrm{BHA}$; 400- $900 \mathrm{~m}$.

SINANPE: Sin registro.

Herbarios peruanos: Ninguno.

Observaciones: Este taxón fue considerado por Brako \& Zarucchi (1993) como un endemismo; sin embargo, no ha sido posible evaluarlo, ni asignarle una categoría.

513. Piperspruceanum C. DC.

Publicación: J. Bot. 4: 216. 1866.

Colección tipo: R. Spruce 4072

Herbarios: $\mathrm{K}$.

Nombre común: D esconocido.

Registro departamental: SM.

Regiones Ecológicas: Sin datos; altitud desconocida.

SINAN PE: Sin registro.

Herbarios peruanos: Ninguno.

Observaciones: Este taxón fue considerado por Brako \& Zarucchi (1993) como un endemismo; sin embargo, no ha sido posible evaluarlo, ni asignarle una categoría. 
Publicación: Annuaire Conserv. Jard. Bot. Geneve 2: 254. 1898.

Colección tipo: C. G ay s.n.

Herbarios: Sin datos.

Nombre común: D esconocido.

Registro departamental: Sin datos.

Regiones Ecológicas: Sin datos; altitud desconocida.

SINAN PE: Sin registro.

Herbarios peruanos: Ninguno.

Observaciones: Estetaxón fue considerado por Brako \& Zarucchi (1993) como un endemismo; sin embargo, no ha sido posible evaluarlo, ni asignarle una categoría.

\section{Piperstevensii Trel.}

Publicación: Field Mus. Nat. Hist., Bot. Ser. 13(2): 237. 1936.

Colección tipo: F.L. Stevens 85

Herbarios: ILL.

Nombre común: D esconocido.

Registro departamental: JU.

Regiones Ecológicas: Sin datos; altitud desconocida.

SINAN PE: Sin registro.

Herbarios peruanos: Ninguno.

Observaciones: Este taxón fue considerado por Brako \& Zarucchi (1993) como un endemismo; sin embargo, no ha sido posible evaluarlo, ni asignarle una categoría.

\section{Piperstomachicum C. DC.}

Publicación: Bot. Jahrb. Syst. 40: 250. 1908.

Colección tipo: A. Weberbauer 3028

Hemarios: B, G; MOL!.

Nombre común: Desconocido.

Registro departamental: AM, AN.

Regiones Ecológicas: MDE; $2200 \mathrm{~m}$.

SINAN PE: Sin registro.

Herbarios penuanos: MOL (lectotipo).

Observaciones: Estetaxón fue considerado por Brako \& Zarucchi (1993) como un endemismo; sin embargo, no ha sido posible evaluarlo, ni asignarle una categoría.

\section{Piper strigillosicaule Trel.}

Publicación: Field Mus. Nat. Hist., Bot. Ser. 13(2): 237. 1936.

Colección tipo: E.P. Killip \& A.C. Smith 27615

Herbarios: US.

Nombre común: D esconocido.

Registro departamental: LO.

Regiones Ecológicas: BHA; $135 \mathrm{~m}$.

SINAN PE: Sin registro.

Herbarios peruanos: Ninguno.

Observaciones: Arbusto conocido del occidente de la Amazonía peruana, en la cuenca del Huallaga. No ha sido posible evaluar esta especie, ni asignarle una categoría.
Publicación: Field Mus. Nat. Hist., Bot. Ser. 13(2): 238. 1936.

Colección tipo: E.P. Killip \& A.C. Smith 27813

Herbarios: US.

Nombre común: D esconocido.

Registro departamental: LO.

Regiones Ecológicas: BHA; 135 m.

SINAN PE: Sin registro.

Herbarios peruanos: Ninguno.

Observaciones: Este taxón fue considerado por Brako \& Zarucchi (1993) como un endemismo; sin embargo, no ha sido posible evaluarlo, ni asignarle una categoría.

\section{Piper stuebelii Trel.}

Publicación: Field Mus. Nat. Hist., Bot. Ser. 13(2): 238. 1936.

Colección tipo: Stuebel 68

Hemarios: B.

Nombre común: D esconocido.

Registro departamental: LO, SM.

Regiones Ecológicas: BHA; altitud desconocida.

SINAN PE: Sin registro.

Herbarios peruanos: Ninguno.

Observaciones: Estetaxón fue considerado por Brako \& Zarucchi (1993) como un endemismo; sin embargo, no ha sido posible evaluarlo, ni asignarle una categoría.

\section{Piperstupposum A. Dietr.}

Publicación: Sp. Pl. 1: 645. 1831.

Colección tipo: T. Haenke s.n.

Hemarios: Sin datos.

Nombre común: Desconocido.

Registro departamental: Sin datos.

Regiones Ecológicas: Sin datos; altitud desconocida.

SINAN PE: Sin registro.

Herbarios peruanos: Ninguno.

Observaciones: Este taxón fue considerado por Brako \& Zarucchi (1993) como un endemismo; sin embargo, no ha sido posible evaluarlo, ni asignarle una categoría.

\section{Pipersubandina Trel.}

Publicación: Field Mus. Nat. Hist., Bot. Ser. 13(2): 98. 1936.

Colección tipo: E.P. Killip \& A.C. Smith 26218

Herbarios: Sin datos.

Nombre común: D esconocido.

Registro departamental: JU.

Regiones Ecológicas: Sin datos; altitud desconocida.

SINANPE: Sin registro.

Herbarios peruanos: Ninguno.

Observaciones: Este taxón fue considerado por Brako \& Zarucchi (1993) como un endemismo; sin embargo, no ha sido posible evaluarlo, ni asignarle una categoría. 
522. Pipersubandinum C. DC.

Publicación: Prodr. 16(1): 275. 1869.

Colección tipo: E.F. Poeppig s.n.

Herbarios: US.

Nombre común: D esconocido.

Registro departamental: HU.

Regiones Ecológicas: Sin datos; altitud desconocida.

SINANPE: Sin registro.

Hemarios peruanos: Ninguno.

Observaciones: Este taxón fue considerado por Brako \& Zarucchi (1993) como un endemismo; sin embargo, no ha sido posible evaluarlo, ni asignarle una categoría.

\section{Piper subcondulatum Trel.}

Publicación: Field Mus. Nat. Hist., Bot Ser. 13(2): 239. 1936.

Colección tipo: E.P. Killip \& A.C. Smith 29794

Herbarios: US.

Nombre común: D esconocido.

Registro departamental: LO.

Regiones Ecológicas: BHA; $110 \mathrm{~m}$.

SINAN PE: Sin registro.

Hemarios peruanos: Ninguno.

Observaciones: Este taxón fue considerado por Brako \& Zarucchi (1993) como un endemismo; sin embargo, no ha sido posible evaluarlo, ni asignarle una categoría.

\section{Piper subflavicans Trel.}

Publicación: Field Mus. Nat. Hist., Bot. Ser. 13(2): 239. 1936.

Colección tipo: T. Haenke s.n.

Herbarios: $M$.

Nombre común: D esconocido.

Registro departamental: Sin datos.

Regiones Ecológicas: Sin datos; altitud desconocida.

SINANPE: Sin registro.

Herbarios peruanos: Ninguno.

Observaciones: Arbusto recolectado en el siglo XVIII. No ha sido posible evaluarlo, ni asignarle una categoría.

\section{Pipersubpatens Trel.}

Publicación: Field Mus. Nat. Hist., Bot. Ser. 13(2): 240. 1936.

Colección tipo: J.F. Macbride \& W. Featherstone 4633

Herbarios:

Nombre común: D esconocido.

Registro departamental: PA.

Regiones Ecológicas: BMHP; $600 \mathrm{~m}$.

SINAN PE: Sin registro.

Herbarios peruanos: Ninguno.

Observaciones: Arbusto conocido de la cuenca del Pozuzo, hoy en el D epartamento de Pasco, pero citada en Brako \& Zarucchi (1993) como de Huánuco. No ha sido posible evaluar esta especie, ni asignarle una categoría.
526. Pipersuffruticosum Trel.

Publicación: Field Mus. Nat. Hist., Bot. Ser. 13(2): 241. 1936.

Colección tipo: E.P. Killip \& A.C. Smith 26586

Herbarios: US

Nombre común: D esconocido.

Registro departamental: PA.

Regiones Ecológicas: BHA; 375 m.

SINANPE: Sin registro.

Herbarios peruanos: Ninguno.

Observaciones: Arbusto conocido de la cuenca del Pichis y citada para el departamento de Junín por Trelease (1936) y Brako \& Zarucchi (1993), pero, hoy reconocida en Pasco. No ha sido posible evaluar esta especie, ni asignarle una categoría.

\section{Pipersumpi Trel.}

Publicación: Field Mus. Nat. Hist., Bot. Ser. 13(2): 241. 1936

Colección tipo: O.F. Cook \& G.B. Gilbert 967

Henbarios: US.

Nombre común: Sumpi.

Registro departamental: CU.

Regiones Ecológicas: BMHM; $2340 \mathrm{~m}$.

SINANPE: Sin registro.

Herbarios peruanos: Ninguno.

Observaciones: Este taxón fue considerado por Brako \& Zarucchi (1993) como un endemismo; sin embargo, no ha sido posible evaluarlo, ni asignarle una categoría.

528. Pipertabinense Trel.

Publicación: Field Mus. Nat. Hist., Bot. Ser. 13(2): 242. 1936.

Colección tipo: W. Lechler 2081

Herbarios: Sin datos.

Nombre común: D esconocido.

Registro departamental: PU.

Regiones Ecológicas: Sin datos; altitud desconocida.

SINANPE: Sin registro.

Herbarios peruanos: Ninguno.

Observaciones: Este taxón fue considerado por Brako \& Zarucchi (1993) como un endemismo; sin embargo, no ha sido posible evaluarlo, ni asignarle una categoría.

\section{Pipertardum Trel.}

\section{CR, Blab(iii)}

Publicación: Field Mus. Nat. Hist., Bot. Ser. 13(2): 242. 1936.

Colección tipo: E.P. Killip \& A.C. Smith 25025

Hemarios: ILL, NY, US.

Nombre común: D esconocido.

Registro departamental: JU.

Regiones Ecológicas: BMHP; $680 \mathrm{~m}$.

SINAN PE: Sin registro.

Herbarios peruanos: Ninguno. 
Observaciones: Arbusto conocido sólo de la cuenca del Paucartambo, donde fue registrado en 1929. Brako \& Zarucchi (1993) incluyeron esta especie en la sinonimia de Piper hispidum; pero Q uijano-Abril et al. (2006) la aceptan, con lo que concordamos. Aligual que para otras especies en la cuenca, cambios en los ambientes boscosos son motivo de preocupación.

\section{Pipertemptum Trel.}

Publicación: Field Mus. Nat. Hist., Bot. Ser. 13(2): 242. 1936.

Colección tipo: A. Mathews 1713

Herbarios: $\mathrm{K}$.

Nombre común: D esconocido.

Registro departamental: Sin datos.

Regiones Ecológicas: Sin datos; altitud desconocida.

SINANPE: Sin registro.

Herbarios peruanos: Ninguno.

Observaciones: Este taxón fue considerado por Brako \& Zarucchi (1993) como un endemismo; sin embargo, no ha sido posible evaluarlo, ni asignarle una categoría.

\section{Pipertenebricosum Trel.}

Publicación: Field Mus. Nat. Hist., Bot. Ser. 13(2): 242. 1936.

Colección tipo: L. Williams 4201

Herbarios: $F$.

Nombre común: Cordoncillo.

Registro departamental: LO.

Regiones Ecológicas: $\mathrm{BHA}$; altitud desconocida.

SINANPE: Sin registro.

Herbarios peruanos: Ninguno.

Observaciones: Este taxón fue considerado por Brako \& Zarucchi (1993) como un endemismo; sin embargo, no ha sido posible evaluarlo, ni asignarle una categoría.

\section{Pipertenuicuspe (Miq.) C. DC. var. tenuiscupe}

\author{
Publicación: \\ Colección tipo: A. Mathews 1704 \\ Herbarios: $\mathrm{K}$. \\ Nombre común: D esconocido. \\ Registro departamental: LO. \\ Regiones Ecológicas: BHA; altitud \\ desconocida. \\ SINANPE: Sin registro. \\ Herbarios peruanos: Ninguno.
}

Observaciones: Este taxón fue considerado por Brako \& Zarucchi (1993) como un endemismo; sin embargo, no ha sido posible evaluarlo, ni asignarle una categoría.

\section{Pipertenuicuspe(Miq.)C.DC.var. nervosiusTrel.}

Publicación: Field Mus. Nat. Hist., Bot. Ser. 13(2): 243. 1936.

Colección tipo: E.F. Poeppig 1463

Herbarios: Sin datos.

Nombre común: D esconocido.

Registro departamental: HU.

Regiones Ecológicas: Sin datos; altitud desconocida.

SINANPE: Sin registro.

Herbarios peruanos: Ninguno.
Observaciones: Este taxón fue considerado por Brako \& Zarucchi (1993) como un endemismo; sin embargo, no ha sido posible evaluarlo, ni asignarle una categoría.

\section{Pipertessmanni Trel.}

Publicación: Field Mus. Nat. Hist., Bot. Ser. 13(2): 243. 1936.

Colección tipo: G. Tessmann 4197

Herbarios: Sin datos.

Nombre común: D esconocido.

Registro departamental: AM.

Regiones Ecológicas: BHA; altitud desconocida.

SINANPE: Sin registro.

Herbarios peruanos: Ninguno.

Observaciones: Este taxón fue considerado por Brako \& Zarucchi (1993) como un endemismo; sin embargo, no ha sido posible evaluarlo, ni asignarle una categoría.

\section{Pipertimbuchianum Trel.}

Publicación: Field Mus. Nat. Hist., Bot. Ser. 13(2): 243-144. 1936.

Colección tipo: L. Williams 1036

Herbarios: F.

Nombre común: D esconocido.

Registro departamental: LO.

Regiones Ecológicas: BHA; altitud desconocida.

SINAN PE: Sin registro.

Herbarios peruanos: Ninguno.

Observaciones: Este taxón fue considerado por Brako \& Zarucchi (1993) como un endemismo; sin embargo, no ha sido posible evaluarlo, ni asignarle una categoría.

536. Pipertocacheanum C. DC.

Publicación: Prodr. 16(1):264. 1869.

Colección tipo: E.F. Poeppig 1918

Herbarios: $B$.

Nombre común: D esconocido.

Registro departamental: HU, SM.

Regiones Ecológicas: BHA; altitud desconocida.

SINANPE: Sin registro.

Herbarios peruanos: Ninguno.

Observaciones: Este taxón fue considerado por Brako \& Zarucchi (1993) como un endemismo; sin embargo, no ha sido posible evaluarlo, ni asignarle una categoría.

\section{Piper tortuosivenosum Trel.}

Publicación: Field Mus. Nat. Hist., Bot. Ser. 13(2): 244. 1936.

Colección tipo: Y. Mexia 6199

Herbarios: UC.

Nombre común: D esconocido.

Registro departamental: AM.

Regiones Ecológicas: BHA; $210 \mathrm{~m}$.

SINAN PE: Sin registro.

Hemarios peruanos: Ninguno. 
Observaciones: Este taxón fue considerado por Brako \& Zarucchi (1993) como un endemismo; sin embargo, no ha sido posible evaluarlo, ni asignarle una categoría.

\section{Pipertranspontinum Trel. var. transpontinum}

Publicación:

Colección tipo: E.P. Killip \& A.C. Smith 25352

Herbarios: US.

Nombre común: D esconocido.

Registro departamental: JU.

Regiones Ecológicas: BMHP; $700 \mathrm{~m}$.

SINAN PE: Sin registro.

Herbarios peruanos: Ninguno.

Observaciones: Este taxón fue considerado por Brako \& Zarucchi (1993) como un endemismo; sin embargo, no ha sido posible evaluarlo, ni asignarle una categoría.

539. Piper transpontinum Trel. var. econdulatum Trel.

Publicación: Field Mus. Nat. Hist., Bot. Ser. 13(2): 245. 1936.

Colección tipo: E.P. Killip \& A.C. Smith 25055

Herbarios: US,

Nombre común: D esconocido.

Registro departamental: JU.

Regiones Ecológicas: BMHP; $680 \mathrm{~m}$.

SINANPE: Sin registro.

Herbarios peruanos: Ninguno.

Observaciones: Este taxón fue considerado por Brako \& Zarucchi (1993) como un endemismo; sin embargo, no ha sido posible evaluarlo, ni asignarle una categoría.

\section{Piper trichostylopse Trel. var. trichostylopse}

Publicación:

Colección tipo: J.F. Macbride 4646

Hembarios: F.

Nombre común: D esconocido.

Registro departamental: PA.

Regiones Ecológicas: BMHP; $600 \mathrm{~m}$.

SINANPE: Sin registro.

Hemarios peruanos: Ninguno.

Observaciones: No ha sido posible evaluar este taxón, ni asignarle una categoría. La localidad original fue citada para el departamento de Huánuco por Trelease (1936) y Brako \& Zarucchi (1993), pero en realidad se halla hoy ubicada en Pasco.

\section{Pipertrichostylopse Trel. var. latum Trel.}

Publicación: Field Mus. Nat. Hist., Bot. Ser. 13(2): 245. 1936.

Colección tipo: J.F. Macbride 4849

Herbarios: $F$.

Nombre común: D esconocido.

Registro departamental: HU, JU.

Regiones Ecológicas: MA; $1500 \mathrm{~m}$.

SINANPE: Sin registro.

Herbarios peruanos: Ninguno.
Observaciones: Este taxón fue considerado por Brako \& Zarucchi (1993) como un endemismo; sin embargo, no ha sido posible evaluarlo, ni asignarle una categoría.

542. Piper trichostylum C. DC.

\section{DD}

Publicación: Bot. Jahrb. Syst. 40: 244. 1908.

Colección tipo: A. Weberbauer 728

Hemarios: B, G; MOL!

Nombre común: D esconocido.

Registro departamental: CA, PU, SM.

Regiones Ecológicas: BMHM; 1900$3000 \mathrm{~m}$.

SINAN PE: PNC

Henbarios penuanos: MOL (lectotipo).

Observaciones: Arbusto conocido de poblaciones dispersas, en las cuencas del Mayo, Llaucano y Huari Huari. Esta especie fue descrita de una planta recolectada en Puno. Se desconoce el estado actual de sus poblaciones.

\section{Pipertristigmum Trel.}

\section{DD}

Publicación: Field Mus. Nat. Hist., Bot. Ser. 13(2): 246. 1936.

Colección tipo: L. Williams 2029

Henbarios: $F$.

Nombre común: D esconocido.

Registro departamental: $\mathrm{LO}$.

Regiones Ecológicas: BHA; altitud desconocida.

SINAN PE: Sin registro.

Herbarios peruanos: Ninguno.

Observaciones: Arbusto conocido de una localidad en la cuenca del Amazonas, muy cerca al límite con Colombia. Se desconoce el estado actual de sus poblaciones.

\section{Piper ucayalianum Trel.}

Publicación: Field Mus. Nat. Hist., Bot. Ser. 13(2): 247. 1936.

Colección tipo: G. Tessmann 3011

Henbarios: S.

Nombre común: D esconocido.

Registro departamental: LO

Regiones Ecológicas: BHA; altitud desconocida.

SINAN PE: Sin registro.

Herbarios peruanos: Ninguno.

Observaciones: Arbusto recolectado en la cuenca del Ucayali, en 1923. No ha sido posible evaluar esta especie, ni asignarle una categońa.

\section{Piperulceratum Trel. var. ulceratum}

Publicación:

Colección tipo: L. Williams 6962

Hemarios: $F$.

Nombre común: D esconocido.

Registro departamental: SM.

Regiones Ecológicas: BMHP; 1350-

$1500 \mathrm{~m}$

SINANPE: Sin registro.

Herbarios peruanos: Ninguno. 
Observaciones: Este taxón fue considerado por Brako \& Zarucchi (1993) como un endemismo; sin embargo, no ha sido posible evaluarlo, ni asignarle una categoría.

546. Piper ulceratum Trel. var. angustifolium Trel.

Publicación: Field Mus. Nat. Hist., Bot. Ser. 13(2): 248. 1936.

Colección tipo: L. Williams 6982

Herbarios: $F$.

Nombre común: D esconocido.

Registro departamental: SM.

Regiones Ecológicas: BMHP; 1350$1500 \mathrm{~m}$.

SINAN PE: Sin registro.

Herbarios peruanos: Ninguno.

Observaciones: Este taxón fue considerado por Brako \& Zarucchi (1993) como un endemismo; sin embargo, no ha sido posible evaluarlo, ni asignarle una categoría.

\section{Piper unguiculatum Ruiz \& Pav.}

Publicación: Fl. Peruv. 1: 34- 35, t. 57, f. b. 1798.

Colección tipo: H. Ruiz \& J. Pavón s.n.

Herbarios: Sin datos.

Nombre común: D esconocido.

Registro departamental: HU, PA.

Regiones Ecológicas: BMHP; altitud desconocida.

SINANPE: Sin registro.

Herbarios peruanos: Ninguno.

Observaciones: Este taxón fue considerado por Brako \& Zarucchi (1993) como un endemismo; sin embargo, no ha sido posible evaluarlo, ni asignarle una categoría.

\section{Piperurubambanum Trel.}

Publicación: Field Mus. Nat. Hist., Bot. Ser. 13(2): 249. 1936.

Colección tipo: O.F. Cook \& G.B. Gilbert 1122 Herbarios: US.

Nombre común: D esconocido.

Registro departamental: CU.

Regiones Ecológicas: BMHM; $1800 \mathrm{~m}$.

SINAN PE: Sin registro.

Herbarios peruanos: Ninguno.

Observaciones: Este taxón fue considerado por Brako \& Zarucchi (1993) como un endemismo; sin embargo, no ha sido posible evaluarlo, ni asignarle una categoría.

\section{Piper velutininervosum Trel.}

Publicación: Field Mus. Nat. Hist., Bot. Ser. 13(2): 249. 1936

Colección tipo: E.P. Killip \& A.C. Smith 24006

Herbarios: US.

Nombre común: D esconocido.

Registro departamental: JU.

Regiones Ecológicas: BMHP; 800 - $1300 \mathrm{~m}$.

SINAN PE: Sin registro.

Herbarios peruanos: Ninguno.
Observaciones: Este taxón fue considerado por Brako \& Zarucchi (1993) como un endemismo; sin embargo, no ha sido posible evaluarlo, ni asignarle una categoría.

\section{Pipervelutinum Kunth}

Publicación: Nov. Gen. Sp. 1: 52. [1816]. 1815. Colección tipo: A. Humboldt 667

Herbarios: B, P.

Nombre común: D esconocido.

Registro departamental: CA, PI.

Regiones Ecológicas: Sin datos; 700$1100 \mathrm{~h}$.

SINAN PE: Sin registro.

Herbarios peruanos: Ninguno.

Observaciones: Este taxón fue considerado por Brako \& Zarucchi (1993) como un endemismo; sin embargo, no ha sido posible evaluarlo, ni asignarle una categoría.

\section{Piperveredianum Trel.}

\section{DD}

Publicación: Field Mus. Nat. Hist., Bot. Ser. 13(2): 250. 1936.

Colección tipo: L. Williams 2106

Herbarios: $F$.

Nombre común: Cordoncillo.

Registro departamental: LO.

Regiones Ecológicas: BHA; altitud desconocida

SINANPE: Sin registro.

Herbanios peruanos: Ninguno.

Observaciones: Arbusto conocido de una localidad en la cuenca del Amazonas, muy cerca al límite con Colombia. Se desconoce el estado actual de sus poblaciones.

\section{Piperverruculaecaule Trel.}

Publicación: Field Mus. Nat. Hist., Bot. Ser. 13(2): 250. 1936.

Colección tipo: E.P. Killip \& A.C. Smith 23025

Herbarios: US.

Nombre común: D esconocido.

Registro departamental: AY.

Regiones Ecológicas: BHA; 400 m.

SINAN PE: Sin registro.

Hemarios peruanos: Ninguno.

Observaciones: Arbusto recolectado en 1929, en la cuenca del A purímac. No ha sido posible evaluar esta especie, ni asignarle una categoría.

\section{Piperverruculaefolium Trel.}

Publicación: Field Mus. Nat. Hist., Bot. Ser. 13(2): 250-251. 1936.

Colección tipo: E.P. Killip \& A.C. Smith 24089

Hembarios: US.

Nombre común: D esconocido.

Registro departamental: JU.

Regiones Ecológicas: BMHP; $700 \mathrm{~m}$.

SINANPE: Sin registro.

Herbarios peruanos: Ninguno. 
Observaciones: Este taxón fue considerado por Brako \& Zarucchi (1993) como un endemismo; sin embargo, no ha sido posible evaluarlo, ni asignarle una categońa.

\section{Pipervillosispicum Trel}

\section{EN, Blab(iii)}

Publicación: Field Mus. Nat. Hist., Bot. Ser. 13(2): 251. 1936.

Colección tipo: E.P. Killip \& A.C. Smith 26178

Hemanios: US.

Nombre común: Desconocido.

Registro departamental: JU.

Regiones Ecológicas: BMHP; 625-900 m.

SINANPE: Sin registro.

Hemarios peruanos: Ninguno.

Observaciones: Árbol conocido depoblaciones dispersas en las cuencas del Mayo y Tulumayo. Al parecer, no ha vuelto a ser recolectada en la última cuenca desde 1929. Quijano-Abril et al. (2006) la reconocieron como un endemismo, paraun análisis biogeogáfico del género. Amenazas a sus poblaciones provienen de la deforestación.

\section{Pipervinidilimbum Trel.}

Publicación: Field Mus. Nat. Hist., Bot. Ser. 13(2): 251. 1936. 1936

Colección tipo: E.P. Killip \& A.C. Smith 22990

Henbarios: US

Nombre común: Desconocido.

Registro departamental: AY.

Regiones Ecológicas: BHA; $400 \mathrm{~m}$.

SINANPE: Sin registro.

Herbarios penuanos: Ninguno.

Observaciones: Este taxón fue considerado por Brako \& Zarucchi (1993) como un endemismo; sin embargo, no ha sido posible evaluarlo, ni asignarle una categoná

556. PipervolubileC.DC.

DD

Publicación: Bot. Jahrb. Syst. 40: 245. 1908.

Colección tipo: A. Weberbauer 3444

Hemarios: B; MOL!

Nombre común: Desconocido

Registro departamental: $\mathrm{HU}$.

Regiones Ecológicas: BMHP; 900— 1000 m.

SINANPE: Sin registro.

Hemanios penuanos: MOL (lectotipo).

Observaciones: Arbusto recolectado en 1903, delacuencadel Monzón Esta cuenca debenía ser de interés para estudios botánicos y esfuerzos de conservación biológica, pues incluye varios otros endemismos y ha sido escasamente herborizada. Se desconoce el estado de sus poblaciones.

\section{Piper woytkowskii Yunck.}

\section{DD}

Publicación: Brittonia 13(1): 60, f. 3 1961.

Colección tipo: F. Woytkowski 1455

Herbarios: DPU, NY; MOL!

Nombre común: D esconocido.

Registro departamental: LO.

Regiones Ecológicas: BMHM; 1500 m.

SINANPE: Sin registro.

Hemarios penuanos: MOL (isotipo).

Observaciones: Arbusto conocido, al parecer sólo de una localidad, la que probablemente se encuentre en el recientemente creado Parque Nacional Cordillera Azul. Se desconoce el estado actual de sus poblaciones.
558. Piperyananoanum Trel.

Publicación: Field Mus. Nat. Hist., Bot. Ser. 13(2): 252. 1936.

Colección tipo: J.F. Macbride 3796

Herbarios: $F$.

Nombre común: D esconocido.

Registro departamental: HU.

Regiones Ecológicas: BMHM; $1800 \mathrm{~m}$.

SINANPE: Sin registro.

Herbarios peruanos: Ninguno.

Observaciones: Este taxón fue considerado por Brako \& Zarucchi (1993) como un endemismo; sin embargo, no ha sido posible evaluarlo, ni asignarle una categoría.

\section{Piperyessupianum Trel.}

\section{DD}

Publicación: Field Mus. Nat. Hist., Bot. Ser. 13(2): 252-253. 1936

Colección tipo: E.P. Killip \& A.C. Smith 26373

Herbarios: US

Nombre común: D esconocido.

Registro departamental: PA.

Regiones Ecológicas: BHA; $400 \mathrm{~m}$.

SINANPE: Sin registro.

Herbarios peruanos: Ninguno.

Observaciones: Arbusto registrado en 1929, de la cuenca del Pichis, en una localidad considerada en el departamento de Junín por Trelease (1936) y Brako \& Zarucchi (1993), pero que se reconoce hoy en Pasco. Se desconoce el estado actual de sus poblaciones. 
Mapa del Perú indicando las abreviaturas de los departamentos

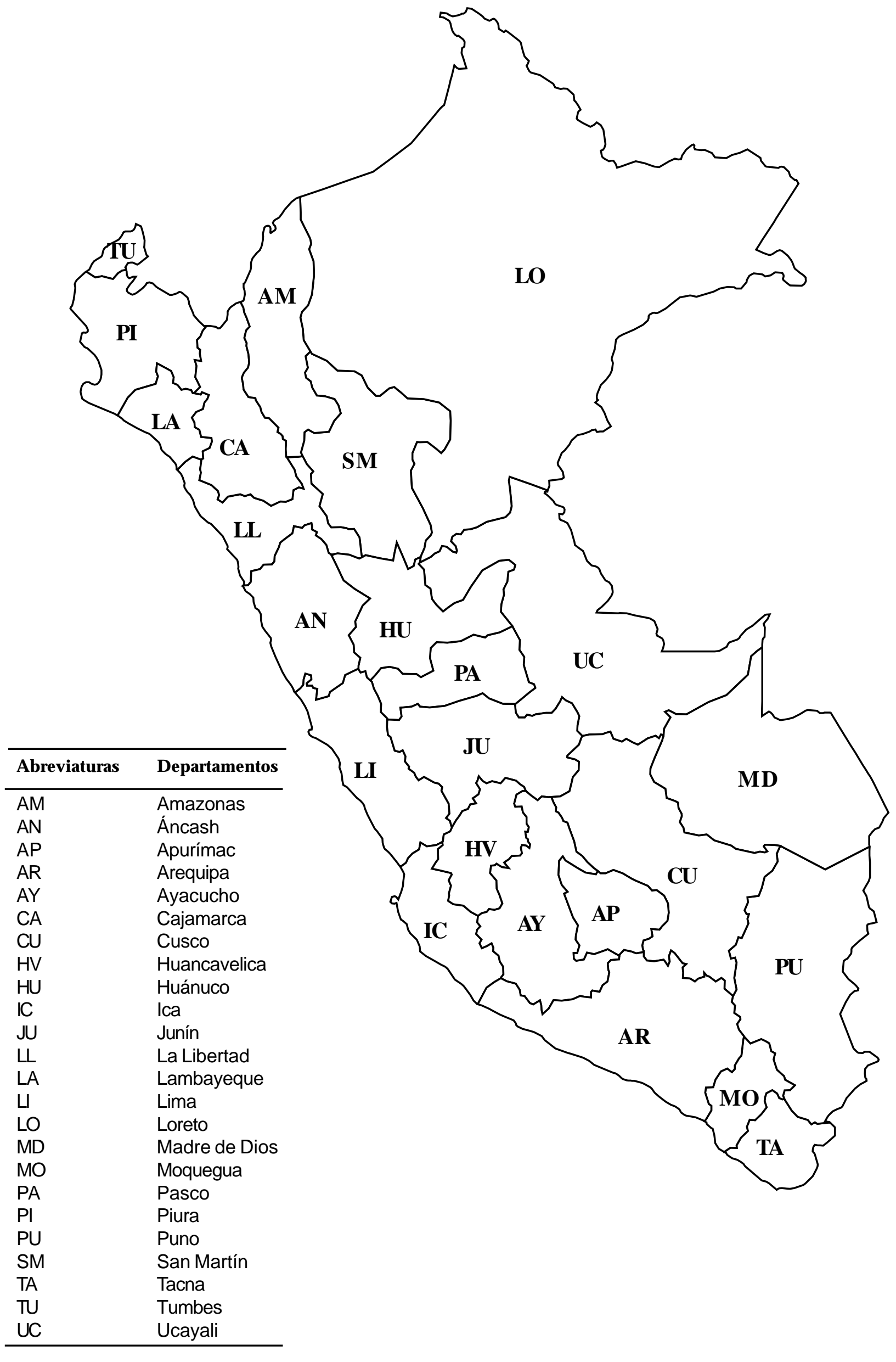

